\title{
Field measurement of ideal saturation flow rate from the highway capacity manual
}

Bruce M. Dunlap

West Virginia University

Follow this and additional works at: https://researchrepository.wvu.edu/etd

\section{Recommended Citation}

Dunlap, Bruce M., "Field measurement of ideal saturation flow rate from the highway capacity manual" (2005). Graduate Theses, Dissertations, and Problem Reports. 1626.

https://researchrepository.wvu.edu/etd/1626

This Thesis is protected by copyright and/or related rights. It has been brought to you by the The Research Repository @ WVU with permission from the rights-holder(s). You are free to use this Thesis in any way that is permitted by the copyright and related rights legislation that applies to your use. For other uses you must obtain permission from the rights-holder(s) directly, unless additional rights are indicated by a Creative Commons license in the record and/ or on the work itself. This Thesis has been accepted for inclusion in WVU Graduate Theses, Dissertations, and Problem Reports collection by an authorized administrator of The Research Repository @ WVU. For more information, please contact researchrepository@mail.wvu.edu. 


\title{
Field Measurement \\ of Ideal Saturation Flow Rate from the \\ Highway Capacity Manual
}

\author{
By \\ Bruce M. Dunlap \\ Thesis submitted to the \\ College of Engineering and Mineral Resources \\ at West Virginia University \\ in partial fulfillment of the requirements \\ for the degree of \\ Master of Science
in
Civil Engineering
}

Dr. Lloyd James French, III, Ph.D., P.E. (Chair)

Dr. Ronald W. Eck, Ph.D., P.E.

Dr. David R. Martinelli, Ph.D.

Department of Civil Engineering

\section{Morgantown, West Virginia \\ 2005}

Keywords: Ideal Saturation Flow Rate, Highway Capacity Manual

Copyright 2005 Bruce M. Dunlap 


\author{
Abstract \\ Field Measurement \\ of Ideal Saturation Flow Rate from the \\ Highway Capacity Manual
}

Bruce M. Dunlap

In all signalized intersection analyses performed with Highway Capacity Manual (HCM), the Pennsylvania Department of Transportation (PENNDOT) District 12-0 uses an ideal saturation flow rate of $1800 \mathrm{pcphgpl}$, which is less than the default value of 1900 pcphgpl provided by HCM. This is to account for the less aggressive characteristics of the local drivers. The purpose of this study is to field measure a sample of saturation flow rates, from which ideal saturation flow rates can be computed, in District 12-0 to determine the appropriateness of the lower ideal saturation flow rate. This study will scientifically test this hypothesis, along with measuring variations over the four-county District area, and variations during different weather conditions. Furthermore, it may be possible to provide anecdotal insight into potential shortcomings in the HCM saturation flow rate model, or the adjustment factors used therein.

In conclusion the use of an 1800pcphgpl saturation flow rate was warranted when used district-wide, however a more localized usage of varying saturation flow rates would be recommended. In addition the HCM correction factors proved to be sufficient with the exception of the lane width correction factor which was determined to be inconclusive. Furthermore the rain study did show tendencies but was over all inconclusive. 


\section{Acknowledgements}

The author would like to express his thanks to the many people who provided guidance and support in completing this thesis. Many thanks to Dr. Jim French, graduate advisor and committee chairperson, for guidance and assistance in the preparation of this thesis. Furthermore, for both their participation on the committee and guidance in the revision process, the author would like to thank Dr. Ronald Eck and Dr. David Martinelli. Finally much gratitude is extended to the Pennsylvania Department of Transportation District 12-0 for needed information provided in the areas of data collection. 


\section{Table of Contents}

Title Page---------------------------------------------------------------------------------------------i

Abstract---------------------------------------------------------------------------------------------ii

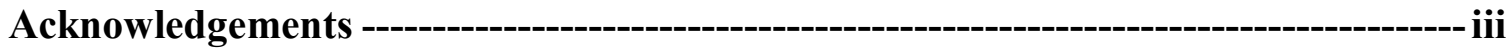

Table of Contents ---------------------------------------------------------------------------------- iv

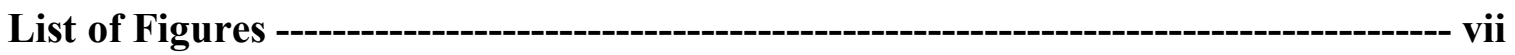

List of Tables ---------------------------------------------------------------------------------------- vii

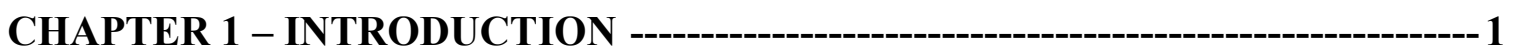

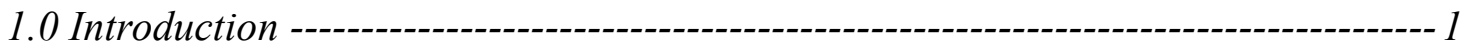

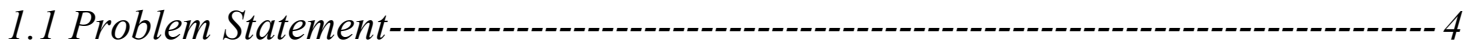

1.2 Project Objectives ------------------------------------------------------------------------- 5

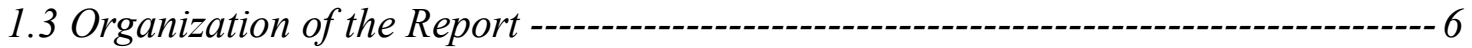

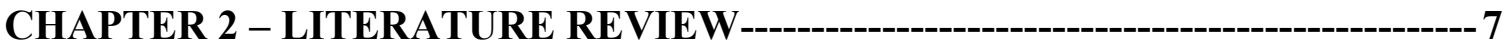

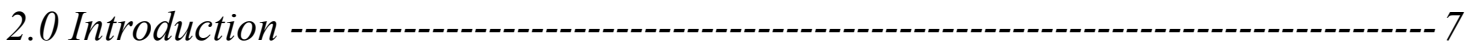

2.1 HCM Saturation Flow Rate Model Structure and Methodology ---------------------- 7

2.2 HCM-Prescribed Methodology for Field Collecting Saturation Flow Rate Data- 15

2.3 Other Related Saturation Flow Rate Literature-------------------------------------- 17

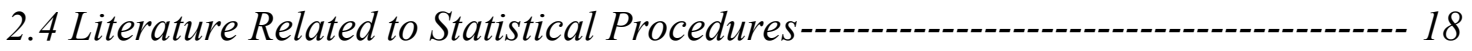

2.5 Concluding Remarks ----------------------------------------------------------------------- 20

Chapter 3 - Methodology ----------------------------------------------------------------------- 21

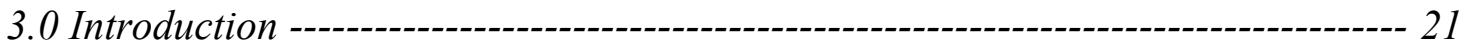

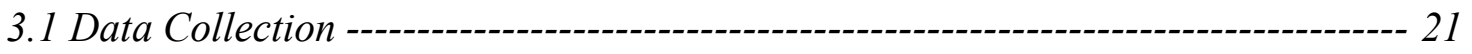

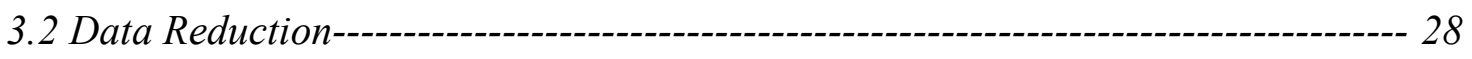

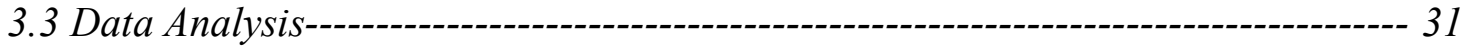

3.3.1 Analysis of Ideal Saturation Flow Rate in District 12-0 ----------------------- 31

3.3.2 Comparison of Ideal Saturation Flow Rate by County ------------------------- 32 
3.3.3 Comparison of Ideal Saturation Flow Rate by Lane Type ------------------- 33

3.3.4 Comparison of Ideal Saturation Flow Rate by Approach Grade --------------- 34

3.3.5 Comparison of Ideal Saturation Flow Rate by Lane Width--------------- 35

3.3.6 Comparison of Ideal Saturation Flow Rate by \% Heavy Vehicles------------ 36

3.3.7 Comparison of Ideal Saturation Flow Rate between Rain and Dry Atmospheric Conditions----------------------------------------------------------------- 37

3.3.8 Comparison of Ideal Saturation Flow Rate by Time of Day-------------------- 38

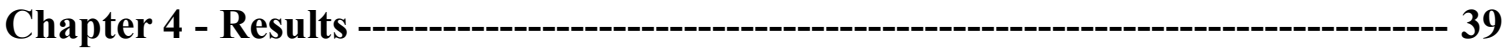

4.0 Introduction --- 39

4.1 District -Wide Assumed Ideal Saturation Flow Rate of 1800pcphgpl ------------- 39

4.2 Ideal Saturation Flow Rate by County ------------------------------------- 40

4.3 Ideal Saturation Flow Rate by Lane Type.--------------------------------------- 43

4.4 Ideal Saturation Flow Rate by Grade.-------------------------------------- 44

4.5 Saturation Flow Rate by Lane Width. -------------------------------------- 44

4.6 Ideal Saturation Flow Rate by the Percentage of Heavy Vehicles. --------------- 46

4.7 Ideal Saturation Flow Rate for Rain vs. Dry ----------- 47

4.8 Ideal Saturation Flow Rate by Time of day---------------------------- 49

4.9 Conclusions and Recommendations ------------------------------------------ 50

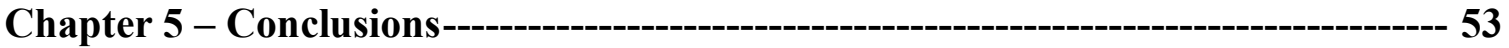

5.0 Conclusions---- 53

5.1 Limitations of the Research and Recommendations for Further Research--------- 55

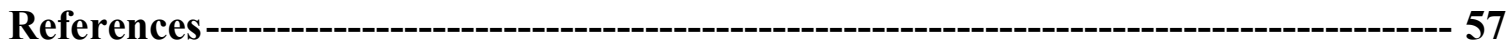

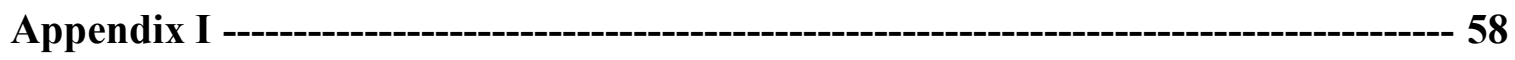

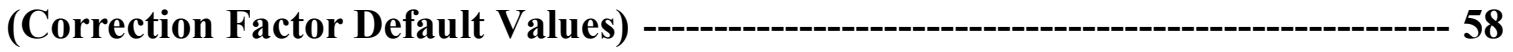

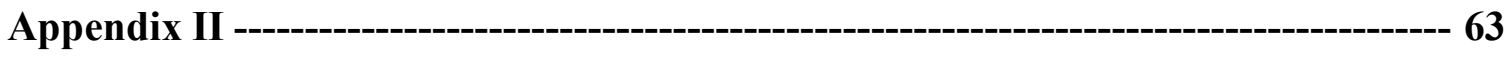

(Data reduction Summary Sheets) -

Appendix III - 67

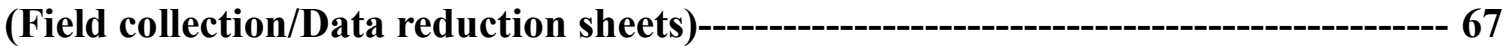

Appendix IV -----_- 95 


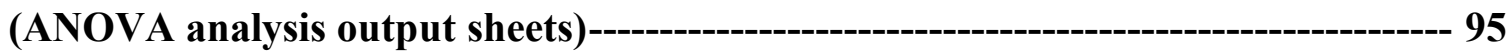

Appendix V - - 108

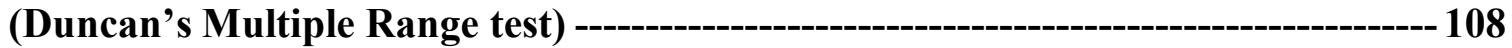

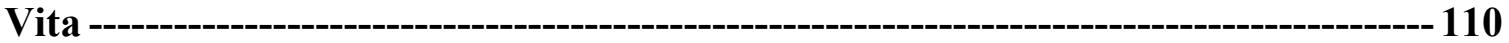




\section{List of Figures}

FigURE 3-1 (NAVTEQ 2003) DisTRICT 12-0 MAP ..............................................22

FigURE 3.2 (TRB, 2000) HCM SFR FIELD COLLECTION WORKSHEET ....................27

FigURE 3.3 ModifiEd FiELD COLLECTION WORKSHEET......................................28

Figure 3.3 Sample Data Collection/Reduction SheEt...................................30

Figure 4.1 (Distance From Urban Core verses Ideal Saturation Flow Rate) .41

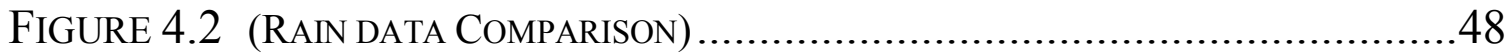

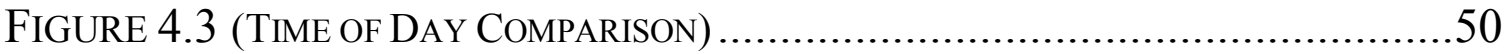

\section{List of Tables}

Table 3.1 - Ideal Saturation Flow Rate Data Used to Compute the District-

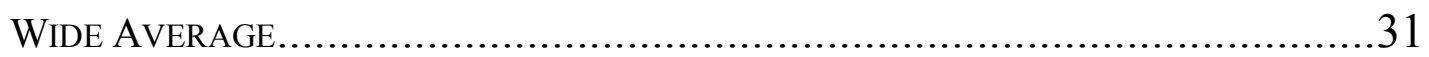

TABle 3.2 Ideal Saturation Flow Rate Data Grouped by County .................32

TABLE 3.3 Ideal Saturation Flow Data Grouped by Lane Type......................34

TABle 3.4 ideal Saturation Flow Rate Data Grouped by Approach Grade ....35

Table 3.5 - Ideal Saturation Flow Rate Data Grouped by Lane Width .........36

Table 3.6 - Ideal Saturation Flow Rate Data Grouped by Percent Heavy

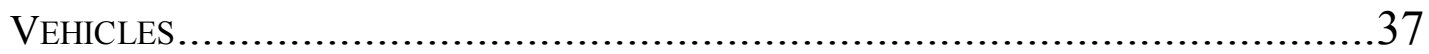

TABle 3.7 Ideal Saturation Flow Rate Data Under Dry and Raining

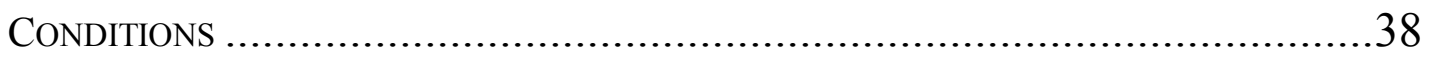

TABLE 4.1 GEOGRAPHICAL COMPARISONS ANOVA SUMMARY .............................43

TABLE 4.2 CORRECTION FACTOR ANOVA SUMMARIES ...................................46 


\section{CHAPTER 1 - INTRODUCTION}

\subsection{Introduction}

The Highway Capacity Manual (HCM) (TRB, 2000) is the most commonly used highway traffic capacity analysis tool. HCM provides the user with the theory and methodologies to determine the capacity and level of service of a wide variety of highway facilities, including the following (TRB, 2000):

- Urban Arterials

- Signalized Intersections

- Unsignalized Intersections

- Pedestrian facilities

- Bicycle facilities

- Rural Two-Lane Highways

- Multilane Highways

- Basic Freeway Segments

- Weaving Freeway Sections

- Ramps

- Transit facilities (e.g. terminals)

As stated, two of the key usages of HCM are to determine capacity and level of service. Capacity is defined as the maximum number of persons or vehicles that a facility can accommodate with reasonable safety during a specified time period (TRB, 2000). It is generally expressed as an hourly flow rate; however, the specified time period is typically fifteen minutes. Level of service is defined as a measure that describes 
operational conditions within a traffic stream, generally in terms of such service measures as speed and travel time, freedom to maneuver, traffic interruptions, and comfort and convenience (TRB, 2000). It is generally expressed as a letter grade between A and F, with A being near free-flow conditions, and $\mathrm{F}$ being over-capacity.

Engineers use the concepts of capacity and level of service in a number of ways. One common usage is to size facilities during design. For example, the computation of capacity and level of service can lead directly to decisions regarding the number of lanes needed on a highway facility. Certain facility types also make specialized usage of these concepts. For example, the level of service and capacity results for a signalized intersection are a key input into the signal timing.

This research deals with the signalized intersection module of HCM. There are five major steps in the computation of capacity and level of service of a signalized intersection. They are as follows (TRB, 2000):

- Input Parameters - Gathering field data related to the geometries, traffic conditions, and signal timings.

- Lane Grouping and Demand Flow Rate - Making adjustments to the hourly traffic volumes to convert to fifteen minute flow rates, the deduction of right-turn on red traffic, and the grouping of lanes with operational dependencies.

- Saturation Flow Rate - Determining the prevailing saturation flow rate, which is defined as the flow in vehicles per hour than can be accommodated by a specified lane group assuming that the green phase was displayed 100 percent of the time (TRB, 2000). 
- Capacity and Volume to Capacity Ratio - The computation of capacity for each lane group is based on the saturation flow rate and the percentage of time the lane group receives a green indication.

- Performance Measures - Average Control Delay per Vehicle is computed and compared to the thresholds for each LOS.

As can be seen, the saturation flow rate is a key input when analyzing capacity, level of service, signal timing and intersection design. The usage of a saturation flow rate that is higher than the prevailing saturation flow rate in the field will make traffic flow appear more efficient than it truly is in the analysis. This can result in intersections that are under-built and / or have signal timing with green intervals and cycle lengths that are too short. Likewise, the usage of a saturation flow rate that is too low will result in overbuilding of intersections and motorist delays due to excessively long cycle lengths.

The model contained in HCM for predicting saturation flow rate is one in which an ideal saturation flow rate is factored to a smaller number based on the prevailing, presumably "non-ideal" conditions. A default value of 1900 passenger cars per hour green per lane (pcphgpl) is provided by $\mathrm{HCM}(\mathrm{TRB}, 2000)$ for the ideal saturation flow rate. A series of factors are then provided to account for the effects of the following:

- The Number of Lanes in the Lane Group

- Lane Widths

- Heavy Vehicles

- Grade

- Parking Activity

- Bus Stops 
- Area Type

- Lane Utilization

- Left-Turns in the Lane Group

- Right-Turns in the Lane Group

- Pedestrians that Interfere with Left-Turns

- Pedestrians and Bicyclists that Interfere with Right-Turns

As can be seen, the value used for ideal saturation flow rate has a one-to-one proportional influence on the resultant prevailing saturation flow rate predicted by the HCM model. Furthermore, there is uncertainty regarding the appropriateness of the default ideal saturation flow rate provided by HCM at all geographic locations.

\subsection{Problem Statement}

In all signalized intersection analyses performed with HCM, the Pennsylvania Department of Transportation (PENNDOT) District 12-0 uses an ideal saturation flow rate of $1800 \mathrm{pcphgpl}$, which is less than the default value of $1900 \mathrm{pcphgpl}$ provided by HCM. This is to account for the less aggressive characteristics of the local drivers. The purpose of this study is to field measure a sample of saturation flow rates, from which ideal saturation flow rates can be computed, in District 12-0 to determine the appropriateness of the lower ideal saturation flow rate and compare it to the distance from the urban core within the district. This study will scientifically test this hypothesis, along with measuring variations over the four-county District area, and variations during different weather conditions. Furthermore, it may be possible to provide anecdotal insight into potential shortcomings in the HCM saturation flow rate model, or the adjustment factors used therein. One of the goals of this project is to evaluate the 
methodology for measuring ideal saturation flow rate. The HCM provides a methodology for measuring prevailing saturation flow rate. This methodology will be used in conjunction with a reverse application of the HCM saturation flow model to estimate ideal saturation flow rate. A key contribution of this work will be a qualitative assessment of the soundness of this approach.

\subsection{Project Objectives}

As noted, the overall goal of the project was to determine whether PENNDOT District $12-0$ is justified in using the ideal saturation flow rate of 1800 pcphgpl. In general, this was performed by collecting saturation flow rate data throughout the District at locations of varying geometric make up. Data collection was also performed in various weather conditions to check for lower saturation flow rate values as a result of environmental conditions. Ideal saturation flow rates were then computed by using the HCM adjustment factors to back calculate the ideal saturation flow rate from the prevailing saturation flow rate. Statistical tests were then performed to determine if the data supported the usage of a lower ideal saturation flow rate during normal or adverse weather conditions. Anecdotal insight was also provided into the usage of the factors required by the HCM model. A list of the specific research objectives is as follows:

- Review literature related to saturation flow rate, particularly the model contained in HCM.

- Collect a statistically valid data set containing data from the four counties in PENNDOT District 12-0, those being Fayette, Greene, Westmoreland, and Washington Counties. 
- Ensure in the data collection some variation in intersection geometries (i.e., grade, lane width, etc.)

- Collect data at one location under two different weather conditions, once under dry conditions and once in the rain.

- Conduct statistical tests to determine if there is statistical evidence that the ideal saturation flow rate in District 12-0 is less than default value of 1900 pcphgpl.

- Conduct statistical tests to determine if there is statistical evidence of a drop in ideal saturation flow rate during adverse weather conditions such as rain.

- Conduct statistical tests to determine if there is some variation between the individual counties.

- Make anecdotal observations about the structure of the HCM saturation flow rate model and its associated factors.

- Present the results, findings, and recommendations in a final report.

\subsection{Organization of the Report}

This chapter has provided background information, problem statement, and the research objectives. Chapter 2 provides a literature review that focuses on the HCM saturation flow rate model. Chapter 3 provides a description of the methodology followed in the research. Chapter 4 presents the results of the research in detail. Chapter 5 concludes the report with a summary of the results, a description of the limitations of the research, and ideas for further research. 


\section{CHAPTER 2 - LITERATURE REVIEW}

\subsection{Introduction}

A review of literature was undertaken to critically evaluate and learn from published research findings on the study of saturation flow rates as well as relevant information pertaining to the validity of the data from a statistical viewpoint.

Objectives of this literature review were:

- Investigate the structure and methodology of the saturation flow rate model in HCM.

- Present the methodology for field collecting saturation flow rate that is prescribed by $\mathrm{HCM}$

- Review other published research reports related to saturation flow rates.

- Gather information related to the statistical testing of the collected data to guide the development of the experimental plan and field data collection.

Each of these is described in a separate section as follows.

\subsection{HCM Saturation Flow Rate Model Structure and Methodology}

The method for determining the ideal saturation flow rate in accordance with HCM is as follows. The saturation flow rate module is contained in the signalized intersection module (Garber, 1999). This model provides for the computation of a saturation flow rate for each lane group. The saturation flow rate is defined as the flow rate in vehicles per hour that the lane group can carry if it has the green indication continuously, that is, if $\mathrm{g} / \mathrm{C}=1(\mathrm{TRB}, 2000)$. The saturation flow rate depends on the ideal saturation flow rate $\left(\mathrm{s}_{\mathrm{o}}\right)$, along with a number of geometric and operational 
variables, $\mathrm{s}_{\mathrm{o}}$ is equal to $1900 \mathrm{pcphgpl}$ according to the $\mathrm{HCM}$ (TRB, 2000). The Ideal Saturation Flow rate of 1900pcphgpl is calculated based on ideal conditions and saturation flow headway of $1.9 \mathrm{sec}$ applied to the following equation.

$$
s=3,600 / h
$$

Where:

$$
\begin{aligned}
& s=\text { saturation flow rate (vphgpl) } \\
& h=\text { saturation headway (sec.) } \\
& 3,600=\text { number of seconds per hour }
\end{aligned}
$$

This ideal saturation flow is then adjusted by factors to account for the prevailing traffic conditions to obtain the saturation flow for the lane group being considered. The adjustment is made by introducing factors that correct for less than ideal conditions produced by the following:

- Number of lanes

- Lane width

- Heavy vehicles in the traffic stream

- Approach grade

- Parking activity

- Buses

- Area type

- Lane utilization

- Right and left-turns

- Pedestrian and bicyclist interference with turning vehicles

The prevailing saturation flow rate is given by the following equation from HCM (TRB, 2000): 
$s=\left(s_{o}\right)(N)\left(f_{w}\right)\left(f_{H V}\right)\left(f_{g}\right)\left(f_{p}\right)\left(f_{a}\right)\left(f_{b b}\right)\left(f_{L U}\right)\left(f_{R T}\right)\left(f_{L T}\right)\left(f_{L p b}\right)\left(f_{R p b}\right)$

Where

$s=$ saturation flow rate for the subject lane group, expressed as a total for all lanes in the lane group under prevailing conditions (vphg)

$s_{o}=$ ideal saturation flow rate per lane, usually taken as $1900(\mathrm{vphg} / \mathrm{ln})$

$N=$ number of lanes in lane group

$\mathrm{f}_{w}=$ adjustment factor for lane width

$f_{H V}=$ adjustment factor for heavy vehicle in the traffic in the traffic stream

$f_{g}=$ adjustment factor for approach grade

$f_{p}=$ adjustment factor for the existence of parking lane adjacent to the lane group and the parking activity on that lane $f_{a}=$ adjustment factor for area type (for Central Business District or CBD, 0.90; for all other areas, 1.00)

$f_{b b}=$ adjustment factor for the blocking effect of local buses stopping within the intersection area

$f_{L u}=$ adjustment factor for lane utilization

$f_{R T}=$ adjustment factor for right turns in the lane groups

$f_{L T}=$ adjustment factor for the left turns in the lane group

$f_{L p b}=$ pedestrian adjustment factor for the left-turns movements

$f_{R p b}=$ pedestrian-bicycle adjustment factor for the right-turns movements.

Each of the adjustment factors is discussed in detail below typical values and the equations used to compute the factors can be seen in Appendix I. 
Lane Width Adjustment Factor, $\boldsymbol{f}_{\boldsymbol{w}}$. This factor depends on the average width of the lanes in a group. It is used to account for both the reduction in saturation flow rates when lane widths are less than $12 \mathrm{ft}$ and the increase in saturation flow rates when lane widths are greater than $12 \mathrm{ft}$. The adjustment factors are obtained from Appendix I (TRB, 2000). Lane width factors should not be computed for lanes less than $8 \mathrm{ft}$ wide. A lane width of $12 \mathrm{ft}$. would result in an adjustment factor of one, which would have no effect on saturation flow rate. A lane width less than $12 \mathrm{ft}$. results in a factor less than one, thus lowering saturation flow rate, and a lane width greater than $12 \mathrm{ft}$. results in a factor that is greater than one, thus increasing saturation flow rate.

Heavy Vehicle Adjustment Factor, $\boldsymbol{f}_{\boldsymbol{H} \boldsymbol{v}}$. The heavy vehicle adjustment factor is related to the percentage of heavy vehicles in the specified lane group. This factor corrects for the additional delay and reduction in saturation flow rate due to the presence of heavy vehicles in the traffic stream. Note that a heavy vehicle is defined as any vehicle that has more than four wheels touching the pavement (TRB, 2000). The additional delay and reduction in saturation flow are due mainly to the difference between the operational capabilities of the heavy vehicles and passenger cars and the additional space taken up by heavy vehicles. The appropriate factor is selected from Appendix I (TRB, 2000).

Grade Adjustment Factor, $\boldsymbol{f}_{\boldsymbol{g}}$. This factor is related to the gradient of the approach being considered. It is used to correct for the effect of gradients on the speed of vehicles, including both passenger cars and heavy vehicles. This effect is different for up-grade and down-grade conditions; therefore, the direction of the grade is also taken into consideration as shown in Appendix I (TRB, 2000). Note that upgrades yield factors 
that are less than one, while downgrades are associated with factors that are greater than one.

Parking Adjustment Factor, $\boldsymbol{f}_{\boldsymbol{p}}$. On-street parking within $250 \mathrm{ft}$ upstream of the stop bar of an intersection causes friction between parking and through vehicles, which results in a reduction of the saturation flow rate. This effect is corrected for by using a parking adjustment factor, which can be found in Appendix I (TRB, 2000). This factor depends on the number of lanes in a lane group and the number of parking maneuvers per hour. Examination of the parking adjustment factors reveals that the higher the number of lanes in a given lane group, the less effect parking has on the saturation flow rate. Conversely, the higher the number of parking maneuvers, the greater the effect. In determining these factors, it is assumed that each parking maneuver (either in or out) blocks traffic on the adjacent lane group for an average duration of $18 \mathrm{sec}$. It should be noted that when the number of parking maneuvers per hour is greater than 180 , a practical limit of 180 should be used. This adjustment factor should be applied only to the lane group immediately adjacent to the parking lane. When parking occurs on both sides of a single lane group, the sum of the number of parking maneuvers on both of sides should be used.

Area Type Adjustment Factor, $\boldsymbol{f}_{\boldsymbol{a}}$. The general types of activities in the area at which the intersection is located have a significant effect on speed and therefore on saturation flow rate on an approach. For example, because of the complexity of intersections located in areas with typical central business district characteristics, such as frequent parking maneuvers, narrow streets, and high pedestrian activities, these intersections operate less efficiently than intersections at other areas. This is corrected 
for by using the area type adjustment factor $\mathrm{f}_{\mathrm{a}}$, which is 0.90 for a central business district (CBD) and 1.0 for all areas not designated as CBD's (TRB 2000)

Bus Blockage Adjustment Factor, $\boldsymbol{f}_{\boldsymbol{b} b}$. When buses have to stop in a travel lane to discharge or pick up passengers, all of the vehicles immediately behind the bus will also have to stop. This results in a decrease in the maximum volume that can be served by that lane. This effect is corrected for by using the bus blockage adjustment factor, which is related to the number of buses in an hour that stop in the travel lane, within 250 $\mathrm{ft}$ upstream or downstream of the stop line, as well as the number of lanes in the lane group. The factors developed in HCM (TRB, 2000) assume an average blockage time of 14.4 sec during a green indication. These values can be seen in Appendix I (TRB, 2000).

Lane Utilization Adjustment Factor, $\boldsymbol{f}_{\boldsymbol{L u}}$. The lane utilization factor is used to adjust the ideal saturation flow rate to account for the unequal utilization of the lanes in a lane group. When a lane group has more than one lane serving a movement (e.g. two lanes for through moving traffic) the lane utilization factor is obtained from the following equation as:

$$
f_{L u i}=\left(v_{g i}\right) /\left(v_{g L i} N_{i}\right)
$$

Where:

$f_{\text {Lui }}=$ lane utilization adjustment factor for lane group $\mathrm{i}$

$v_{g i}=$ unadjusted demand flow rate for lane group $\mathrm{i}$

$v_{g L i}=$ unadjusted demand flow rate on the single lane of group I with the highest volume

$N_{i}=$ number of lanes in lane group $\mathrm{i}$ 
It is recommended that actual field data be used for computing $f_{\text {Lui }}$. Values shown in Appendix I, however, can be used as default values when field information is not available (TRB, 2000).

Right-Turn Adjustment Factor, $\boldsymbol{f}_{\boldsymbol{R}}$. This factor accounts for the effect of rightturning vehicles on saturation flow rate. It depends on the right-turn protection provided in the phase plan (protected, permitted, or protected plus permitted), the conflicting pedestrian volume, and the proportion of right-turning vehicles that use the protected portion of the protected-plus-permitted phase. This portion can be determined from a field study or, alternatively, can be estimated from the signal timing by assuming that the proportions of the right-turning phase are approximately equal. The right-turning volume may also be reduced if right-turn-on-red is always allowed, by subtracting the number of vehicles that turn during the red phase from the total right-turn volume. Appendix I gives the right turn adjustment factors (TRB, 2000).

Left-Turn Adjustment Factor, $\boldsymbol{f}_{\boldsymbol{L} T}$. This adjustment factor is used to account for the fact that left-turn movements take more time to execute than through movements. The values of this factor also depends on the type of phasing (protected, permitted, or protected-plus-permitted), the type of lane used for the left-turns (exclusive or shared lane), and the proportion of left-turn vehicles using a shared lane. Appendix I gives leftturn adjustment factors (TRB, 2000).

Adjustment for Pedestrians and Bicyclists $f_{L p b,} f_{R p b}$. The procedure to determine the left-turn pedestrian-bicycle factor, $\mathrm{f}_{\mathrm{Lpb}}$, and the right-turn pedestrian-bicycle adjustment factor, $\mathrm{f}_{\mathrm{Rpb}}$, consist of four steps. The first step is to determine average pedestrian occupancy, which only accounts for the pedestrian effect. Next, the relevant 
conflict zone occupancy, which accounts for both pedestrian and bicycle effects is determined. Relevant conflict zone occupancy takes into account whether other traffic is also in conflict (e.g. adjacent bicycle flow for the case of right-turns or opposing vehicle flow for the case of left turns). In either case, adjustments to the initial occupancy are made. The portion of green time in which the conflict zone is occupied is determined as a function of the relevant occupancy and the number of receiving lanes for the turning vehicles.

The proportion of right-turns using the protected sequence of a protected-pluspermitted phase is also needed. This proportion should be determined by field observation, but a gross estimate can be made from the signal timing by assuming that the proportion of the right-turning vehicles using the protected phase is approximately equal to the proportion of the turning phase that is protected. If $\mathrm{P}_{\mathrm{RTA}}=1.0$ (that is, the right turn is completely protected from conflicting pedestrian), a pedestrian volume of zero should be used.

Finally, the saturation flow rate adjustment factor is calculated from the final occupancy on the basis of the turning movement protection status and the percent of turning traffic in the lane group. All information required to compute this factor from the appropriate field data is provided in Appendix I (TRB, 2000).

In conclusion, these factors are used in the HCM saturation flow rate model to account for less than ideal conditions with prevailing traffic and intersection conditions to compute prevailing saturation flow rate. They will be used in reverse during this research, as the prevailing saturation flow rate will be measured and factored up to the ideal 
saturation flow rate based on the prevailing conditions. Note that all factors not used later in the study were not present at the data collection location.

\subsection{HCM-Prescribed Methodology for Field Collecting Saturation}

\section{Flow Rate Data}

To eliminate variation in the field collection of saturation flow rate data, HCM (TRB, 2000) prescribes a detailed procedure for its collection. The methodology is illustrated by the following example (TRB, 2000).

This example describes a single-lane saturation flow survey. A two-person field crew is recommended, however, one person will suffice. The field notes and tasks identified in the following section must be adjusted accordingly.

1. General Tasks

a. Record the area type and width and grade of the lane being studied.

b. Fill out the survey identification data shown in Figure 3.2 completely.

c. Select an observation point where the stop line for the surveyed lane and corresponding signal heads are clearly visible.

d. The reference point is normally the stop line. Vehicles should consistently stop behind this line. When a vehicle crosses it unimpeded, it has entered the intersection conflict space for the purpose of saturation flow rate measurement. Left- or right-turning vehicles yielding to opposing through traffic or yielding to pedestrians are not recorded until they proceed through the opposing traffic.

2. Recorder Tasks

a. Note the last vehicle in the stopped queue when the signal turns green. 
b. Describe the last vehicle to the timer.

c. Note on the worksheet which vehicles are heavy vehicles and which vehicles turn left or right.

d. Record the time called out by the timer.

3. Timer tasks

a. Start the stopwatch at the beginning of the green and notify the recorder.

b. Count aloud each vehicle in the queue as its rear axle crosses the stop line.

c. Call out the time of the fourth, tenth, and last vehicle in the queue.

d. If queued vehicles are still entering the intersection at the end of the green, call out "saturation through the end of green-last vehicle was number XX."

Note any unusual events that may have influenced the saturation flow rate, such as buses, stalled vehicles, and unloading trucks. The period of saturation flow rate that begins when the rear axle of the fourth vehicle in the queue crosses the stop line or reference point and ends when the rear axle of the last queued vehicle at the beginning of the green time crosses the stop line.

Measurements are taken cycle by cycle. To reduce the data for each cycle, the time recorded for the fourth vehicle is subtracted from the time recorded for the last vehicle in the queue. This value is total headway for $(n-4)$ vehicles, where $\mathrm{n}$ is the number of the last vehicle surveyed (this may not be the last vehicle in the queue). The total headway is divided by $(n-4)$ to obtain the average headway per vehicle under saturation flow. The saturation flow rate is 3,600 divided by this value. For example, if 
the time for the fourth vehicle was observed as $10.2 \mathrm{sec}$ and the time for the $14^{\text {th }}$ and last vehicle surveyed was $36.5 \mathrm{sec}$, the average saturation headway per vehicle would be

$$
(36.5-10.2) /(14-4)=26.3 / 10=2.63 \mathrm{sec} / \mathrm{veh}
$$

And the prevailing saturation flow rate in that cycle would be

$$
3,600 / 2.63=1,369 \text { vphgpl }
$$

In order to obtain a statistically significant value, a minimum of 15 signal cycles with more than 8 vehicles in the initial queue is usually needed (TRB, 2000). An average of the saturation flow rate values in individual cycles represents then the prevailing local saturation flow rate for the surveyed lane. The percentage of heavy vehicles and turning vehicles in the sample used in the computations should be determined and noted for reference.

\subsection{Other Related Saturation Flow Rate Literature}

(McMahon, Krane, \& Federico, 1997) conducted a similar study in the state of Florida, in which they performed a study to test for geographical differences in saturation flow rate among the five south Florida counties that make up the Florida Department of Transportation (FDOT) District Four. These five counties were Broward, Palm Beach, Martin, St. Lucie and Indian River. These counties varied in their level of development from urban to rural much like PENNDOT District 12-0. FDOT hypothesized that there were variations in saturation flow rates between the five counties and desired to develop a database to support localized saturation flow rate assumptions used in traffic operations analysis. The same HCM methodology was used for collecting the field data with the exception of the minimum number of vehicles required in each queue. The FDOT study 
used a minimum of six vehicles due to a change in the HCM from the second to the third edition. Some of the conclusions of their study were as follows:

- Contrary to original hypothesis that a geographical difference exists among saturation flow rates throughout District Four, it was established that more significant variation was exhibited by the number of through lanes per approach.

- There was substantial similarity of saturation flow rates among roadways that have three through approach lanes.

- It was inconclusive whether there was a geographical difference among single-lane and two-lane approaches throughout the District.

Also, a few of the following recommendations from the study are listed below:

- An examination of the entire data set ranked in the order of decreasing saturation flow rates, by cycle, and its comparison with other research and the HCM value of 1900 could provide valuable insight regarding the "true" south Florida saturation flow rate.

- A more thorough analysis of the impact of heavy vehicles based on the percentage of trucks may provide additional insight into truck adjustment factors for South Florida.

- Analysis of shared through/turn-lane characteristics relative to percent turns could provide additional information relative to adjustment factors for shared lanes.

\subsection{Literature Related to Statistical Procedures}

The goal of this project was to design and conduct an experiment to test the validity of the usage of a lower ideal saturation flow in PENNDOT District 12-0. As such, some background information on statistical testing and experimental design was needed. This section provides the necessary background to establish the experimental design and analysis that is described in Chapter 3. 
(Lum,1991) states, in Statistical Shortcomings in Traffic Studies, "Over the years, the Federal Highway Administration (FHWA) has been receiving more and more research reports in which the authors use statistical techniques of analysis of variance and regression analysis. Many of these studies are flawed due to a lack of understanding of the assumptions underlying these statistical techniques. Consequently, the findings and conclusions presented in the reports may be open to questions and challenge.

Furthermore, from (Walpole et al., 1998), a few statistical tests that will prove the worth of the data are as follows:

- ANOVA analysis

- Duncan's Multiple Range Test

Analysis-of-Variance (ANOVA) is used to test variation in F-distribution between two or more sample populations. This test is conducted by comparing variability within a sample to variability between samples, in this case using a 95\% confidence interval. For example, ANOVA analysis can be performed between sets of ideal saturation flow rates collected in two different counties to determine whether there is a statistically significantly difference. ANOVA analysis can compare two populations of different sample size, which is useful in this study because an equal number of ideal saturation flow rate observations were not made in each county.

A second test that can be performed is the Duncan's multiple-range test. This procedure is based on the general notion of studentized range along with a normal distribution. The range of any subset of $\mathrm{p}$ sample means must exceed a certain value before any of the $\mathrm{p}$ means are found to be different, this test was conducted using a $95 \%$ 
confidence interval with 19 degrees of freedom. This test proves to be useful here to compare all four counties to each other instead of a one on one basis.

\subsection{Concluding Remarks}

This chapter has investigated important literature and background information needed to support the research goals of this project. Important observations relative to the research experiment design were made and will be directly incorporated into the project methodology, to be described in Chapter 3. 


\section{Chapter 3 - Methodology}

\subsection{Introduction}

This chapter describes the methodology followed in the execution of this research. Each primary step in the research is covered in a separate section. Section 3.1 describes the data collection sites, the dates of the data collection, and any important circumstances, under which the data were collected, (e.g., rain). Section 3.2 describes the data reduction and storage, and describes the process under which the prevailing saturation flow rates were used to estimate ideal saturation flow rates. Section 3.3 describes the data analysis that was performed, including the analysis of the $1800 \mathrm{pcphgpl}$ district-wide ideal saturation flow rate, the comparison of ideal saturation flow rates by county, the comparison of ideal saturation flow rates by other site characteristics, and the analysis of adverse weather conditions on ideal saturation flow rate.

\subsection{Data Collection}

Data were collected in the four counties comprising Pennsylvania Department of Transportation - Engineering District 12. These four counties are located in southwestern Pennsylvania and are as follows: Fayette, Greene, Westmoreland, and Washington. The Pittsburgh metropolitan area is just to the north of the study area, and its suburban area spills into both Westmoreland and Washington Counties. See Figure 3-1 for a Site Map of the area including the locations of data collection. 
Figure 3-1 (Navteq 2003) District 12-0 Map

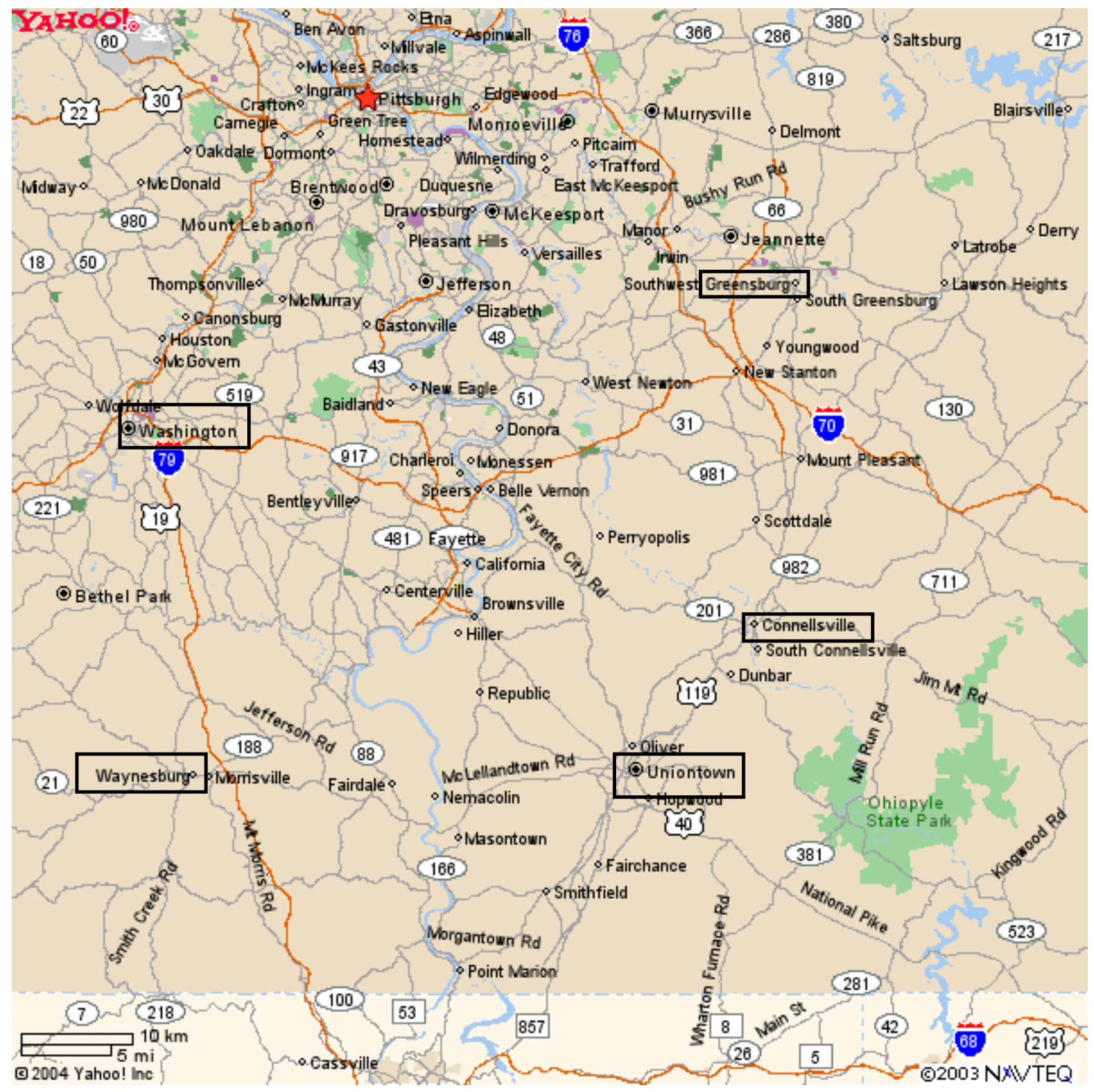

The locations of data collection were as follows:

- Uniontown and Connellsville in Fayette County

- Greensburg in Westmoreland County

- Waynesburg in Greene County 


\section{- Washington in Washington County}

These locations vary in driver characteristics, as the Washington and Greensburg sites are more indicative of suburban Pittsburgh drivers, while the Fayette and Greene County sites are more indicative of rural drivers. As such, comparisons can be made between presumably aggressive and less-aggressive drivers. With the exception of Connellsville, all municipalities were county seats. Furthermore, these locations were selected because they had signalized intersections that had significant queuing for an extended duration during the peak periods. This was required to conduct the saturation flow rate study and obtain an adequate sample.

At each selected signalized intersection, lanes were selected for study with a wide range of characteristics to enable the comparison between correction factors such as lane type, lane width, and grade. Data were collected at the following lanes / signalized intersections on the following dates:

- May 29-2002 (Wednesday)

Uniontown, Intersection of PA 21 and Brewer Drive:

- PA 21 Eastbound shared through (TH) \& right (RT)

Uniontown, Intersection of PA 21 at Matthew Drive and US 40 / 119 Ramps:

- PA 21 Westbound left (LT) Only

- Northbound Ramps LT Only

- Southbound Matthew Drive shared TH and RT

- Northbound Ramps 40 TH Only

- June 4, 2002 (Tuesday)

Waynesburg, Intersection of US 19 and PA 21: 
- US 19 southbound LT Only

Waynesburg, Intersection of PA 21 and McDonalds:

- PA 21 Eastbound TH Only

- June 5, 2002 (Wednesday)

Uniontown, Intersection of PA 21 at Matthew Drive and US 40 / 119 Ramps:

- Northbound from 40 LT Only (hard rain)

Uniontown, @ intersection of PA 21 and Work Parkway:

- PA 21 Westbound TH Only

- PA 21 Eastbound shared TH and RT

- June 10,2002 (Monday)

Connellsville, Intersection of US 119 SB and PA 711

- US 119 Southbound shared LT and TH

Connellsville, Intersection of US 119 NB and PA 711

- US 119 Northbound shared LT and TH

- June 12, 2002 (Wednesday)

Greensburg, Intersection of US 119 and US 30 Ramps

- US 119 Northbound LT Only (to US 30 Westbound)

- US 119 Southbound TH Only

- US 119 Northbound LT Only (to US 30 Eastbound)

- July 8, 2002 (Monday)

Washington, Intersection of US 19 and Trinity Point / Strabane Square access

- Westbound from Strabane Square shared LT and TH

- US 19 Southbound TH Only (right lane) 
- Eastbound from Trinity Point LT Only

- US 19 Northbound LT Only

- October 102002 (Thursday)

Uniontown, @ intersection of PA 21 at Matthew Drive and US 40 / 119 Ramps:

(All rain data)

- PA 21 Westbound LT Only

- Northbound Ramps LT Only

- Southbound Matthew Drive shared TH and RT

- October 23, 2002 (Wednesday)

Uniontown, @ intersection of PA 21 at Matthew Drive and US 40 / 119 Ramps:

(Time of day study)

- Northbound Ramps LT Only (In 1 hour increments from 12:00 to $5: 00)$

As can be seen, the majority of the data collection was performed in June 2002, with the exception of a few days of data collection in May, July, and October of that year. Following preliminary data reduction, a follow-up was performed in mid-October to address some initial findings. The October $11^{\text {th }}$ collection was done at repeat location while raining to compare results between the two scenarios. In addition, the October $23^{\text {rd }}$ collection was done at a repeat location studying the same lane from 12:00 pm to 5:00 pm to check for differences in data for varying time of day.

The data collection was performed in accordance with the Highway Capacity Manual 2000 (TRB, 2000) by one person and was as follows. The saturation flow rate 
was measured by recording the time and number of vehicles crossing a stop bar from a standing queue when the signal indication turned green. A like point on all vehicles was used (rear axle) to start and stop the timing to eliminate any variation in the data collection. There was a minimum of eight vehicles required in the standing queue to collect the data. Time was recorded from the fourth vehicle in the queue to the last. HCM recommended a minimum of 15 cycles to be recorded for each approach to achieve a representative sample. In this study, 20 cycles were sampled to further ensure the validity of the sample. Shown below are field collection sheets from HCM in Figure 3.2, as well as a simplified collection sheet used in this study in Figure 3.3. Figure 3.3 may vary from the HCM format below due to site specific features. If field measurements were to include the grade and lane dimensions, they were also recorded on the field observation sheet. 
Figure 3.2 (TRB, 2000) HCM SFR Field Collection Worksheet

\section{FIELD SATURATION FLOW RATE STUDY WORKSHEET}

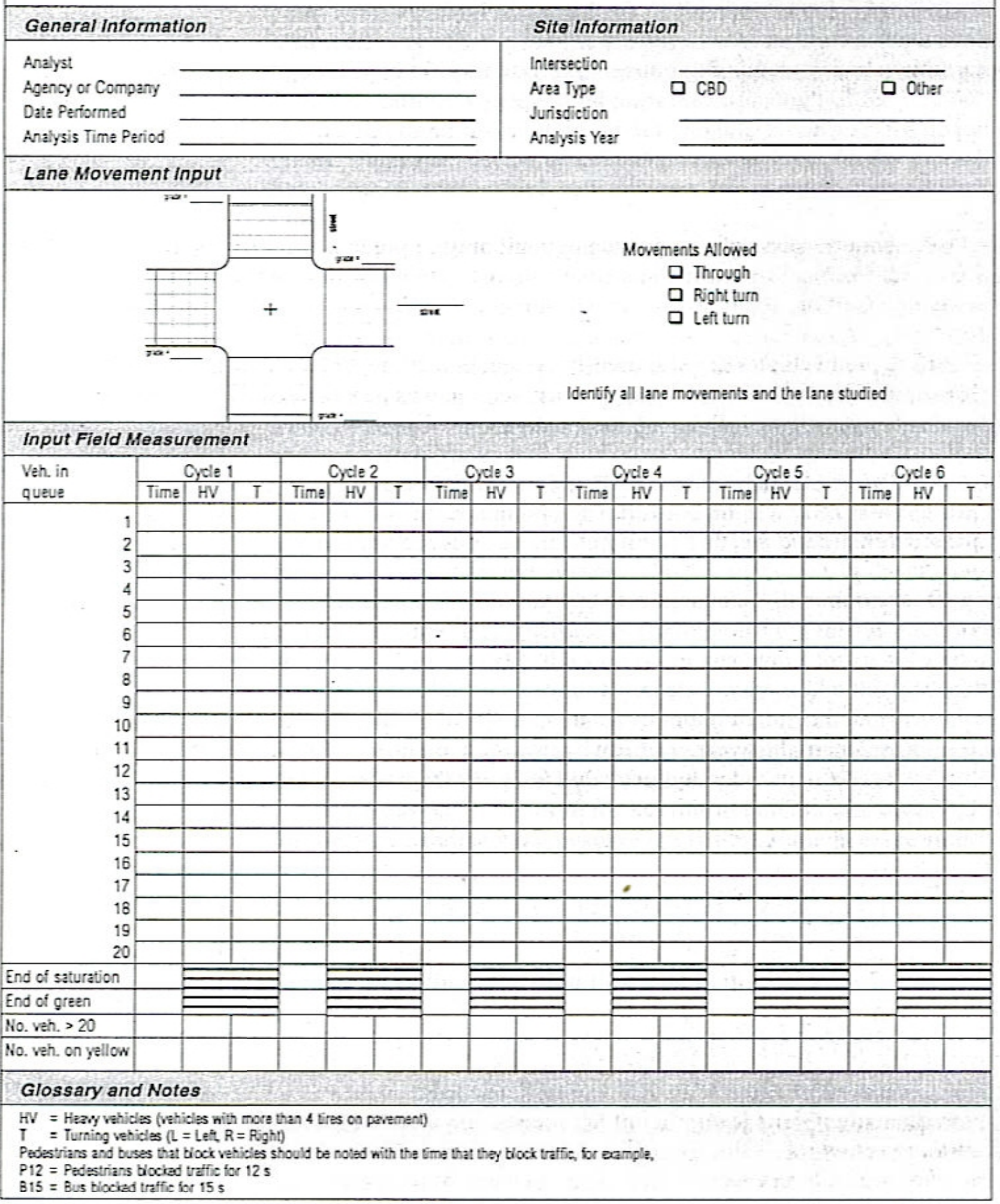


Figure 3.3 Modified Field collection Worksheet

North/South:

East/West:

Approach studied:

Weather:

Pavement Condition:

City:
State:
Technician:
Time:
Date:

\begin{tabular}{|c|c|c|c|c|}
\hline \# Of Counts & $\begin{array}{c}\text { Elapsed } \\
\text { Time } \\
\text { (sec.) }\end{array}$ & $\begin{array}{l}\text { Total \# of } \\
\text { vehicles }\end{array}$ & $\begin{array}{c}\text { \# Of } \\
\text { heavy } \\
\text { vehicles }\end{array}$ & $\begin{array}{c}\text { \# Of R/L } \\
\text { Turns }\end{array}$ \\
\hline \multicolumn{5}{|l|}{1} \\
\hline \multicolumn{5}{|l|}{2} \\
\hline \multicolumn{5}{|l|}{3} \\
\hline \multicolumn{5}{|l|}{4} \\
\hline \multicolumn{5}{|l|}{5} \\
\hline \multicolumn{5}{|l|}{6} \\
\hline \multicolumn{5}{|l|}{7} \\
\hline \multicolumn{5}{|l|}{8} \\
\hline \multicolumn{5}{|l|}{9} \\
\hline \multicolumn{5}{|l|}{10} \\
\hline \multicolumn{5}{|l|}{11} \\
\hline \multicolumn{5}{|l|}{12} \\
\hline \multicolumn{5}{|l|}{13} \\
\hline \multicolumn{5}{|l|}{14} \\
\hline \multicolumn{5}{|l|}{15} \\
\hline \multicolumn{5}{|l|}{16} \\
\hline \multicolumn{5}{|l|}{17} \\
\hline \multicolumn{5}{|l|}{18} \\
\hline \multicolumn{5}{|l|}{19} \\
\hline 20 & & & & \\
\hline
\end{tabular}

\subsection{Data Reduction}

From the raw data which can be seen in Appendix II and III, the prevailing saturation flow rate was computed for each cycle, then aggregated using both an unweighted and weighted (according to number of vehicles) average. Concurrently, all geometric information was obtained for the sample intersections using the permit drawings that were provided by PENNDOT. Permit drawings are engineering drawings 
of the intersection that contain pertinent signal-related design features, including approach grades and lane widths, which were critical to this study. Then using the average field-measured saturation flow rate and the adjustment factors from HCM that corresponded to each non-ideal condition, the ideal saturation flow rate was computed. Additionally, the standard deviation, variance, median, and coefficient of variation were also computed in the prevailing saturation flow rate to gauge the variability of the data and for use in subsequent statistical analyses. See Figure 3.3 for a sample computation sheet from Microsoft Excel. 
Figure 3.3 Sample Data Collection/Reduction Sheet

North/South: $B$ Brewer Drive
East/West:PA 21
Approach studied:PA 21 EB TH / RT
Weather: 82 , clear
Pavement Condition:

City: Uniontown State: $\mathrm{Pa}$.

Technician: $\mathrm{BMD}$

Time:1:07-2:10pm

Date: $\overline{5 / 29 / 02}$

\begin{tabular}{|c|c|c|c|c|c|}
\hline \# Of Counts & Elapsed Time (sec.) & Total \# of vehicles & $\begin{array}{c}\text { \# Of heavy } \\
\text { vehicles }\end{array}$ & $\begin{array}{c}\text { \# Of Rt. } \\
\text { Turns }\end{array}$ & Calculated SFR \\
\hline 1 & 16.28 & 8 & 0 & 1 & 1769.04 \\
\hline 2 & 35.25 & 16 & 1 & 1 & 1634.04 \\
\hline 3 & 22.69 & 9 & 2 & 0 & 1427.94 \\
\hline 4 & 26.01 & 10 & 2 & 2 & 1384.08 \\
\hline 5 & 30.22 & 10 & 2 & 2 & 1191.26 \\
\hline 6 & 27.15 & 8 & 2 & 0 & 1060.77 \\
\hline 7 & 23.85 & 13 & 0 & 0 & 1962.26 \\
\hline 8 & 24.25 & 11 & 0 & 0 & 1632.99 \\
\hline 9 & 21.22 & 9 & 0 & 0 & 1526.86 \\
\hline 10 & 25.03 & 12 & 1 & 1 & 1725.93 \\
\hline 11 & 29.16 & 13 & 2 & 0 & 1604.94 \\
\hline 12 & 17.02 & 8 & 0 & 1 & 1692.13 \\
\hline 13 & 25.38 & 10 & 2 & 1 & 1418.44 \\
\hline 14 & 21.94 & 10 & 0 & 2 & 1640.84 \\
\hline 15 & 26.75 & 11 & 1 & 1 & 1480.37 \\
\hline 16 & 28.69 & 10 & 2 & 1 & 1254.79 \\
\hline 17 & 28.68 & 12 & 2 & 0 & 1506.28 \\
\hline 18 & 29.15 & 12 & 2 & 0 & 1481.99 \\
\hline 19 & 17.91 & 9 & 0 & 0 & 1809.05 \\
\hline 20 & 28.35 & 12 & 1 & 0 & 1523.81 \\
\hline & 504.98 & 213 & 22 & 13 & 30727.82 \\
\hline
\end{tabular}

$g=-3 \%$

$L w=11^{\prime}$

\begin{tabular}{|c|c|c|}
\hline$\%$ Heavy veh.: & 10.3 & \\
\hline \% Rt turns: & 6.1 & Ideal: \\
\hline Average SFR: & 1536.39 & 1741 \\
\hline $\begin{array}{r}\text { Weighted Average } \\
\text { SFR: }\end{array}$ & 1518.48 & 1721 \\
\hline Standard deviation: & 215.85 & \\
\hline $\begin{array}{r}\text { Coefficient of } \\
\text { Variation: }\end{array}$ & 14.21 & \\
\hline Median: & 1525.34 & 1729 \\
\hline Variance: & 46591.33 & \\
\hline
\end{tabular}




\subsection{Data Analysis}

The following is a summation of all analyses and comparisons performed with the database of saturation flow rates.

\subsubsection{Analysis of Ideal Saturation Flow Rate in District 12-0}

A District-wide average of ideal saturation flow rate was computed to test the soundness of the use of a 1800 pcphgpl ideal saturation flow rate by the District, as opposed to the HCM default value of 1900 pcphgpl. For the District-wide analysis and comparison of the 1800 pcphgpl saturation flow rate, all initial data, excluding follow-up studies, was used. Please refer to Table 3.1. Note that in this table and throughout this chapter, all references to "average," "weighted average," and "median" refer to Ideal Saturation Flow Rates.

Table 3.1 - Ideal Saturation Flow Rate Data Used to Compute the District-Wide Average

\begin{tabular}{|c|l|l|c|c|c|c|c|}
\hline Sheet \# & Location & Intersection & $\begin{array}{c}\text { Lane } \\
\text { Type }\end{array}$ & $\begin{array}{c}\text { Total } \\
\text { Volume }\end{array}$ & Average & $\begin{array}{c}\text { Weighted } \\
\text { Average }\end{array}$ & Median \\
\hline 1 & Uniontown & 21 EB @ Brew. & TH/RT & 213 & 1741 & 1721 & 1729 \\
\hline 2 & Uniontown & 21 WB @ Math. & LT & 136 & 1860 & 1872 & 1897 \\
\hline 3 & Uniontown & Math. NB @ 21 & LT & 162 & 1676 & 1670 & 1702 \\
\hline 4 & Uniontown & Math. SB @ 21 & TH/RT & 152 & 1623 & 1629 & 1663 \\
\hline 5 & Uniontown & Math. NB @ 21 & TH & 130 & 1636 & 1626 & 1645 \\
\hline 7 & Uniontown & 21 WB @ McD's & TH/RT & 119 & 1721 & 1707 & 1684 \\
\hline 8 & Uniontown & 21 WB @ McD's & TH/RT & 100 & 1478 & 1454 & 1526 \\
\hline 9 & Connellsville & 119 NB @ Sheets & TH/LT & 132 & 1610 & 1589 & 1612 \\
\hline 10 & Connellsville & 119 SB @ Wendys & TH/LT & 156 & 1593 & 1567 & 1596 \\
\hline 11 & Greensburg & 119 NB @ ramps AB & LT & 85 & 1814 & 1799 & 1828 \\
\hline 12 & Greensburg & 119 NB @ ramps CD & LT & 96 & 1829 & 1776 & 1915 \\
\hline 13 & Greensburg & 119 SB @ ramps AB & TH & 82 & 1818 & 1807 & 1824 \\
\hline 14 & Waynesburg & 21 EB @ McD's & TH & 93 & 1539 & 1524 & 1536 \\
\hline 15 & Waynesburg & 19 SB @ 21 & LT & 87 & 1667 & 1651 & 1655 \\
\hline 16 & Washington & Trin.Pt. @ 19 & LT & 83 & 1742 & 1728 & 1709 \\
\hline 17 & Washington & 19 NB @ Trin. Pt. & LT & 83 & 2034 & 2024 & 2036 \\
\hline 18 & Washington & 19 SB @ Trin. Pt. & TH & 98 & 1833 & 1814 & 1815 \\
\hline 19 & Washington & Stra.Sq. @ 19 & TH/LT & 91 & 1881 & 1870 & 1873 \\
\hline
\end{tabular}




\subsubsection{Comparison of Ideal Saturation Flow Rate by County}

The ideal saturation flow rate data were also grouped by county to determine if a significant difference existed among the counties. For example, it was hypothesized that Westmoreland and Washington Counties have an ideal saturation flow rate that is higher than Fayette and Greene due to their more aggressive drivers. Table 3.2 shows the data grouped by county. After the data were grouped, they were then entered into Microsoft Excel and compared using single factor ANOVA analysis with a 95\% confidence level.

Table 3.2 Ideal Saturation Flow Rate Data Grouped by County

\begin{tabular}{|c|c|c|c|c|c|c|c|c|}
\hline County & Sheet \# & Location & Intersection & $\begin{array}{l}\text { Lane } \\
\text { Type } \\
\end{array}$ & \begin{tabular}{|c} 
Total \\
Volume \\
\end{tabular} & Average & $\begin{array}{c}\text { Weighted } \\
\text { Average } \\
\end{array}$ & Median \\
\hline \multirow[t]{9}{*}{ Fayette } & 1 & Uniontown & 21 EB @ Brew. & TH/RT & 213 & 1741 & 1721 & 1729 \\
\hline & 2 & Uniontown & 21 WB @ Math. & $\mathrm{LT}$ & 136 & 1860 & 1872 & 1897 \\
\hline & 3 & Uniontown & Math. NB @ 21 & LT & 162 & 1676 & 1670 & 1702 \\
\hline & 4 & Uniontown & Math. SB @ 21 & TH/RT & 152 & 1623 & 1629 & 1663 \\
\hline & 5 & Uniontown & Math. NB @ 21 & $\mathrm{TH}$ & 130 & 1636 & 1626 & 1645 \\
\hline & 7 & Uniontown & 21 WB @ McD's & TH/RT & 119 & 1721 & 1707 & 1684 \\
\hline & 8 & Uniontown & 21 WB @ McD's & TH/RT & 100 & 1478 & 1454 & 1526 \\
\hline & 9 & Connellsville & 119 NB @ Sheets & TH/LT & 132 & 1610 & 1589 & 1612 \\
\hline & 10 & Connellsville & 119 SB @ Wendys & TH/LT & 156 & 1593 & 1567 & 1596 \\
\hline \multirow[t]{3}{*}{ Westmoreland } & 11 & Greensburg & 119 NB @ ramps AB & LT & 85 & 1814 & 1799 & 1828 \\
\hline & 12 & Greensburg & 119 NB @ ramps CD & LT & 96 & 1829 & 1776 & 1915 \\
\hline & 13 & Greensburg & 119 SB @ ramps AB & $\mathrm{TH}$ & 82 & 1818 & 1807 & 1824 \\
\hline \multirow[t]{2}{*}{ Greene } & 14 & Waynesburg & 21 EB @ McD's & $\mathrm{TH}$ & 93 & 1539 & 1524 & 1536 \\
\hline & 15 & Waynesburg & 19 SB @ 21 & LT & 87 & 1667 & 1651 & 1655 \\
\hline \multirow{4}{*}{ Washington } & 16 & Washington & Trin.Pt. @19 & LT & 83 & 1742 & 1728 & 1709 \\
\hline & 17 & Washington & 19 NB @ Trin. Pt. & LT & 83 & 2034 & 2024 & 2036 \\
\hline & 18 & Washington & 19 SB @ Trin. Pt. & $\mathrm{TH}$ & 98 & 1833 & 1814 & 1815 \\
\hline & 19 & Washington & Stra.Sq. @ 19 & TH/LT & 91 & 1881 & 1870 & 1873 \\
\hline
\end{tabular}

The ANOVA analysis was performed using all three calculated Ideal Saturation Flow Rate Values, Average, Weighted Average and Median, thus giving three independent sets of results. ANOVA analyses were also conducted to test for significant differences between Fayette and Greene, and Washington and Westmoreland. Finally, ANOVA 
analyses were performed to test for significant differences between the combination of Fayette and Greene (rural counties) and the combination of Washington and Westmoreland (urban counties). In addition, Duncan's multiple-range test was performed using the weighted averages between the four counties. This test was conducted to add an additional method for validating the findings.

\subsubsection{Comparison of Ideal Saturation Flow Rate by Lane Type}

The ideal saturation flow rate data were then grouped according to lane type. Three lane types were sample in this study: exclusive left-turn lanes, exclusive through lanes, and shared through and right or left-turn lanes. The grouped data are shown in Table 3.3. It was hypothesized that if a significant difference emerged among the various lane types, there might be an indication that the lane group factors in HCM were flawed. Single factor ANOVA analysis was then performed to check the hypothesis using a $95 \%$ confidence level. 
Table 3.3 Ideal Saturation Flow Data Grouped by Lane Type

\begin{tabular}{|c|c|c|c|c|c|c|c|c|}
\hline Lane type & Sheet \# & Location & Intersection & $\begin{array}{l}\text { Lane } \\
\text { Type }\end{array}$ & $\begin{array}{l}\text { Total } \\
\text { Volume }\end{array}$ & Average & $\begin{array}{l}\text { Weighted } \\
\text { Average }\end{array}$ & Median \\
\hline \multirow[t]{7}{*}{ Left turn only } & 2 & Uniontown & 21 WB @ Math. & $\mathrm{LT}$ & 136 & 1860 & 1872 & 1897 \\
\hline & 3 & Uniontown & Math. NB @ 21 & LT & 162 & 1676 & 1670 & 1702 \\
\hline & 11 & Greensburg & 119 NB @ ramps AB & LT & 85 & 1814 & 1799 & 1828 \\
\hline & 12 & Greensburg & 119 NB @ ramps CD & LT & 96 & 1829 & 1776 & 1915 \\
\hline & 15 & Waynesburg & 19 SB @ 21 & LT & 87 & 1667 & 1651 & 1655 \\
\hline & 16 & Washington & Trin.Pt. @ 19 & LT & 83 & 1742 & 1728 & 1709 \\
\hline & 17 & Washington & 19 NB @ Trin. Pt. & LT & 83 & 2034 & 2024 & 2036 \\
\hline \multirow[t]{4}{*}{ Thru only } & 5 & Uniontown & Math. NB @ 21 & $\mathrm{TH}$ & 130 & 1636 & 1626 & 1645 \\
\hline & 13 & Greensburg & 119 SB @ ramps AB & $\mathrm{TH}$ & 82 & 1818 & 1807 & 1824 \\
\hline & 14 & Waynesburg & 21 EB @ McD's & $\mathrm{TH}$ & 93 & 1539 & 1524 & 1536 \\
\hline & 18 & Washington & 19 SB @ Trin. Pt. & $\mathrm{TH}$ & 98 & 1833 & 1814 & 1815 \\
\hline \multirow{7}{*}{$\begin{array}{r}\text { Thru and } \\
\text { (Right or left) }\end{array}$} & 1 & Uniontown & 21 EB @ Brew. & TH/RT & 213 & 1741 & 1721 & 1729 \\
\hline & 4 & Uniontown & Math. SB @ 21 & TH/RT & 152 & 1623 & 1629 & 1663 \\
\hline & 7 & Uniontown & 21 WB @ McD's & TH/RT & 119 & 1721 & 1707 & 1684 \\
\hline & 8 & Uniontown & 21 WB @ McD's & TH/RT & 100 & 1478 & 1454 & 1526 \\
\hline & 9 & Connellsville & 119 NB @ Sheets & TH/LT & 132 & 1610 & 1589 & 1612 \\
\hline & 10 & Connellsville & 119 SB @ Wendys & TH/LT & 156 & 1593 & 1567 & 1596 \\
\hline & 19 & Washington & Stra.Sq. @ 19 & TH/LT & 91 & 1881 & 1870 & 1873 \\
\hline
\end{tabular}

\subsubsection{Comparison of Ideal Saturation Flow Rate by Approach Grade}

Similar to the "lane type" comparisons that were made, comparisons were also made according to approach grade. Sites were grouped into three categories as shown in Table 3.4: downgrades, upgrades, and level (values ranged from $-8.0 \%$ to $+6.7 \%$ ). It was hypothesized that if a significant difference emerged, the approach grade factors in HCM might be flawed. Again, the test was performed using single factor ANOVA. 
Table 3.4 Ideal Saturation Flow Rate Data Grouped by Approach Grade

\begin{tabular}{|c|c|c|c|c|c|c|c|c|}
\hline Grade & Sheet \# & Location & Intersection & $\begin{array}{l}\text { Lane } \\
\text { Type }\end{array}$ & $\begin{array}{c}\text { Total } \\
\text { Volume } \\
\end{array}$ & Average & $\begin{array}{c}\text { Weighted } \\
\text { Average }\end{array}$ & Median \\
\hline \multirow[t]{9}{*}{ Downgrade } & 1 & Uniontown & 21 EB @ Brew. & TH/RT & 213 & 1741 & 1721 & 1729 \\
\hline & 2 & Uniontown & 21 WB @ Math. & LT & 136 & 1860 & 1872 & 1897 \\
\hline & 4 & Uniontown & Math. SB @ 21 & TH/RT & 152 & 1623 & 1629 & 1663 \\
\hline & 8 & Uniontown & 21 WB @ McD's & TH/RT & 100 & 1478 & 1454 & 1526 \\
\hline & 13 & Greensburg & 119 SB @ ramps AB & $\mathrm{TH}$ & 82 & 1818 & 1807 & 1824 \\
\hline & 14 & Waynesburg & 21 EB @ McD's & $\mathrm{TH}$ & 93 & 1539 & 1524 & 1536 \\
\hline & 16 & Washington & Trin.Pt. @ 19 & LT & 83 & 1742 & 1728 & 1709 \\
\hline & 17 & Washington & 19 NB @ Trin. Pt. & LT & 83 & 2034 & 2024 & 2036 \\
\hline & 19 & Washington & Stra.Sq. @ 19 & TH/LT & 91 & 1881 & 1870 & 1873 \\
\hline \multirow[t]{4}{*}{ Level } & 7 & Uniontown & 21 WB @ McD's & TH/RT & 119 & 1721 & 1707 & 1684 \\
\hline & 9 & Connellsville & 119 NB @ Sheets & TH/LT & 132 & 1610 & 1589 & 1612 \\
\hline & 10 & Connellsville & 119 SB @ Wendys & TH/LT & 156 & 1593 & 1567 & 1596 \\
\hline & 12 & Greensburg & 119 NB @ ramps CD & LT & 96 & 1829 & 1776 & 1915 \\
\hline \multirow[t]{5}{*}{ Upgrade } & 3 & Uniontown & Math. NB @ 21 & LT & 162 & 1676 & 1670 & 1702 \\
\hline & 5 & Uniontown & Math. NB @ 21 & $\mathrm{TH}$ & 130 & 1636 & 1626 & 1645 \\
\hline & 11 & Greensburg & 119 NB @ ramps AB & LT & 85 & 1814 & 1799 & 1828 \\
\hline & 15 & Waynesburg & 19 SB @ 21 & LT & 87 & 1667 & 1651 & 1655 \\
\hline & 18 & Washington & 19 SB @ Trin. Pt. & $\mathrm{TH}$ & 98 & 1833 & 1814 & 1815 \\
\hline
\end{tabular}

\subsubsection{Comparison of Ideal Saturation Flow Rate by Lane Width}

To investigate the HCM correction factor for lane width using ANOVA analysis, the ideal saturation flow rate data were grouped into three categories: lane widths less than 12 feet, equal to 12 feet, and greater than 12 feet (values ranged from 10 feet to 14 feet). These are shown in Table 3.5. Single factor ANOVA analysis was then used to compare the three categories. 
TABle 3.5 - Ideal Saturation Flow Rate Data Grouped by Lane WidTh

\begin{tabular}{|c|c|c|c|c|c|c|c|c|}
\hline Lane Width & Sheet \# & Location & Intersection & $\begin{array}{l}\text { Lane } \\
\text { Type }\end{array}$ & \begin{tabular}{|c|} 
Total \\
Volume \\
\end{tabular} & Average & $\begin{array}{c}\text { Weighted } \\
\text { Average }\end{array}$ & Median \\
\hline \multirow[t]{8}{*}{$<12$ feet } & 1 & Uniontown & 21 EB @ Brew. & TH/RT & 213 & 1741 & 1721 & 1729 \\
\hline & 2 & Uniontown & 21 WB @ Math. & LT & 136 & 1860 & 1872 & 1897 \\
\hline & 7 & Uniontown & 21 WB @ McD's & TH/RT & 119 & 1721 & 1707 & 1684 \\
\hline & 11 & Greensburg & 119 NB @ ramps AB & LT & 85 & 1814 & 1799 & 1828 \\
\hline & 12 & Greensburg & 119 NB @ ramps CD & LT & 96 & 1829 & 1776 & 1915 \\
\hline & 13 & Greensburg & 119 SB @ ramps AB & $\mathrm{TH}$ & 82 & 1818 & 1807 & 1824 \\
\hline & 17 & Washington & 19 NB @ Trin. Pt. & LT & 83 & 2034 & 2024 & 2036 \\
\hline & 18 & Washington & 19 SB @ Trin. Pt. & $\mathrm{TH}$ & 98 & 1833 & 1814 & 1815 \\
\hline \multirow[t]{8}{*}{12 feet } & 3 & Uniontown & Math. NB @ 21 & $\mathrm{LT}$ & 162 & 1676 & 1670 & 1702 \\
\hline & 4 & Uniontown & Math. SB @ 21 & TH/RT & 152 & 1623 & 1629 & 1663 \\
\hline & 5 & Uniontown & Math. NB @ 21 & $\mathrm{TH}$ & 130 & 1636 & 1626 & 1645 \\
\hline & 8 & Uniontown & 21 WB @ McD's & TH/RT & 100 & 1478 & 1454 & 1526 \\
\hline & 9 & Connellsville & 119 NB @ Sheets & $\mathrm{TH} / \mathrm{LT}$ & 132 & 1610 & 1589 & 1612 \\
\hline & 15 & Waynesburg & 19 SB @ 21 & LT & 87 & 1667 & 1651 & 1655 \\
\hline & 16 & Washington & Trin.Pt. @ 19 & $\mathrm{LT}$ & 83 & 1742 & 1728 & 1709 \\
\hline & 19 & Washington & Stra.Sq. @ 19 & TH/LT & 91 & 1881 & 1870 & 1873 \\
\hline \multirow[t]{2}{*}{$>12$ feet } & 10 & Connellsville & 119 SB @ Wendys & $\mathrm{TH} / \mathrm{LT}$ & 156 & 1593 & 1567 & 1596 \\
\hline & 14 & Waynesburg & 21 EB @ McD's & $\mathrm{TH}$ & 93 & 1539 & 1524 & 1536 \\
\hline
\end{tabular}

\subsubsection{Comparison of Ideal Saturation Flow Rate by \% Heavy Vehicles}

Similarly, statistical tests were performed to determine if there were differences with respect to the percentage of heavy vehicles on the approach. The sites were grouped into three groups as follows and as shown in Table 3.6: less than four percent heavy vehicles, four to ten percent heavy vehicles, and greater than ten percent (values ranged from $0.0 \%$ to $14.9 \%$ ). Like the other statistical tests for significant differences, these three groups were compared using single factor ANOVA analysis with a 95\% confidence level. 
Table 3.6 - Ideal Saturation Flow Rate Data Grouped by Percent Heavy Vehicles

\begin{tabular}{|c|c|c|c|c|c|c|c|c|}
\hline $\begin{array}{l}\% \text { Heavy } \\
\text { Vehicle }\end{array}$ & Sheet \# & Location & Intersection & $\begin{array}{l}\text { Lane } \\
\text { Type }\end{array}$ & \begin{tabular}{|c|} 
Total \\
Volume \\
\end{tabular} & Average & $\begin{array}{c}\text { Weighted } \\
\text { Average }\end{array}$ & Median \\
\hline \multirow[t]{12}{*}{$<4 \%$} & 2 & Uniontown & 21 WB @ Math. & LT & 136 & 1860 & 1872 & 1897 \\
\hline & 4 & Uniontown & Math. SB @ 21 & TH/RT & 152 & 1623 & 1629 & 1663 \\
\hline & 5 & Uniontown & Math. NB @ 21 & $\mathrm{TH}$ & 130 & 1636 & 1626 & 1645 \\
\hline & 8 & Uniontown & 21 WB @ McD's & TH/RT & 100 & 1478 & 1454 & 1526 \\
\hline & 10 & Connellsville & 119 SB @ Wendys & TH/LT & 156 & 1593 & 1567 & 1596 \\
\hline & 13 & Greensburg & 119 SB @ ramps AB & $\mathrm{TH}$ & 82 & 1818 & 1807 & 1824 \\
\hline & 14 & Waynesburg & 21 EB @ McD's & $\mathrm{TH}$ & 93 & 1539 & 1524 & 1536 \\
\hline & 15 & Waynesburg & 19 SB @ 21 & LT & 87 & 1667 & 1651 & 1655 \\
\hline & 16 & Washington & Trin.Pt. @ 19 & LT & 83 & 1742 & 1728 & 1709 \\
\hline & 17 & Washington & 19 NB @ Trin. Pt. & LT & 83 & 2034 & 2024 & 2036 \\
\hline & 18 & Washington & 19 SB @ Trin. Pt. & $\mathrm{TH}$ & 98 & 1833 & 1814 & 1815 \\
\hline & 19 & Washington & Stra.Sq. @ 19 & TH/LT & 91 & 1881 & 1870 & 1873 \\
\hline \multirow[t]{4}{*}{$4 \%$ to $10 \%$} & 7 & Uniontown & 21 WB @ McD's & TH/RT & 119 & 1721 & 1707 & 1684 \\
\hline & 9 & Connellsville & 119 NB @ Sheets & TH/LT & 132 & 1610 & 1589 & 1612 \\
\hline & 11 & Greensburg & 119 NB @ ramps AB & LT & 85 & 1814 & 1799 & 1828 \\
\hline & 12 & Greensburg & 119 NB @ ramps CD & LT & 96 & 1829 & 1776 & 1915 \\
\hline \multirow[t]{2}{*}{$>10 \%$} & 1 & Uniontown & 21 EB @ Brew. & TH/RT & 213 & 1741 & 1721 & 1729 \\
\hline & 3 & Uniontown & Math. NB @ 21 & LT & 162 & 1676 & 1670 & 1702 \\
\hline
\end{tabular}

\subsubsection{Comparison of Ideal Saturation Flow Rate between Rain and Dry Atmospheric Conditions}

Ideal saturation flow rate data were collected at three approaches of the same intersection under dry (not raining) conditions, and then collected a second time during a moderate steady rain. It was hypothesized that the ideal saturation flow rate would be lower during a rain event. The data are shown in Table 3.7. The data were then compared graphically to determine if there was a difference. 
TABle 3.7 Ideal SATURATION Flow RATE Data UNDER DRy AND RAINING CONDitions

\begin{tabular}{|c|l|l|c|c|c|c|c|}
\hline Sheet \# & Location & Intersection & $\begin{array}{c}\text { Lane } \\
\text { Type }\end{array}$ & $\begin{array}{c}\text { Total } \\
\text { Volume }\end{array}$ & Average & $\begin{array}{c}\text { Weighted } \\
\text { Average }\end{array}$ & Median \\
\hline 2 & Uniontown & 21 WB @ Math. & LT & 136 & 1860 & 1872 & 1897 \\
\hline 3 & Uniontown & Math. NB @ 21 & LT & 162 & 1676 & 1670 & 1702 \\
\hline 4 & Uniontown & Math. SB @ 21 & TH/RT & 152 & 1623 & 1629 & 1663 \\
\hline $2 \mathrm{R}($ rain) & Uniontown & 21 WB @ Math. & LT & 140 & 1671 & 1662 & 1692 \\
\hline $3 R($ rain) & Uniontown & Math. NB @ 21 & LT & 144 & 1601 & 1588 & 1563 \\
\hline 4R(rain) & Uniontown & Math. SB @ 21 & TH/RT & 146 & 1686 & 1689 & 1690 \\
\hline
\end{tabular}

\subsubsection{Comparison of Ideal Saturation Flow Rate by Time of Day}

The time of day comparison was brought about by findings in the initial data collection. It was hypothesized that the ideal saturation flow rate may vary by the time of day, particularly during the commuting hours as opposed to the rest of the day.

Therefore, ideal saturation flow data was continuously collected in the left-turn lane of the northbound ramp approach to the intersection of PA 21 with Matthew Drive and US 40 / 119 Ramps. The data were collected from 12:00 to 5:00 p.m. and were grouped in one-hour increments. The information collected can be seen in Table 3.8. Data were graphically compared.

TABLE 3.8 IDEAL SATURATION FLOW RATES VERSUS TIME

\begin{tabular}{c|c|l|l|c|c|c|c|c|}
\cline { 2 - 8 } $\begin{array}{c}\text { Time } \\
\text { (military) }\end{array}$ & Sheet \# & Location & Intersection & $\begin{array}{c}\text { Lane } \\
\text { Type }\end{array}$ & $\begin{array}{c}\text { Total } \\
\text { Volume }\end{array}$ & Average & $\begin{array}{c}\text { Weighted } \\
\text { Average }\end{array}$ & Median \\
\hline $1200-1300$ & $3-12$ & Uniontown & Math. NB @ 21 & LT & 96 & 1814 & 1791 & 1812 \\
\hline $1300-1400$ & $3-1$ & Uniontown & Math. NB @ 22 & LT & 101 & 1755 & 1749 & 1727 \\
$1400-1500$ & $3-2$ & Uniontown & Math. NB @ 23 & LT & 97 & 1744 & 1731 & 1739 \\
$1500-1600$ & $3-3$ & Uniontown & Math. NB @ 24 & LT & 141 & 1898 & 1910 & 1938 \\
\hline $1600-1700$ & $3-4$ & Uniontown & Math. NB @ 25 & LT & 138 & 1895 & 1895 & 1923 \\
\hline
\end{tabular}




\section{Chapter 4 - Results}

\subsection{Introduction}

In this chapter, the results of the computations, tests, and comparisons described in Chapter 3 will be presented. Predicted values for ideal saturation flow rate will be discussed and compared to actual findings. Throughout this chapter, summaries of ANOVA analyses that were performed are presented. Details for all ANOVA analyses are provided in Appendix IV. Related graphs are also attached accordingly.

\subsection{District -Wide Assumed Ideal Saturation Flow Rate of}

\section{0pcphgpl}

The weighted average Ideal Saturation Flow Rate was computed for all preliminary data in one lump sum. That value was determined to be 1701pcphgpl, which can be compared to the District-wide assumed value of 1800pcphgpl, and the Highway Capacity Manual default value of 1900pcphgpl. This is viewed as a relatively large discrepancy, and one that could have a significant impact on traffic capacity analyses and signal timing efforts. This analysis indicates that the use of $1800 \mathrm{pcphpl}$ for ideal saturation flow rate at all locations in the District might be inappropriate. However, a District-wide value of $1700 \mathrm{pcphpl}$ is not recommended. As will be seen in the Section 4.2, the ideal saturation flow rate in Westmoreland and Washington Counties is statistically significantly higher than that in Fayette and Greene, and it is likely that at least two ideal saturation flow rates should be used in the District. Furthermore, as will be seen in Section 4.8, it is possible 
that the lower ideal saturation flow rate reported in this Section is a function of the time of day in which the data were collected. It is possible that while a lower ideal saturation flow rate might prevail during the midday off peak hours, during the peak hours, the 1800 pcphgpl value may in fact be appropriate, if a single value is to be used District-wide.

\subsection{Ideal Saturation Flow Rate by County}

The weighted average of each county was determined for the purpose comparing ideal saturation flow rate vs. distance from Pittsburgh. Listed are the average ideal saturation flow rates for each individual county: Greene - 1585pcphgpl, Fayette 1656pcphgpl, Westmoreland - 1793pcphgpl, and Washington - 1857pcphpl. There was a difference of 272pcphgpl between the highest and lowest value. Figure 4.1 shows the relationship between distance from the urban core and the corresponding ideal saturation flow rates of the collection areas. As seen below, there was an obvious increase in the values as the distance from the urban core decreases. These findings strengthen the notion that ideal saturation flow rate varies across the District, and provide insight into the selection of an appropriate rate if a more localized analysis is to be performed. It is possible that additional data collection might support an analysis to find a mathematical relationship between the two variables. The data collected in this research are considered too geographically limited to support such an analysis. While comparisons are made between saturation flow rate and distance for the purpose of simplicity, the true variable is population density. 
Figure 4.1 (Distance from Urban Core verses Ideal Saturation Flow Rate)

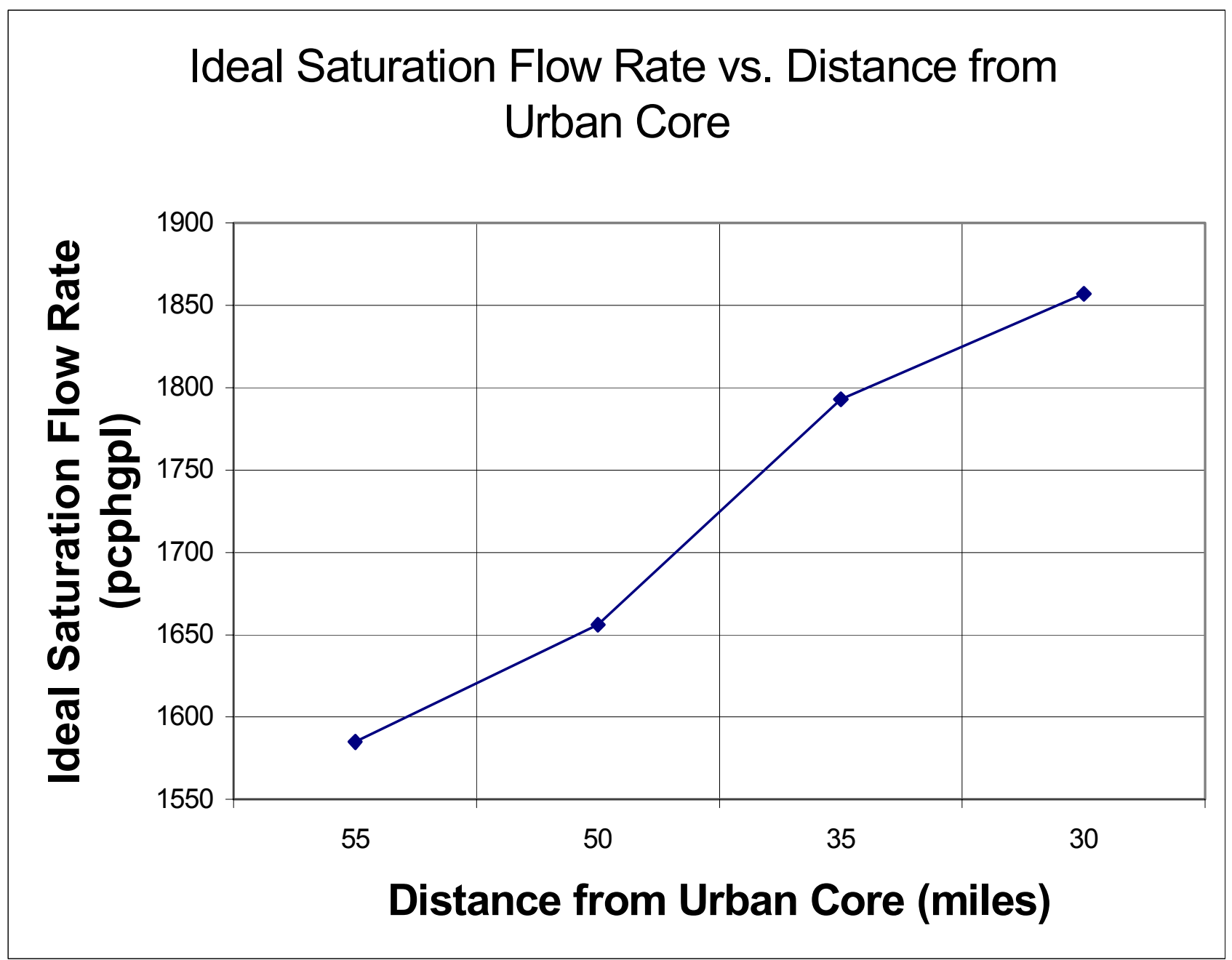

Furthermore, six ANOVA analyses were performed between the four counties, the first three compared the four counties against each other. The first of these compared the weighted average, the second the unweighted average, and third the median value of the SFR's for those counties. All ANOVA results can be seen in Table 4.1. The purpose for testing all three (weighted, unweighted, and median) was to check for variation between the three methods used to determining the Ideal Saturation Flow Rate knowing the data used for all three were identical. All three of the analyses indicated there was a statistically significant difference between the counties. The remaining four analyses 
were conducted using the weighted average of ideal saturation flow rate for the counties. The fourth test compared Fayette with Greene Counties, as both are located more than 50 miles from the urban core. The fifth test compared Westmoreland with Washington County, as both are located less than 35 miles from the urban core. By grouping the counties with similar geographical characteristics, both tests found no significant differences between the counties (see Table 4.1). In the sixth test, the above-mentioned pairs were tested against each other to establish whether there was a statistically significant difference between the two pairs. As can be seen in Table 4.1, a statistically significant difference was detected between the ideal saturation flow rates in Fayette and Greene Counties, and those in Westmoreland and Washington Counties. Typical for all ANOVA results, to result in No Significant Difference, the F-value must be greater than the F-critical value and the P-value greater than 0.05 . If either of the criteria is not met, then the data shows a Statistically Significant Difference. In addition, Duncan's Test was performed between all four counties and produced a result of; Fayette and Greene counties not being significantly different, Washington and Westmoreland counties not being significantly different, but there was a significant difference between the two groups themselves just as ANOVA concluded. All work performed for Duncan's test can be seen in Appendix V. 
Table 4.1 Geographical comparisons ANOVA summary

\begin{tabular}{l|c|c|c|c|}
\hline Comparison to be made & F-value & P-value & F-critical & Result \\
\hline County Weighted average & 4.9807 & 0.0148 & 3.3439 & S.S.D. \\
\hline County unweighted average & 5.8386 & 0.0084 & 3.3439 & S.S.D. \\
\hline County Median & 5.3777 & 0.0113 & 3.3439 & S.S.D. \\
\hline Fayette vs. Greene Co. & 0.4696 & 0.5104 & 5.1174 & N.S.D. \\
\hline Washington vs. Westmoreland Co. & 0.7697 & 0.4205 & 6.6079 & N.S.D. \\
\hline Fay.\&Greene vs. Wash.\&West. Co. & 14.5831 & 0.0015 & 4.4940 & S.S.D. \\
\hline
\end{tabular}

S.S.D. - Statistically Significant Difference

N.S.D. - No Significant Difference

Consequently, averaging the ideal saturation flow rates for Fayette and Greene Counties and rounding to the nearest 100pcphpl would yield an ideal saturation flow rate of 1600 pcphgpl. A similar computation for Westmoreland and Washington Counties would yield an ideal saturation flow rate of $1800 \mathrm{pcphgpl}$, which is the current District-wide ideal saturation flow rate. Again, however, Section 4.8 will demonstrate that it is possible that these are underestimated due to the time of day in which the supporting data were collected.

\subsection{Ideal Saturation Flow Rate by Lane Type.}

Having addressed the issue of finding appropriate ideal saturation flow rates for usage in PENNDOT District 12-0, the data were used in additional tests to approach more specific questions. As noted previously, the ideal saturation flow rates were arrived at by field measuring the prevailing saturation flow rate and using the HCM adjustment factors in reverse. As such, it was hypothesized that if statistically significant differences could be detected among sites that used different values for a given adjustment factor, that there may be something faulty with the adjustment factors themselves. There were four such comparisons made, the first of which dealt with lane type. 
HCM does not have a lane type adjustment factor, but does have adjustment factors for both right- and left-turns. These factors vary depending on whether the lanes are exclusive and how the turns are treated in the phase plan. For this test, the ideal saturation flow rate data were grouped into three categories: exclusive left-turn lanes, exclusive through lanes, and shared through and right- or left-turn lanes. It was determined from ANOVA analysis there was no statistical difference in the three categories as seen in Table 4.2. As such, there is no reason to suspect that the type of lane studied had an influence on the outcome of this research, or that issue might be taken with the adjustment factors in HCM related to lane type.

\subsection{Ideal Saturation Flow Rate by Grade.}

HCM contains a specific factor for grade, with level being considered ideal, uphill grades resulting in factors that are less than one, and downhill grades resulting in factors that are greater than one. All ideal saturation flow data were grouped into three categories: downhill, level, and uphill on the studied approaches. If a problem existed with the correction factor for grade, the ANOVA analysis might detect a pattern in one of the three grade classifications. Table 4.2 shows the output from the analysis. There was no statistical difference found in the three different categories, therefore suggesting that the results of this research were not influenced by the grade factor, and that there is not cause for concern with the HCM factors for grade.

\subsection{Saturation Flow Rate by Lane Width.}

This assessment was done with the ideal saturation flow rate sorted according to lane width. HCM has a specific correction factor to account for lane width. Widths of 12-ft are considered ideal. Lane widths over 12 -ft have a factor greater than one, indicating 
that saturation flow rate is increased by these greater widths. Similarly, lane widths less than 12-ft have a factor less than one.

The data were grouped into three categories: less than $12 \mathrm{ft}$, equal to $12 \mathrm{ft}$, and greater than $12 \mathrm{ft}$. Initial findings determined there was a statistically significant difference in the three categories, indicating a possible issue with the HCM correction factors or a possible influence of the lane width adjustment factor on this research. A realignment of the data was done to eliminate the HCM's correction factor and change those lanes falling above or below 12 feet to a factor of 1.0. A second comparison was performed using this data and it concluded there was not a statistical difference in the two categories, both ANOVA outputs can be seen in Table 4.2. Numerous attempts were made to pinpoint the problem in the correction factor by eliminating factors for lanes greater than 12 feet and again by eliminating factors for lanes less than 12 feet all analysis can be seen in Appendix IV. For both cases, the test indicated a statistically significant difference. Therefore, no specific reason could be identified for the problems with of the correction factor for lane width. Such results warrant further data collection and statistical testing to verify the findings. Calculations were done to determine the impact of the lane width factor on this study. This was done by manipulating all lane width data in numerous ways, the first was to evaluate the data as is, second to eliminate all positive correction factors, third eliminate all negative correction factors and finally change all correction factors to a value of 1.0. By evaluating the weighted average saturation flow rates using the four-abovementioned steps, the overall effect the correction factor has on the study can be seen. Upon review on a district-wide level, the factor can increase the ideal saturation flow rate a maximum of approximately 
15pcphgpl. Furthermore, it is assumed that the results of this study have not been significantly impacted by the potential problem with the lane width adjustment factor.

\subsection{Ideal Saturation Flow Rate by the Percentage of Heavy}

\section{Vehicles.}

HCM has a specific factor to account for the presence of heavy vehicles in the traffic stream. In general, it is assumed that each truck has a passenger car equivalency of two vehicles. No trucks in the traffic stream is considered the ideal condition; adjustment factors decrease as the percentage of trucks increases.

The data were grouped into three classes for the Heavy Vehicle factor comparison. The classes were less than four percent, four percent to ten percent, and greater than ten percent. ANOVA analysis revealed there was no difference between the three classes as seen in Table 4.2.

In summary, with the exception of the lane width factor, there were no statistically significant differences detecting among sites with varying factors, suggesting that they did not unduly influence the results of the District 12-0 ideal saturation flow rate research, nor is any issue raised with their validity.

TABLE 4.2 CORRECTION FACTOR ANOVA SUMMARIES

\begin{tabular}{|l|c|c|c|c|}
\hline Comparison to be made & F-value & P-value & F-critical & Result \\
\hline Lane type factor & 2.0026 & 0.1695 & 3.6823 & N.S.D. \\
\hline Grade factor & 0.3819 & 0.6890 & 3.6823 & N.S.D. \\
\hline Lane width factor & 7.5257 & 0.0055 & 3.6823 & S.S.D. \\
\hline Revised Lane width, all LW factors $=1$ & 2.1322 & 0.1636 & 4.4940 & N.S.D. \\
\hline Heavy vehicle Factor comparison & 0.0158 & 0.9843 & 3.6823 & N.S.D. \\
\hline $\begin{array}{l}\text { S.S.D. - Statistically Significant Difference } \\
\text { N.S.D. - No Significant Difference }\end{array}$
\end{tabular}




\subsection{Ideal Saturation Flow Rate for Rain vs. Dry}

Two additional analyses were performed on the ideal saturation flow rate: comparisons of rainy conditions to dry conditions and comparisons of data collected at different times of the day. These were conducted not only to preliminarily determine if a variation that merits further study might be present, but also to determine if the results of the District 12-0 ideal saturation flow rate research might have been impacted by these variables.

For the rain versus dry comparison, all data were collected in Uniontown at the intersection of S.R. 0021 and S.R. 0119 / 0040 Ramps. The same approaches were studied once under dry conditions and once while raining. The approaches studied were as follows: S.R. 0021 Westbound left turn approach lane was designated as collection 2 under dry conditions and 2R under wet conditions, from S.R. 0119/ 0040 Ramps left turn onto S.R. 0021 westbound approach lane was designated collection 3 under dry conditions and $3 \mathrm{R}$ under wet conditions, and from southbound Matthew Drive through/Right turn approach lane was designated collection 4 under dry conditions and 4R under wet conditions. All data collection sheets can be seen in the Appendix III. The weighted averages for the Ideal Saturation Flow Rate are as follows, under dry conditions, the SFR was 1717pcphgpl; under rain conditions, a value of 1646pcphgpl was determined. While the weighted averages were approximately $70 \mathrm{pcphgpl}$ higher for the dry data, Figure 4.2 shows the data.

While the first two pairs show an obvious reduction in SFR under wet conditions, as would be expected, the third does not. Data for the first two observation pairs were collected at approximately the same time of day. The first two observations (collections 2 and 3) were both done under dry conditions both from approximately 1:15 to 2:15p.m. 
and under wet conditions from approximately 2:30 to 3:30 p.m.. Furthermore, the third data pair (collection 4) was done under dry conditions from approximately 2:15 to 3:15p.m. and under wet conditions from approximately 3:30 to 4:30p.m., the first during off-peak traffic and the other during peak traffic. The reason for the third collection pair not conforming to the expected pattern may by due to an increase in the Ideal Saturation Flow Rate during peak hours of the day. This inconsistency led to further data collection covered in the Section 4.8. The purpose of establishing a link between the Ideal Saturation Flow Rate and rain conditions would be to use varying Ideal SFR values in geographical locations that have adverse weather conditions a significant percent of the time.

Figure 4.2 (Rain data Comparison)

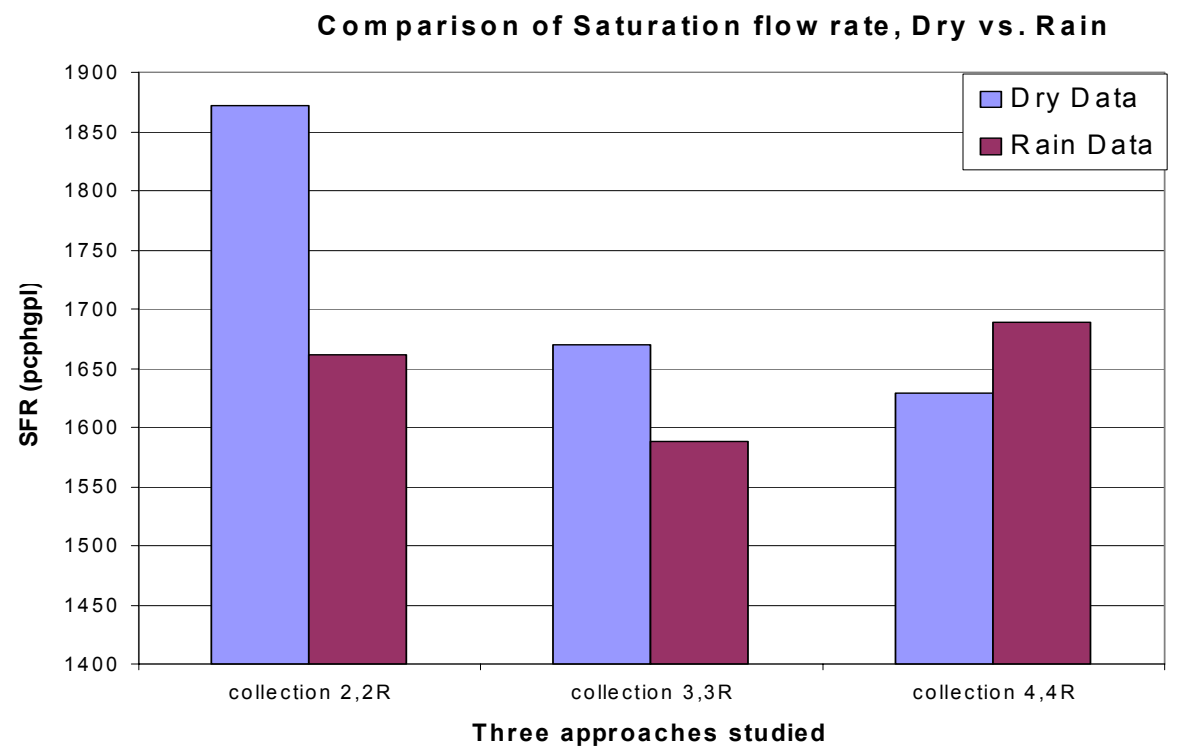




\subsection{Ideal Saturation Flow Rate by Time of day}

Due to the findings in Section 4.7, additional data were collected at one intersection to check for variation in the Ideal Saturation Flow Rate from hour-to-hour throughout the day. The intersection of S.R. 0119 / S.R. 0040 Ramps and S.R. 0021 in Uniontown was studied continuously for five hours; results are shown in Figure 4.3. This is the same intersection studied in the adverse weather condition data collection. For a continuous five-hour period, data were collected for the traffic lane from S.R. 0119 / S.R. 0040 Ramps left-turn onto S.R. 0021. As seen in Figure 4.3, the one-hour collection periods were used to determine a single ideal saturation flow rate shown on the figure at the end of the one-hour period. At 12:00 the ideal saturation flow rate is at approximately 1790pcphgpl. From that time to $2: 45 \mathrm{pm}$ the ideal saturation flow rate steadily decreases

to $1731 \mathrm{pcphgpl}$. At that point, the ideal saturation flow rate begins to increase until 4:30 where it peaks at approximately 1910pcphgpl.

These findings would be useful for more technologically advanced signal controllers offering the ability to vary signal timings over the course of the day. 
Figure 4.3 (Time of Day Comparison)

\section{Variation in SFR vs. Time of day (Uniontown S.R. 0040 Ramp left-turn onto S.R. 0021)}

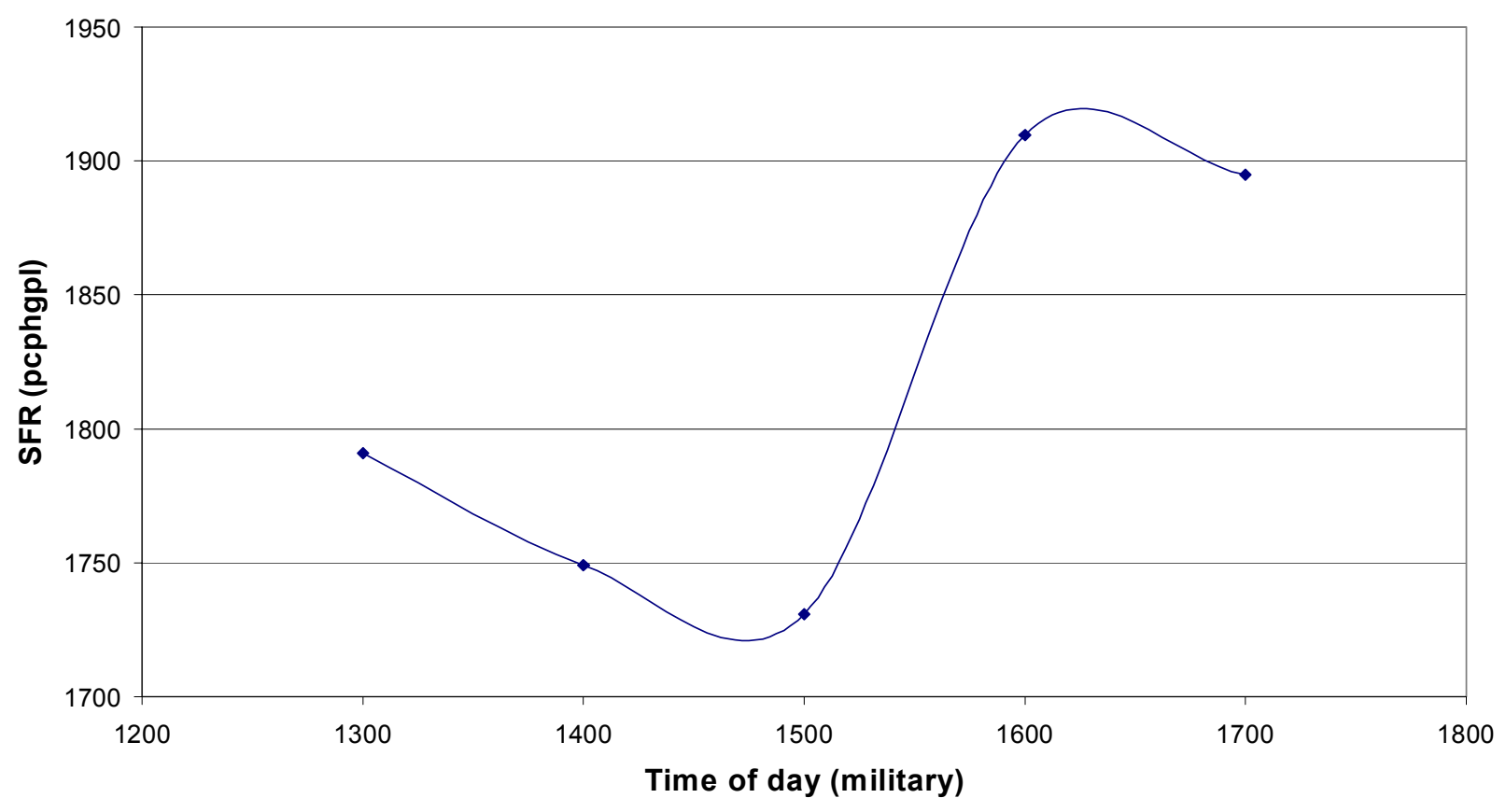

\subsection{Conclusions and Recommendations}

In conclusion, the primary objective of this study was to determine if the District-wide use of a 1800pcphgpl ideal saturation flow rate was warranted vs. the Highway Capacity Manual's recommended value of 1900pcphgpl. A quick glance at the results shows that shows the weighted Ideal Saturation Flow Rate over the four-county region making up PENNDOT District 12 was 1701 pcphgpl, 100pcphgpl less than the ideal saturation flow rate used by the district and 200pcphgpl less than the recommended value from the HCM. It is evident from the later sections of the study that it would not be accurate to rely on the above-mentioned information alone. Due to the time of day study, final adjustments had to be made to the findings increasing the overall average in District 12-0 about 
100pcphgpl and bringing the district-wide ideal saturation flow rate to $1801 \mathrm{pcphgpl}$. If PENNDOT District 12-0 is to use one ideal saturation flow rate district wide, the current value of $1800 \mathrm{pcphgpl}$ is appropriate. In addition, the correction factors associated with the HCM were tested. While the factors for lane type, grade, and heavy vehicle proved to be adequate, the findings for the lane width correction factor were uncertain. Due to the relationship between the Ideal Saturation Flow Rate and the correction factors, the impact that the lane width factor could have on the study as a whole had to be accounted for. Calculations were done to determine the impact of the lane width factor. It was determined in this case the effects are minimal. When looked at on a district-wide level, the factor can increase the Ideal SFR a maximum of approximately $15 \mathrm{pcphgpl}$. Furthermore, the only other section in this study that could affect the district- wide ideal saturation flow rate would be the time-of-day study. Initial data collection was done between the hours of 11:00 a.m. and 5:00 p.m. the majority falling between 12:00 p.m. and 2:00 p.m., due to the findings in the adverse weather study, a secondary collection was done to check for variation in the saturation flow rate throughout that time frame. The findings were conclusive revealing an increase in the saturation flow rate of approximately 100pcphgpl from off peak-to-peak travel times during the day. This proves to be very important for accurately determining what the ideal saturation flow rate for District 12 should be. As stated above, it was determined the saturation flow rate for the district was $1701 \mathrm{pcphgpl}$. Due to the majority of the data used in this finding being collected at off-peak travel times, it would be necessary to adjust the SFR accordingly. By doing so, the corrected District 12 ideal saturation flow rate would be approximately 1800pcpgpl, which is the value currently used by the District. Thus it is concluded due to 
the reasonableness and stability of the results, that the methodology for estimating ideal saturation flow rate is sound.

These findings would affect the comparisons done between counties and the individual SFR's for the counties. However increasing the SFR for the counties an equal amount would not affect the relationship between them. The results for the comparison of counties were also conclusive, showing a linear relationship between the saturation flow rate and the geographical distance from the urban core. Additional research would need to be done to more specifically determine the relationship and how it could be used to adjust Ideal SFR for specific areas due to their geographical characteristics. A general plan from the findings of this study alone would be to combine Fayette and Greene counties with a proposed Ideal saturation flow rate of 1720pcphgpl, as well as Washington and Westmoreland counties with a proposed ideal saturation flow rate of 1925pcphgpl. Note that both of the previous values recommended were adjusted due to the findings in the time of day study.

The study for adverse weather conditions did show patterns but was overall inconclusive due mainly to the change in ideal saturation flow rate between peak and off-peak periods. The first two collection pairs revealed the weather conditions unfavorably affected the SFR, but the last pair was skewed due to the collection under dry conditions during offpeak period travel and under wet conditions during peak period travel. Further data collection would need to be done while closely coordinating the collection times with hours of the day to firmly prove or disprove the hypotheses.

While numerous tests were performed on various scenarios concerning the adjustment factor for lane width, no conclusive evidence was found pinpointing the exact fault with 
the factor. Extensive data collection that is beyond the scope of this research would need to be done to arrive at a conclusion to the issue.

\section{Chapter 5 - Conclusions}

\subsection{Conclusions}

The primary objective of this study was to determine if the District-wide use of an 1800pcphgpl ideal saturation flow rate was warranted vs. the default value of 1900 pcphgpl recommended by the Highway Capacity Manual. Taking into consideration all of the aforementioned findings, the current ideal saturation flow rate of 1800pcphgpl, used by PENNDOT District 12-0, is appropriate if one value is used throughout the district. From this study, due to there geographical characteristics it is evident that a more localized approach should be used combining Fayette and Greene counties using an ideal saturation flow rate of 1720pcphgpl and also combining Washington and Westmoreland counties using an ideal saturation flow rate of 1925pcphgpl. In addition, the adjustment factors associated with the HCM were tested, while the factors for lane type, grade, and heavy vehicle proved to be adequate, the findings for the lane width correction factor were uncertain. Due to the direct relation between the ideal saturation flow rate and the correction factors, the impact the lane width factor could have on the study as a whole had to be accounted for. Calculations were done to see specifically what the impact the lane width factor could be and it was determined in this case the effects are negligible. When looked at on a district-wide level, the factor can increase the ideal saturation flow rate a maximum of approximately $15 \mathrm{pcphgpl}$. 
Moreover, the only other segment in this study that could affect the District-wide ideal saturation flow rate would be the time-of-day study. Initial data collection was done between the hours of 11:00 a.m. and 5:00 p.m., with the majority falling between 12:00 p.m. and 2:00 p.m.. Due to the findings in the adverse weather study, a secondary collection was done to check for inconsistency in the ideal saturation flow rate throughout that time frame. The findings were conclusive, revealing an increase in the ideal saturation flow rate of approximately 100pcphgpl from off-peak to peak travel times during the day. This proves to be crucial for determining what the ideal saturation flow rate for District 12 should be. As stated above, it was determined the ideal saturation flow rate for the District was 1701 pcphgpl. However, due to the majority of the data used in this finding being collected at off peak travel times it would be necessary to adjust the SFR accordingly. By doing so, the corrected District 12 ideal saturation flow rate would be approximately $1800 \mathrm{pcphgpl}$, which is the value currently used by the district at this time. Therefore it is concluded based on reasonableness and stability of the results that the methodology for estimating the ideal saturation flow rate appears to be a sound one.

These findings would affect the comparisons done between counties and the individual SFR's for the counties also. Conversely, increasing the SFR for all counties by an equal amount would not influence the relationship between them. The results for the comparison of counties were also conclusive, showing a linear relationship between the saturation flow rate and the population density. Additional research would need to be done to establish a relationship and how that relationship could be used to adjust ideal saturation flow rate for specific areas based their geographical location. 
The study for adverse weather conditions did show patterns that supported the hypothesis of a reduced ideal saturation flow rate during rain events, but was overall inconclusive due mainly to the change in ideal saturation flow rate over the course of a day. The first two collection pairs proved the rainy weather conditions unfavorably affected the ideal saturation flow rate, but the last pair was skewed due to the collection under dry conditions during off-peak travel and under wet conditions during peak travel. Further data collection would need to be done while closely coordinating the collection times with the peak travel times to decisively prove or disprove the theory.

While numerous tests were performed on an assortment of scenarios concerning the correction factor for lane width no conclusive evidence was found pinpointing the exact

trouble with the factor. Additional research that is beyond the scope of this project would be needed to adequately represent all variations of the factor including lanes less than, equal to, and greater than the ideal lane width of 12 feet.

\subsection{Limitations of the Research and Recommendations for Further}

\section{Research}

Upon completion of the project, a few limitations of the research should be identified. First, a larger data set allows for more in-depth and conclusive data reduction to be performed as well as addressing all areas to have a sufficient data set (i.e. lane width). By doing so it will prevent unrelated factors from having an effect on the data set, specific attention should be given making sure all data collection is done noting all exterior factors (i.e. time of day and weather).

Some ideas for additional research would be to perform detailed time specific data collection, which could be analyzed for determining varying ideal saturation flow rates 
over the entire length of a day. Also, due to the problem encountered with the lane width correction factor, extensive collection should be done to examine the validity of the numbers used for the non-ideal lane widths. 


\section{References}

\subsection{References}

Garber, Nicholas J. and Hoel, Lester A. Traffic and Highway Engineering Second Edition. Brooks/Cole Publishing Company, 1999. 399-415, 460-469.

Lum, Harry S. "Statistical Shortcomings in Traffic Studies." Public Roads Vol. 54, No. 4 (1991): 283-287

McMahon, Joseph W., Krane, John P., Federico, Albert P. "Saturation Flow Rates by Facility Type.” ITE Journal January (1997): 46-50

NAVTEQ Inc. “Geographical Map” NAVTEQ Inc. 2003/Yahoo Inc. 2004 (10 March 2004) http://www.maps.yahoo.com/

Transportation Research Board National Research Council. Highway Capacity Manual 2000. Washington D.C.: TRB 2000. 16-9 to 16-18, 16-158 to 16-160

Walpole, Ronald E., Myers, Raymond H., Myers, Sharon L. Probability and Statistics for Engineers and Scientists Sixth Edition. Prentice Hall, Inc. 1998. 234-235, 461463 
Appendix I

(Correction Factor Default Values) 
Default Values: All information in the following tables is from (Garber,1999/ TRB,2000)

Adjustment Factor for Average Lane Width $\left(f_{w}\right)$

\begin{tabular}{|c|c|}
\hline $\begin{array}{c}\text { Average Lane } \\
\text { Width, W (ft) }\end{array}$ & $\begin{array}{c}\text { Lane Width } \\
\text { Factor, } f_{w}\end{array}$ \\
\hline 8 & 0.867 \\
\hline 9 & 0.900 \\
\hline 10 & 0.933 \\
\hline 11 & 0.967 \\
\hline 12 & 1.000 \\
\hline 13 & 1.033 \\
\hline 14 & 1.067 \\
\hline 16 & 1.100 \\
\hline Note: $f_{w}=1+(\mathrm{W}-12) / 30 ; \mathrm{W} \geq 8$ (If $\mathrm{W}>16$, a two lane analysis may be considered). \\
\hline
\end{tabular}

Adjustment Factor for Heavy Vehicles $\left(f_{H V}\right)$

\begin{tabular}{|c|c|}
\hline $\begin{array}{c}\text { Percent Heavy Vehicles, } \\
\% \text { HV }\end{array}$ & Heavy Vehicle Factor, \\
\hline 0 & $f_{H V}$ \\
2 & 1.000 \\
4 & 0.980 \\
6 & 0.962 \\
8 & 0.943 \\
10 & 0.926 \\
15 & 0.909 \\
20 & 0.870 \\
25 & 0.833 \\
30 & 0.800 \\
35 & 0.769 \\
40 & 0.741 \\
45 & 0.714 \\
50 & 0.690 \\
75 & 0.667 \\
100 & 0.571 \\
\hline
\end{tabular}

Note: $f_{H V}=100 /\left(100+\% \mathrm{HV}\left(\mathrm{E}_{\mathrm{r}}-1\right)\right) ; 0 \leq \% \mathrm{HV} \mathrm{U} \leq 100$. Where $\mathrm{E}_{\mathrm{r}}=2.0$ passenger cars per heavy vehicle. 
Adjustment Factor for Grade $\left(f_{g}\right)$

\begin{tabular}{|c|c|c|}
\hline \multicolumn{2}{|c|}{ Grade, $\% \mathrm{G}$} & Grade Factor, $f_{g}$ \\
\hline Type & Percent & 1.030 \\
& -6 or less & 1.020 \\
& -4 & 1.010 \\
Level & -2 & 1.000 \\
Uphill & 0 & 0.990 \\
& +2 & 0.980 \\
& +4 & 0.970 \\
& +6 & 0.960 \\
& +8 & 0.950 \\
\hline \multicolumn{2}{|c|}{+10 or more } \\
\hline
\end{tabular}

Adjustment Factor for Parking $\left(f_{p}\right)$

\begin{tabular}{|c|c|c|c|c|c|c|}
\hline \multirow{2}{*}{$\begin{array}{l}\text { No. of } \\
\text { Lanes in } \\
\text { Lane } \\
\text { Group, N }\end{array}$} & \multirow{2}{*}{$\begin{array}{c}\text { No } \\
\text { Parking }\end{array}$} & \multicolumn{5}{|c|}{ No. of Parking Maneuvers per Hour, $\mathrm{N}_{\mathrm{m}}$} \\
\hline & & 0 & 10 & 20 & 30 & $40^{\mathrm{a}}$ \\
\hline 1 & 1.000 & 0.900 & 0.850 & 0.800 & 0.750 & 0.700 \\
\hline 2 & 1.000 & 0.950 & 0.925 & 0.900 & 0.875 & 0.850 \\
\hline $3^{\mathrm{a}}$ & 1.000 & 0.967 & 0.950 & 0.933 & 0.917 & 0.900 \\
\hline \multicolumn{7}{|c|}{$\begin{array}{l}\text { Note: } f_{p}=\left(\mathrm{N}-0.1-18 \mathrm{~N}_{\mathrm{m}} / 3600\right) / \mathrm{N} ; 0 \leq \mathrm{N}_{\mathrm{m}} \leq 180, f_{p} \geq 0.05 \text {. } \\
\text { a Use formula for more than } 3 \text { lanes of more than } 40 \text { maneuvers per hour. }\end{array}$} \\
\hline
\end{tabular}

Adjustment Factor for Bus Blockage $\left(f_{b b}\right)$

\begin{tabular}{|l|l|l|l|l|l|}
\hline $\begin{array}{l}\text { No. of Lanes } \\
\text { in Lane } \\
\text { Group, N }\end{array}$ & 0 & \multicolumn{6}{l|}{ No. of Buses Stopping Per Hour, $\mathrm{N}_{\mathrm{B}}$} \\
\cline { 2 - 6 } & & 10 & 20 & 30 & 40 \\
\hline 1 & 1.000 & 0.960 & 0.920 & 0.880 & 0.840 \\
$3^{\mathrm{a}}$ & 1.000 & 0.980 & 0.960 & 0.940 & 0.920 \\
\hline & 1.000 & 0.987 & 0.973 & 0.960 & 0.947 \\
\hline
\end{tabular}

Note: $f_{b b}=\left(\mathrm{N}-14.4 \mathrm{~N}_{\mathrm{B}} / 3600\right) / \mathrm{N} ; 0 \leq \mathrm{N}_{\mathrm{B}} \leq 250, f_{b b} \geq 0.05$

${ }^{\mathrm{a}}$ Use formula for more than 3 lanes or more than 40 buses stopping per hour. 
Default lane utilization factors $\left(f_{L u}\right)$

\begin{tabular}{|c|c|c|c|}
\hline $\begin{array}{c}\text { Lane Group } \\
\text { Movements }\end{array}$ & $\begin{array}{c}\text { No. of Lanes } \\
\text { In Lane Group }\end{array}$ & $\begin{array}{c}\text { Percent of Traffic in } \\
\text { Most Heavily } \\
\text { Traveled Lane }\end{array}$ & $\begin{array}{c}\text { Lane Utilization } \\
\text { Factor }\left(f_{L u}\right)\end{array}$ \\
\hline \multirow{3}{*}{ Through or shared } & 1 & 100.0 & 1.00 \\
\cline { 2 - 4 } & 2 & 52.5 & 0.95 \\
Exclusive left turn & $3^{\mathrm{a}}$ & 36.7 & 0.91 \\
\cline { 2 - 4 } Exclusive right turn & 1 & 100.0 & 1.00 \\
\cline { 2 - 4 } & $2^{\mathrm{a}}$ & 51.5 & 0.97 \\
\hline
\end{tabular}

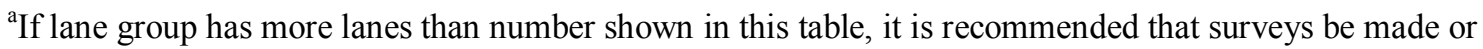
the largest $f_{L u}$-factor shown for that type of lane group be used

Adjustment Factor for Left Turns $\left(f_{L T}\right)$

\begin{tabular}{|c|c|}
\hline Lane Type (Protected Phasing) & Formula \\
\hline Exclusive Lane & $f_{L T}=0.95$ \\
\hline Shared Lane & $f_{L T}=1 /\left(1.0+0.05 \mathrm{P}_{\mathrm{LT}}\right)$ \\
\hline Note: $\mathrm{P}_{\mathrm{LT}}=$ proportion of left turns in lane group. \\
\hline
\end{tabular}

Adjustment Factor for Right Turns $\left(f_{R T}\right)$

\begin{tabular}{|c|c|}
\hline Lane Type & Formula \\
\hline Exclusive Lane & $f_{R T}=0.85$ \\
\hline Shared Lane & $f_{R T}=1.0-(0.15) \mathrm{P}_{\mathrm{RT}}$ \\
\hline Single Lane & $f_{R T}=1.0-(0.135) \mathrm{P}_{\mathrm{RT}}$ \\
\hline Note: $\mathrm{P}_{\mathrm{RT}}=$ proportion of right turns in lane group, $f_{R T} \geq 0.050$ \\
\hline
\end{tabular}


Adjustment Factor for Pedestrian-bicycle blockage $\left(f_{L p b}\right)$, and $\left(f_{R p b}\right)$

\begin{tabular}{|c|c|}
\hline Adjustment Direction & Formula \\
\hline Left Adjustment & $f_{L p b}=1.0-\mathrm{P}_{\mathrm{LT}}\left(1-\mathrm{A}_{\mathrm{pbt}}\right)\left(1-\mathrm{P}_{\mathrm{LTA}}\right)$ \\
\hline $\begin{array}{r}\text { Right Adjustment } \\
\end{array}$ & $f_{R p b}=1.0-\mathrm{P}_{\mathrm{RT}}\left(1-\mathrm{A}_{\mathrm{pbt}}\right)\left(1-\mathrm{P}_{\mathrm{RTA}}\right)$ \\
\hline \multicolumn{2}{|c|}{$\begin{aligned} \text { Notes: } & \mathrm{P}_{\mathrm{LT}}=\text { proportion of left turns in lane group } \\
& \mathrm{A}_{\mathrm{pbt}}=\text { permitted phase adjustment } \\
& \mathrm{P}_{\mathrm{LTA}}=\text { proportion of left turn protected green over total left turn green } \\
& \mathrm{P}_{\mathrm{RT}}=\text { proportion of right turns in lane group } \\
& \mathrm{P}_{\mathrm{RTA}}=\text { proportion of right turn protected green over total right turn green }\end{aligned}$} \\
\hline
\end{tabular}


Appendix II

(Data reduction Summary Sheets) 
All initial data*

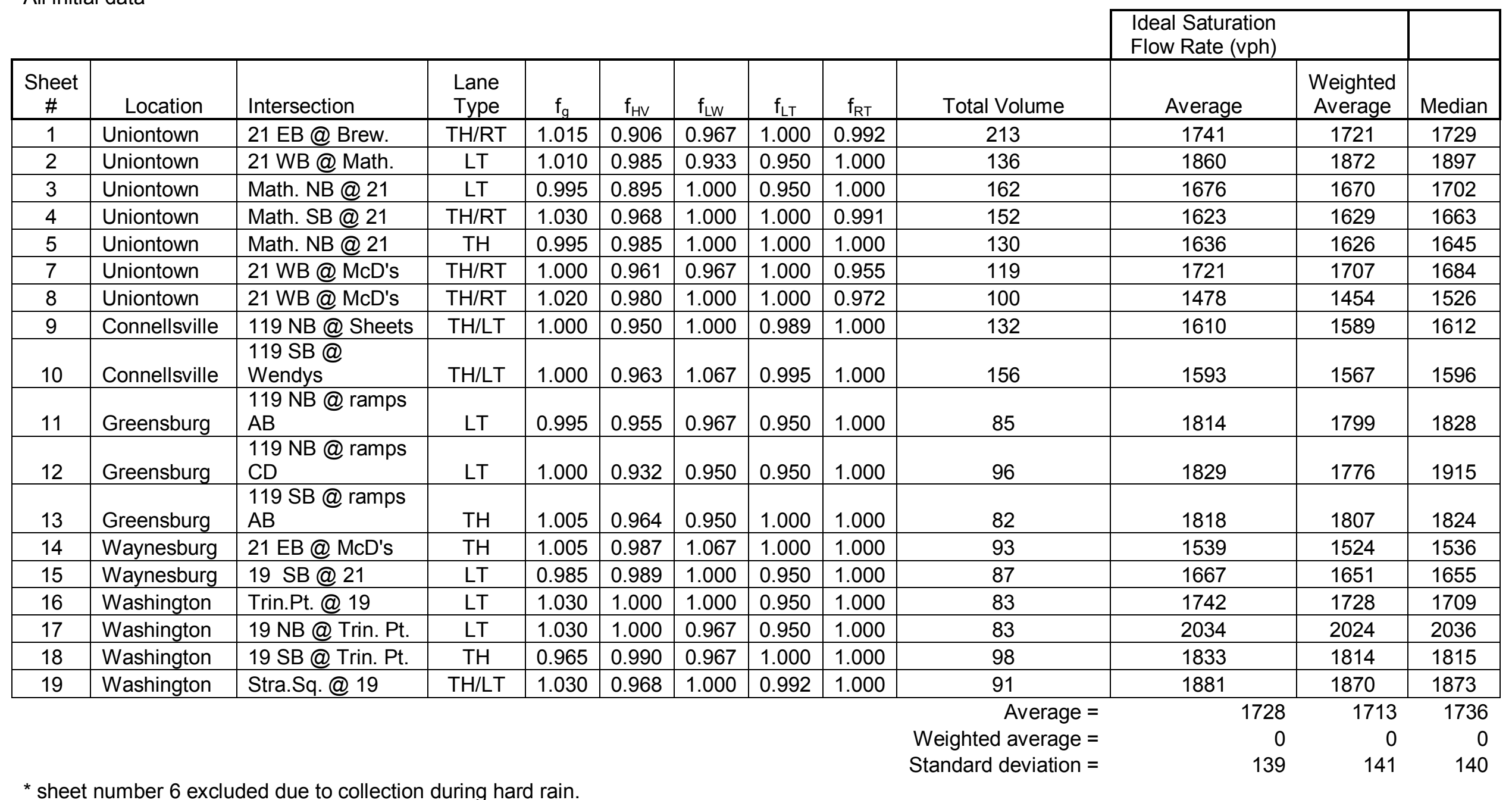




\begin{tabular}{|c|c|c|c|c|c|c|c|c|c|c|c|c|}
\hline \multicolumn{10}{|c|}{ HARD rain } & \multicolumn{2}{|c|}{$\begin{array}{l}\text { Ideal Saturation } \\
\text { Flow Rate (vph) }\end{array}$} & \multirow[b]{2}{*}{ Median } \\
\hline $\begin{array}{c}\text { Sheet } \\
\#\end{array}$ & Location & Intersection & $\begin{array}{l}\text { Lane } \\
\text { Type }\end{array}$ & $f_{g}$ & $\mathrm{f}_{\mathrm{HV}}$ & $f_{L W}$ & $f_{L T}$ & $f_{R T}$ & Total Volume & Average & $\begin{array}{c}\text { Weighted } \\
\text { Average }\end{array}$ & \\
\hline 6 & Uniontown & Math. NB @ 21 & $\mathrm{LT}$ & 0.995 & 0.870 & 1.000 & 0.950 & 1.000 & 87 & 1294 & 1665 & 1628 \\
\hline
\end{tabular}

Sheet 2, 3, \& 4 for comparison under dry conditions shown here and 2R, 3R, \& 4R under wet conditions shown below

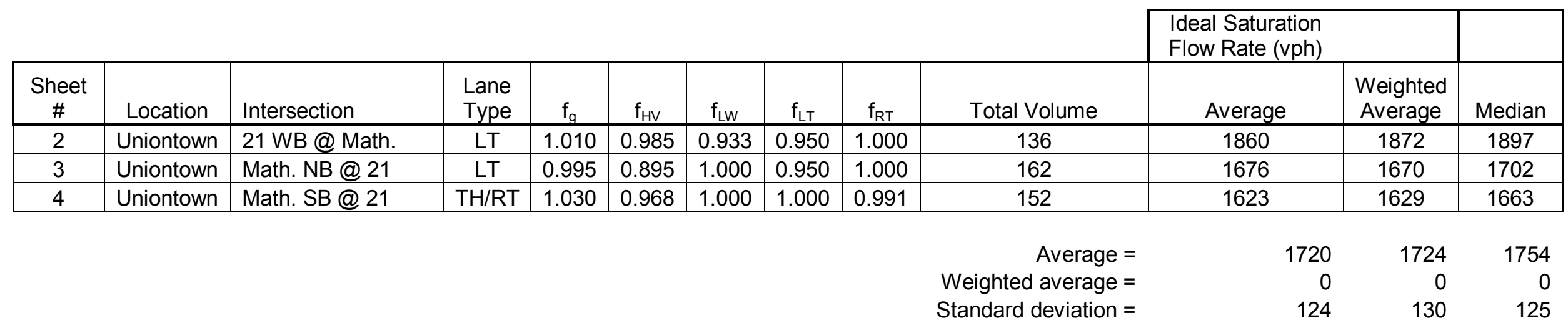

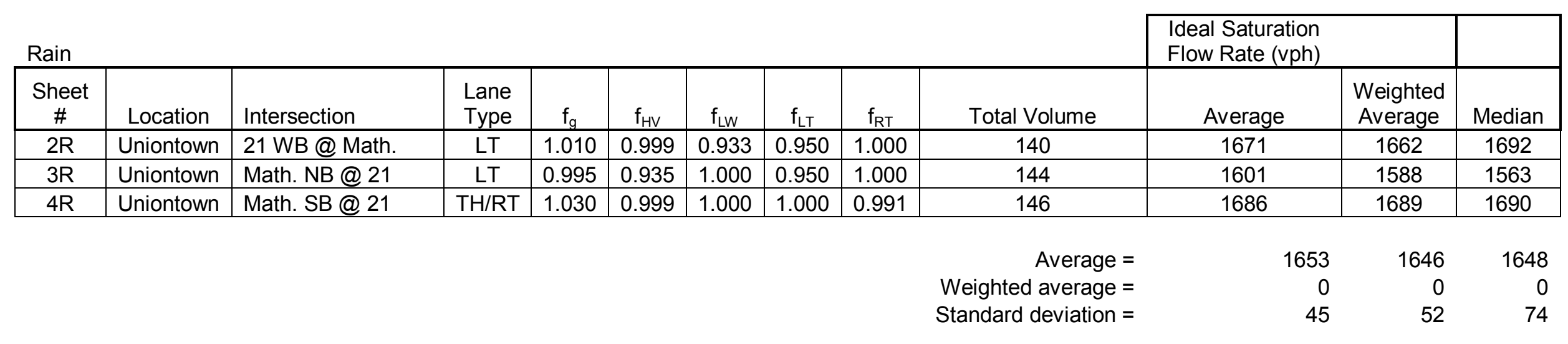


Sheets 3-12 to 3-4 are of collections of the same intersection for a continuous five hour period 12:00 to 4:00 p.m.

\begin{tabular}{|c|c|c|c|c|c|c|c|c|c|c|c|c|}
\hline \multirow[b]{2}{*}{ Sheet \# } & \multirow[b]{2}{*}{ Location } & \multirow[b]{2}{*}{ Intersection } & \multirow[b]{2}{*}{$\begin{array}{l}\text { Lane } \\
\text { Type }\end{array}$} & \multirow[b]{2}{*}{$f_{g}$} & \multirow[b]{2}{*}{$\mathrm{f}_{\mathrm{HV}}$} & \multirow[b]{2}{*}{$\mathrm{f}_{\mathrm{LW}}$} & \multirow[b]{2}{*}{$\mathrm{f}_{\mathrm{LT}}$} & \multirow[b]{2}{*}{$f_{R T}$} & \multirow[b]{2}{*}{ Total Volume } & \multicolumn{2}{|c|}{$\begin{array}{l}\text { Ideal Saturation } \\
\text { Flow Rate (vph) }\end{array}$} & \multirow[b]{2}{*}{ Median } \\
\hline & & & & & & & & & & Average & $\begin{array}{l}\text { Weighted } \\
\text { Average }\end{array}$ & \\
\hline $3-12$ & Uniontown & Math. NB @ 21 & $\mathrm{LT}$ & 0.995 & 0.941 & 1.000 & 0.950 & 1.000 & 96 & 1814 & 1791 & 1812 \\
\hline $3-1$ & Uniontown & Math. NB @ 22 & LT & 0.995 & 0.927 & 1.000 & 0.950 & 1.000 & 101 & 1755 & 1749 & 1727 \\
\hline $3-2$ & Uniontown & Math. NB @ 23 & LT & 0.995 & 0.924 & 1.000 & 0.950 & 1.000 & 97 & 1744 & 1731 & 1739 \\
\hline $3-3$ & Uniontown & Math. NB @ 24 & LT & 0.995 & 0.923 & 1.000 & 0.950 & 1.000 & 141 & 1898 & 1910 & 1938 \\
\hline $3-4$ & Uniontown & Math. NB @ 25 & $\overline{L T}$ & 0.995 & 0.920 & 1.000 & 0.950 & 1.000 & 138 & 1895 & 1895 & 1923 \\
\hline
\end{tabular}

\begin{tabular}{|c|c|c|c|}
\hline $\begin{array}{r}\text { Average }= \\
\text { Weighted average }\end{array}$ & 1821 & 1815 & 1828 \\
\hline & 0 & 0 & 0 \\
\hline $\begin{array}{r}\text { Standard deviation } \\
=\end{array}$ & 74 & 83 & 99 \\
\hline
\end{tabular}




\section{Appendix III}

(Field collection/Data reduction sheets) 
City: Uniontown

State: $\mathrm{Pa}$.

Technician: BMD

Time: 12:07-1:10pm

Date: $\quad 5 / 29 / 2002$

\begin{tabular}{|c|c|c|c|c|c|}
\hline \# of Counts & Elapsed Time (sec.) & Total \# of vehicles & $\begin{array}{c}\text { \# of } \\
\text { heavy } \\
\text { vehicles }\end{array}$ & $\begin{array}{c}\text { \# of Rt. } \\
\text { Turns }\end{array}$ & $\begin{array}{c}\text { Calculated } \\
\text { SFR }\end{array}$ \\
\hline 1 & 16.28 & 8 & 0 & 1 & 1769.04 \\
\hline 2 & 35.25 & 16 & 1 & 1 & 1634.04 \\
\hline 3 & 22.69 & 9 & 2 & 0 & 1427.94 \\
\hline 4 & 26.01 & 10 & 2 & 2 & 1384.08 \\
\hline 5 & 30.22 & 10 & 2 & 2 & 1191.26 \\
\hline 6 & 27.15 & 8 & 2 & 0 & 1060.77 \\
\hline 7 & 23.85 & 13 & 0 & 0 & 1962.26 \\
\hline 8 & 24.25 & 11 & 0 & 0 & 1632.99 \\
\hline 9 & 21.22 & 9 & 0 & 0 & 1526.86 \\
\hline 10 & 25.03 & 12 & 1 & 1 & 1725.93 \\
\hline 11 & 29.16 & 13 & 2 & 0 & 1604.94 \\
\hline 12 & 17.02 & 8 & 0 & 1 & 1692.13 \\
\hline 13 & 25.38 & 10 & 2 & 1 & 1418.44 \\
\hline 14 & 21.94 & 10 & 0 & 2 & 1640.84 \\
\hline 15 & 26.75 & 11 & 1 & 1 & 1480.37 \\
\hline 16 & 28.69 & 10 & 2 & 1 & 1254.79 \\
\hline 17 & 28.68 & 12 & 2 & 0 & 1506.28 \\
\hline 18 & 29.15 & 12 & 2 & 0 & 1481.99 \\
\hline 19 & 17.91 & 9 & 0 & 0 & 1809.05 \\
\hline 20 & 28.35 & 12 & 1 & 0 & 1523.81 \\
\hline & 504.98 & 213 & 22 & 13 & 30727.82 \\
\hline
\end{tabular}

$$
\begin{aligned}
& g=-3 \% \\
& L w=11^{\prime}
\end{aligned}
$$

Pavement

Condition: dry

East/West: Rt. 21

21 Eastbound St / Rt

Weather: 82, clear 
North/South: 40 access

East/West: Rt. 21

21 Westbound Lt.

Approach studied: Turn

Weather: 82, clear

Pavement

Condition: dry
City: Uniontown

State: $\mathrm{Pa}$.

Technician: BMD

Time: 1:15-2:15pm

Date: $\quad 5 / 29 / 2002$

\begin{tabular}{|c|c|c|c|c|}
\hline \# of Counts & Elapsed Time (sec.) & Total \# of vehicles & $\begin{array}{c}\text { \# of } \\
\text { heavy } \\
\text { vehicles }\end{array}$ & $\begin{array}{c}\text { Calculated } \\
\text { SFR }\end{array}$ \\
\hline 1 & 11.12 & 4 & 0 & 1294.96 \\
\hline 2 & 10.41 & 5 & 0 & 1729.11 \\
\hline 3 & 14.53 & 6 & 0 & 1486.58 \\
\hline 4 & 23.22 & 10 & 0 & 1550.39 \\
\hline 5 & 10 & 5 & 0 & 1800.00 \\
\hline 6 & 8.43 & 4 & 0 & 1708.19 \\
\hline 7 & 16.59 & 8 & 0 & 1735.99 \\
\hline 8 & 18.46 & 10 & 0 & 1950.16 \\
\hline 9 & 10.5 & 5 & 0 & 1714.29 \\
\hline 10 & 19.44 & 9 & 0 & 1666.67 \\
\hline 11 & 14.5 & 7 & 0 & 1737.93 \\
\hline 12 & 13.38 & 6 & 0 & 1614.35 \\
\hline 13 & 23.56 & 11 & 1 & 1680.81 \\
\hline 14 & 25.96 & 13 & 0 & 1802.77 \\
\hline 15 & 19.82 & 9 & 0 & 1634.71 \\
\hline 16 & 11 & 5 & 0 & 1636.36 \\
\hline 17 & 10.38 & 4 & 0 & 1387.28 \\
\hline 18 & 9.84 & 5 & 0 & 1829.27 \\
\hline 19 & 11.4 & 5 & 0 & 1578.95 \\
\hline 20 & 13.96 & 5 & 1 & 1289.40 \\
\hline & 296.5 & 136 & 2 & 32828.17 \\
\hline
\end{tabular}

$$
\begin{aligned}
& g=-2 \% \\
& L w=10^{\prime}
\end{aligned}
$$

\begin{tabular}{rcc} 
\% heavy veh.: & 1.5 & Ideal: \\
Average SFR: & 1641.41 & 1860 \\
\cline { 2 - 2 } Weighted Average & & 1872 \\
SFR: & 1651.26 & \\
${ } }$ & 172.47 & \\
Coefficient of & & \\
Variation: & $\frac{10.44}{1673.74}$ & 1897 \\
Median: & $\frac{1674}{29747.31}$ & \\
Variance: &
\end{tabular}


North/South: 40 access

East/West: Rt. 21

from $40 \mathrm{Lt}$

Approach studied:

Weather:

turn

Pavement

Condition: dry
City: Uniontown

State: $\mathrm{Pa}$.

Technician: BMD

Time: 1:15-2:25pm

Date: $\quad 5 / 29 / 2002$

\begin{tabular}{|c|c|c|c|c|}
\hline \# of Counts & $\begin{array}{c}\text { Elapsed } \\
\text { Time (sec.) }\end{array}$ & Total \# of vehicles & $\begin{array}{c}\text { \# of } \\
\text { heavy } \\
\text { vehicles }\end{array}$ & $\begin{array}{c}\text { Calculated } \\
\text { SFR }\end{array}$ \\
\hline 1 & 19.87 & 8 & 2 & 1449.42 \\
\hline 2 & 21.44 & 8 & 2 & 1343.28 \\
\hline 3 & 16.82 & 6 & 1 & 1284.19 \\
\hline 4 & 37.37 & 14 & 2 & 1348.68 \\
\hline 5 & 22.15 & 6 & 2 & 975.17 \\
\hline 6 & 17.68 & 8 & 0 & 1628.96 \\
\hline 7 & 19.12 & 6 & 0 & 1129.71 \\
\hline 8 & 19.2 & 8 & 0 & 1500.00 \\
\hline 9 & 29.25 & 13 & 1 & 1600.00 \\
\hline 10 & 10.73 & 5 & 0 & 1677.54 \\
\hline 11 & 14.69 & 5 & 1 & 1225.32 \\
\hline 12 & 15.25 & 6 & 0 & 1416.39 \\
\hline 13 & 9.81 & 4 & 0 & 1467.89 \\
\hline 14 & 10.06 & 4 & 0 & 1431.41 \\
\hline 15 & 28.38 & 13 & 0 & 1649.05 \\
\hline 16 & 29.12 & 14 & 1 & 1730.77 \\
\hline 17 & 21.44 & 9 & 2 & 1511.19 \\
\hline 18 & 25.69 & 9 & 2 & 1261.19 \\
\hline 19 & 27.53 & 8 & 3 & 1046.13 \\
\hline 20 & 17 & 8 & 0 & 1694.12 \\
\hline & 412.6 & 162 & 19 & 28370.41 \\
\hline Sum: & & & & \\
\hline & & & 0 & 0 \\
\hline
\end{tabular}

$$
\begin{aligned}
& g=+1 \% \\
& L w=12^{\prime}
\end{aligned}
$$

\begin{tabular}{rcc} 
\% heavy veh.: & 11.7 & Ideal: \\
Average SFR: & 1418.52 & 1676 \\
\cline { 2 - 2 } Weighted Average & & 1670 \\
SFR: & 1413.48 & \\
Standard deviation: & 217.52 & \\
Coefficient of & & \\
Variation: & $\frac{15.39}{1440.42}$ & 1702 \\
Median: & $\frac{140.11}{47316.11}$ &
\end{tabular}


North/South: 40 access

East/West: Rt. 21 from Walmart towards 40

Approach studied: St. / Rt.

Weather: 82, clear

Pavement

Condition: dry
City: Uniontown

State: $\mathrm{Pa}$.

Technician: BMD

Time: 2:15-3:20pm

Date: $\quad 5 / 29 / 2002$

\begin{tabular}{|c|c|c|c|c|c|}
\hline \# of Counts & $\begin{array}{c}\text { Elapsed Time } \\
(\text { sec. })\end{array}$ & Total \# of vehicles & $\begin{array}{c}\text { \# of heavy } \\
\text { vehicles }\end{array}$ & $\begin{array}{c}\text { \# of Rt. } \\
\text { Turns }\end{array}$ & $\begin{array}{c}\text { Calculated } \\
\text { SFR }\end{array}$ \\
\hline 1 & 13.63 & 8 & 1 & 0 & 2112.99 \\
\hline 2 & 8.5 & 4 & 0 & 0 & 1694.12 \\
\hline & & & & & \\
\hline 3 & 21.41 & 10 & 0 & 1 & 1681.46 \\
\hline 4 & 16.9 & 8 & 0 & 0 & 1704.14 \\
\hline 5 & 12.88 & 4 & 1 & 0 & 1118.01 \\
\hline 6 & 23.72 & 12 & 0 & 1 & 1821.25 \\
\hline 7 & 22.44 & 10 & 0 & 0 & 1604.28 \\
\hline 8 & 18.25 & 8 & 0 & 0 & 1578.08 \\
\hline 9 & 20.57 & 9 & 0 & 1 & 1575.11 \\
\hline 10 & 21.35 & 11 & 0 & 0 & 1854.80 \\
\hline 11 & 13.25 & 6 & 0 & 2 & 1630.19 \\
\hline 12 & 16.31 & 7 & 0 & 0 & 1545.06 \\
\hline 13 & 18.81 & 9 & 0 & 2 & 1722.49 \\
\hline 14 & 14.09 & 7 & 1 & 0 & 1788.50 \\
\hline 15 & 13.41 & 4 & 1 & 0 & 1073.83 \\
\hline 16 & 18.03 & 5 & 1 & 1 & 998.34 \\
\hline 17 & 17.38 & 8 & 0 & 0 & 1657.08 \\
\hline 18 & 20.44 & 9 & 0 & 2 & 1585.13 \\
\hline 19 & 12.97 & 7 & 0 & 0 & 1942.95 \\
\hline 20 & 15.53 & 6 & 0 & 0 & 1390.86 \\
\hline & 339.87 & 152 & 5 & 10 & 32078.65 \\
\hline & & & & &
\end{tabular}

$\mathrm{g}=-7.7 \%$

$\mathrm{Lw}=12^{\prime}$
$\%$ heavy veh.:

$\%$ Rt turns.:

Average SFR:

Weighted Average

SFR:

$\frac{3.3}{6.6}$

1603.93

Ideal: 1623

Standard deviation:

Coefficient of

Variation:

Median:

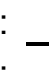




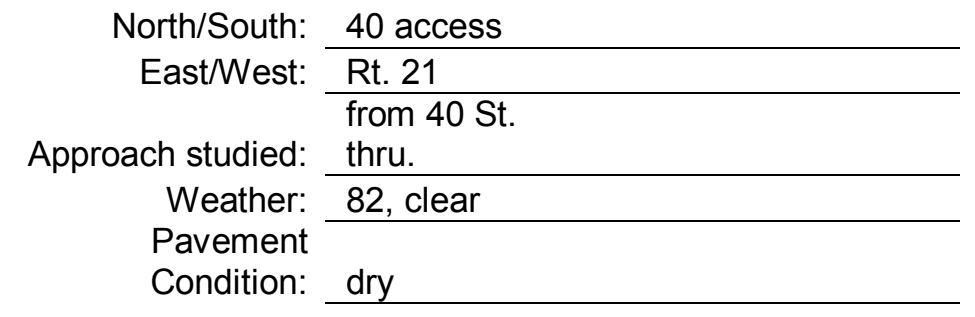

City: Uniontown

State: $\mathrm{Pa}$.

Technician: BMD

Time: 3:36-4:45pm

Date: $\quad 5 / 29 / 2002$

\begin{tabular}{|c|c|c|c|c|}
\hline \# of Counts & $\begin{array}{c}\text { Elapsed Time } \\
(\text { sec.) }\end{array}$ & $\begin{array}{c}\text { \# of } \\
\text { heavy } \\
\text { vehicles }\end{array}$ & $\begin{array}{c}\text { Calculated } \\
\text { SFR }\end{array}$ \\
\hline 1 & 7.75 & 4 & 0 & 1858.06 \\
\hline 2 & 8.06 & 4 & 0 & 1786.60 \\
\hline 3 & 9.78 & 4 & 0 & 1472.39 \\
\hline 4 & 12.85 & 6 & 0 & 1680.93 \\
\hline 5 & 10.62 & 5 & 0 & 1694.92 \\
\hline 6 & 12.72 & 5 & 0 & 1415.09 \\
\hline 7 & 19.1 & 9 & 0 & 1696.34 \\
\hline 8 & 9.37 & 4 & 0 & 1536.82 \\
\hline 9 & 18.17 & 8 & 0 & 1585.03 \\
\hline 10 & 8.28 & 4 & 0 & 1739.13 \\
\hline 11 & 20 & 9 & 1 & 1620.00 \\
\hline 12 & 23.78 & 11 & 0 & 1665.26 \\
\hline 13 & 18.69 & 7 & 0 & 1348.31 \\
\hline 14 & 21.37 & 10 & 0 & 1684.60 \\
\hline 15 & 8.81 & 4 & 0 & 1634.51 \\
\hline 16 & 16.35 & 7 & 0 & 1541.28 \\
\hline 17 & 18.04 & 8 & 1 & 1596.45 \\
\hline 18 & 16.71 & 7 & 0 & 1508.08 \\
\hline 19 & 12.95 & 5 & 0 & 1389.96 \\
\hline 20 & 20.22 & 9 & 2 & 1602.37 \\
\hline & 293.62 & 130 & & \\
\hline & & & 0 & 32056.16 \\
\hline
\end{tabular}

$$
\begin{aligned}
& g=-7.7 \% \\
& L w=12^{\prime}
\end{aligned}
$$

\begin{tabular}{|c|c|c|}
\hline \multirow{3}{*}{$\begin{array}{r}\text { \% heavy veh.: } \\
\text { Average SFR: } \\
\text { Weighted Average }\end{array}$} & 1.5 & Ideal: \\
\hline & 1602.81 & 1636 \\
\hline & 1593.90 & 1626 \\
\hline Standard deviation: & 132.29 & \\
\hline $\begin{array}{l}\text { Coefficient of } \\
\text { Variation: }\end{array}$ & 8.30 & \\
\hline Median: & 1611.19 & 1645 \\
\hline Variance: & 17501.63 & \\
\hline
\end{tabular}


North/South: 40 access

East/West: Rt. 21 from 40 Lt. Onto 21

Approach studied: West

Weather: 75, Hard rain 3-3:15

Pavement

Condition: wet
City: Uniontown

State: $\mathrm{Pa}$.

Technician: BMD

Time: 3:00-4:00pm

Date: $6 / 5 / 2002$

\begin{tabular}{|c|c|c|c|c|}
\hline \# of Counts & Elapsed Time (sec.) & Total \# of vehicles & $\begin{array}{c}\text { \# of } \\
\text { heavy } \\
\text { vehicles }\end{array}$ & $\begin{array}{c}\text { Calculated } \\
\text { SFR }\end{array}$ \\
\hline 1 & 24.31 & 9 & 1 & 1332.78 \\
\hline 2 & 9.65 & 5 & 1 & 1865.28 \\
\hline 3 & 20.13 & 5 & 1 & 894.19 \\
\hline 4 & 10.75 & 4 & 1 & 1339.53 \\
\hline 5 & 14.47 & 4 & 0 & 995.16 \\
\hline 6 & 18.5 & 6 & 1 & 1167.57 \\
\hline 7 & 12.81 & 6 & 0 & 1686.18 \\
\hline 8 & 21.38 & 10 & 1 & 1683.82 \\
\hline 9 & 17.5 & 6 & 2 & 1234.29 \\
\hline 10 & 8.5 & 4 & 0 & 1694.12 \\
\hline 11 & 7.6 & 4 & 1 & 1894.74 \\
\hline 12 & 19.34 & 8 & 1 & 1489.14 \\
\hline 13 & 17.85 & 6 & 2 & 1210.08 \\
\hline 14 & 14.09 & 5 & 0 & 1277.50 \\
\hline 15 & 11.84 & 5 & 1 & 1520.27 \\
\hline & 228.72 & 87 & 13 & 21284.66 \\
\hline
\end{tabular}

$$
\begin{aligned}
& g=+1 \% \\
& L W=12^{\prime}
\end{aligned}
$$

$\%$ heavy veh.:

14.9

Ideal:

Average SFR: $1064.23 \quad 1294$

Weighted Average

SFR: $\quad 1369.36$

Standard Deviation: 303.28

Coefficient of

Variation:

$$
\frac{22.15}{1339.53}
$$

1628

Variance: $\quad 91978.19$

Data not used due to very hard rain at time of collection! 
North/South: McDonalds access

East/West: Rt. 21

21 Westbound St.

Approach studied: thru.

Weather: 87, clear

Pavement

Condition: dry
City: Uniontown

State: $\mathrm{Pa}$.

Technician: BMD

Time: 1:14-2:00pm

Date: $6 / 5 / 2002$

\begin{tabular}{|c|c|c|c|c|c|}
\hline \# of Counts & Elapsed Time (sec.) & Total \# of vehicles & $\begin{array}{c}\text { \# of } \\
\text { heavy } \\
\text { vehicles }\end{array}$ & $\begin{array}{c}\text { \# of Rt. } \\
\text { Turns }\end{array}$ & $\begin{array}{c}\text { Calculated } \\
\text { SFR }\end{array}$ \\
\hline 1 & 13.06 & 5 & 1 & 3 & 1378.25 \\
\hline 2 & 11.72 & 5 & 0 & 3 & 1535.84 \\
\hline 3 & 19.6 & 8 & 1 & 2 & 1469.39 \\
\hline 4 & 17.25 & 7 & 0 & 3 & 1460.87 \\
\hline 5 & 11.97 & 5 & 1 & 1 & 1503.76 \\
\hline 6 & 17.12 & 7 & 0 & 4 & 1471.96 \\
\hline 7 & 12.56 & 3 & 0 & 3 & 859.87 \\
\hline 8 & 10.21 & 5 & 0 & 2 & 1762.98 \\
\hline 9 & 23.03 & 10 & 0 & 3 & 1563.18 \\
\hline 10 & 16.09 & 7 & 0 & 1 & 1566.19 \\
\hline 11 & 13.47 & 7 & 0 & 1 & 1870.82 \\
\hline 12 & 14.41 & 5 & 0 & 2 & 1249.13 \\
\hline 13 & 17.01 & 7 & 0 & 3 & 1481.48 \\
\hline 14 & 11.13 & 5 & 0 & 1 & 1617.25 \\
\hline 15 & 7.82 & 4 & 0 & 1 & 1841.43 \\
\hline 16 & 15.19 & 6 & 0 & 2 & 1421.99 \\
\hline 17 & 15.53 & 6 & 1 & 3 & 1390.86 \\
\hline 18 & 12.45 & 6 & 0 & 0 & 1734.94 \\
\hline 19 & 9.93 & 4 & 0 & 1 & 1450.15 \\
\hline 20 & 13.35 & 7 & 1 & 1 & 1887.64 \\
\hline & 282.9 & 119 & 5 & 40 & 30517.99 \\
\hline
\end{tabular}

$$
\mathrm{g}=+4 \%
$$$$
\mathrm{LW}=11^{\prime}
$$

\begin{tabular}{|c|c|c|}
\hline \multirow{2}{*}{$\begin{array}{r}\% \text { heavy veh.: } \\
\% \text { Rt turns.: }\end{array}$} & 4.2 & \\
\hline & 33.6 & Ideal: \\
\hline Average SFR: & 1525.90 & 1721 \\
\hline $\begin{array}{r}\text { Weighted Average } \\
\text { SFR: }\end{array}$ & 1514.32 & 1707 \\
\hline Standard deviation: & 235.12 & \\
\hline $\begin{array}{r}\text { Coefficient of } \\
\text { Variation: }\end{array}$ & 15.53 & \\
\hline Median: & 1492.62 & 1684 \\
\hline Variance: & 55279.41 & \\
\hline
\end{tabular}


McDonalds

access (work

North/South: Parkway)

East/West: Rt. 21

21 Eastbound

Approach studied: Rt. / St. thru

Weather: 87, clear

Pavement Condition: dry

City: Uniontown

State: $\mathrm{Pa}$.

Technician: BMD

Time: 2:00-2:50pm

Date: 6/5/2002

\begin{tabular}{|c|c|c|c|c|c|}
\hline \# of Counts & $\begin{array}{c}\text { Elapsed Time } \\
\text { (sec.) }\end{array}$ & $\begin{array}{l}\text { Total \# of } \\
\text { vehicles }\end{array}$ & $\begin{array}{c}\text { \# of heavy } \\
\text { vehicles }\end{array}$ & $\begin{array}{c}\text { \# of Rt. } \\
\text { Turns }\end{array}$ & Calculated SFR \\
\hline 1 & 12.44 & 4 & 1 & 2 & 1157.56 \\
\hline 2 & 12.78 & 4 & 0 & 0 & 1126.76 \\
\hline 3 & 9.5 & 4 & 0 & 2 & 1515.79 \\
\hline 4 & 9.94 & 4 & 0 & 0 & 1448.69 \\
\hline 5 & 12.97 & 5 & 0 & 2 & 1387.82 \\
\hline 6 & 13.97 & 4 & 0 & 1 & 1030.78 \\
\hline 7 & 9.25 & 4 & 0 & 2 & 1556.76 \\
\hline 8 & 21.81 & 9 & 0 & 2 & 1485.56 \\
\hline 9 & 18.47 & 6 & 1 & 2 & 1169.46 \\
\hline 10 & 16.82 & 6 & 0 & 2 & 1284.19 \\
\hline 11 & 20.22 & 8 & 0 & 1 & 1424.33 \\
\hline 12 & 13.97 & 5 & 0 & 0 & 1288.48 \\
\hline 13 & 8.59 & 4 & 0 & 2 & 1676.37 \\
\hline 14 & 9.72 & 4 & 0 & 0 & 1481.48 \\
\hline 15 & 8.52 & 4 & 0 & 0 & 1690.14 \\
\hline 16 & 8.78 & 4 & 0 & 1 & 1640.09 \\
\hline 17 & 8.81 & 4 & 0 & 1 & 1634.51 \\
\hline 18 & 19.3 & 9 & 0 & 0 & 1678.76 \\
\hline 19 & 9.4 & 4 & 0 & 1 & 1531.91 \\
\hline 20 & 9.47 & 4 & 0 & 0 & 1520.59 \\
\hline Sum: & 254.73 & 100 & 2 & 21 & 28730.02 \\
\hline
\end{tabular}

$$
\begin{aligned}
& g=-4 \% \\
& L W=12^{\prime}
\end{aligned}
$$

$\%$ heavy veh.:

$\%$ Rt turns.:

Average SFR:

Weighted

Average SFR:

Standard

deviation:

Coefficient of

Variation:

Median:

Variance:

\begin{tabular}{l|l}
$\frac{2.0}{21.0}$ & Ideal: \\
\hline$\frac{1436.50}{1413.26}$ & 1478 \\
\hline$\frac{200.00}{14.15}$ & 1454 \\
\hline$\frac{1483.52}{40000.56}$ & \\
\hline
\end{tabular}


North/South: 119

East/West: 711 at corner of sheets

$119 \mathrm{~N}$-bound Lt./St. (Lt.

Approach studied: Lane)

Weather: 86, Hazy

Pavement

Condition: dry
City: Connellsville

State: Pa.

Technician: BMD

Time: 2:15-3:10pm

Date: $\quad 6 / 10 / 2002$

\begin{tabular}{|c|c|c|c|c|c|}
\hline \# of Counts & Elapsed Time (sec.) & Total \# of vehicles & $\begin{array}{c}\# \text { of } \\
\text { heavy } \\
\text { vehicles }\end{array}$ & $\begin{array}{c}\text { \# of Lt. } \\
\text { Turns }\end{array}$ & $\begin{array}{c}\text { Calculated } \\
\text { SFR }\end{array}$ \\
\hline 1 & 13.53 & 6 & 0 & 2 & 1596.45 \\
\hline 2 & 13.5 & 5 & 0 & 0 & 1333.33 \\
\hline 3 & 19.58 & 10 & 0 & 1 & 1838.61 \\
\hline 4 & 17.97 & 8 & 0 & 3 & 1602.67 \\
\hline 5 & 15.72 & 5 & 1 & 1 & 1145.04 \\
\hline 6 & 17.35 & 6 & 1 & 1 & 1244.96 \\
\hline 7 & 10.13 & 5 & 0 & 1 & 1776.90 \\
\hline 8 & 14.36 & 6 & 0 & 1 & 1504.18 \\
\hline 9 & 19.56 & 7 & 1 & 1 & 1288.34 \\
\hline 10 & 17.37 & 7 & 0 & 1 & 1450.78 \\
\hline 11 & 16.23 & 7 & 0 & 2 & 1552.68 \\
\hline 12 & 17.59 & 7 & 0 & 1 & 1432.63 \\
\hline 13 & 9.44 & 4 & 0 & 0 & 1525.42 \\
\hline 14 & 14.06 & 9 & 0 & 1 & 2304.41 \\
\hline 15 & 13.53 & 7 & 0 & 1 & 1862.53 \\
\hline 16 & 17.47 & 8 & 0 & 1 & 1648.54 \\
\hline 17 & 16.44 & 8 & 0 & 10 & 1751.82 \\
\hline 18 & 16.16 & 4 & 2 & 0 & 891.09 \\
\hline 19 & 22.84 & 7 & 2 & 1 & 1103.33 \\
\hline 20 & 15.38 & 6 & 0 & 1 & 1404.42 \\
\hline Sum: & 318.21 & 132 & 7 & 30 & 30258.14 \\
\hline
\end{tabular}

$$
\begin{gathered}
g=0 \% \\
L W=12^{\prime}
\end{gathered}
$$

$\%$ heavy veh.:

$\%$ Rt turns.:

Average SFR:

Weighted Average

SFR:

Standard deviation:

Coefficient of

Variation:

Median: 1514.80

Variance: 99110.70 
North/South: 119

East/West:

711 intersection at

Approach studied:

Weather:

Pavement

Condition: dry

$$
\text { Lt lane, } 119 \text { south St }
$$

and $\mathrm{Lt}$

$y$
City: Connellsville

State: $\mathrm{Pa}$.

Technician: BMD

Time: 3:30-4:21pm

Date: $6 / 10 / 2002$

\begin{tabular}{|c|c|c|c|c|c|}
\hline \# of Counts & Elapsed Time (sec.) & Total \# of vehicles & $\begin{array}{c}\text { \# of } \\
\text { heavy } \\
\text { vehicles }\end{array}$ & $\begin{array}{c}\text { \# of Lt. } \\
\text { Turns }\end{array}$ & $\begin{array}{c}\text { Calculated } \\
\text { SFR }\end{array}$ \\
\hline 1 & 15.53 & 7 & 0 & 0 & 1622.67 \\
\hline 2 & 15.18 & 7 & 1 & 2 & 1660.08 \\
\hline 3 & 18.94 & 9 & 1 & 2 & 1710.67 \\
\hline 4 & 15.59 & 6 & 0 & 1 & 1385.50 \\
\hline 5 & 29.47 & 10 & 2 & 4 & 1221.58 \\
\hline 6 & 15.5 & 7 & 0 & 0 & 1625.81 \\
\hline 7 & 15.03 & 7 & 0 & 0 & 1676.65 \\
\hline 8 & 12.81 & 8 & 0 & 0 & 2248.24 \\
\hline 9 & 16.59 & 5 & 1 & 1 & 1084.99 \\
\hline 10 & 14.6 & 8 & 0 & 0 & 1972.60 \\
\hline 11 & 18.65 & 8 & 0 & 1 & 1544.24 \\
\hline 12 & 16.19 & 9 & 0 & 0 & 2001.24 \\
\hline 13 & 16.24 & 6 & 0 & 0 & 1330.05 \\
\hline 14 & 20.72 & 9 & 0 & 2 & 1563.71 \\
\hline 15 & 17.06 & 8 & 0 & 2 & 1688.16 \\
\hline 16 & 18.22 & 8 & 0 & 1 & 1580.68 \\
\hline 17 & 17.39 & 7 & 1 & 0 & 1449.11 \\
\hline 18 & 11.88 & 6 & 0 & 0 & 1818.18 \\
\hline 19 & 20.66 & 10 & 0 & 0 & 1742.50 \\
\hline 20 & 24.21 & 11 & 0 & 1 & 1635.69 \\
\hline & 350.46 & 156 & 6 & 17 & 32562.33 \\
\hline
\end{tabular}

$$
\begin{gathered}
g=0 \% \\
L W=15^{\prime}
\end{gathered}
$$


North/South: 119

East/West: 30 119 North, Lt turn

Approach studied: onto 30 West

Weather: 82, Hazy

Pavement

Condition: dry
City: Greensburg

State: $\mathrm{Pa}$.

Technician: BMD

Time: 2:20-3:10pm

Date: $6 / 12 / 2002$

\begin{tabular}{|c|c|c|c|c|}
\hline \# of Counts & Elapsed Time (sec.) & Total \# of vehicles & $\begin{array}{c}\text { \# of } \\
\text { heavy } \\
\text { vehicles }\end{array}$ & $\begin{array}{c}\text { Calculated } \\
\text { SFR }\end{array}$ \\
\hline 1 & 10.53 & 4 & 1 & 1367.52 \\
\hline 2 & 8.93 & 4 & 0 & 1612.54 \\
\hline 3 & 8.18 & 4 & 0 & 1760.39 \\
\hline 4 & 9.45 & 4 & 0 & 1523.81 \\
\hline 5 & 9.63 & 4 & 0 & 1495.33 \\
\hline 6 & 8.69 & 4 & 0 & 1657.08 \\
\hline 7 & 11.96 & 4 & 1 & 1204.01 \\
\hline 8 & 9.85 & 4 & 0 & 1461.93 \\
\hline 9 & 10.22 & 5 & 0 & 1761.25 \\
\hline 10 & 10.49 & 4 & 1 & 1372.74 \\
\hline 11 & 7.97 & 4 & 0 & 1806.78 \\
\hline 12 & 10.28 & 5 & 0 & 1750.97 \\
\hline 13 & 9.25 & 4 & 0 & 1556.76 \\
\hline 14 & 10.39 & 4 & 1 & 1385.95 \\
\hline 15 & 14.22 & 6 & 0 & 1518.99 \\
\hline 16 & 8.87 & 4 & 0 & 1623.45 \\
\hline 17 & 8.34 & 4 & 0 & 1726.62 \\
\hline 18 & 9.12 & 4 & 0 & 1578.95 \\
\hline 19 & 8.37 & 4 & 0 & 1720.43 \\
\hline 20 & 10.11 & 5 & 0 & 1780.42 \\
\hline & 194.85 & 85 & 4 & 31665.90 \\
\hline
\end{tabular}

$\mathrm{g}=+1.1 \%$

$\mathrm{LW}=11^{\prime}$
$\%$ heavy veh.:

Average SFR:

Weighted Average

SFR:

4.7

1583.30

Ideal:

1814

1799

Standard deviation: 167.30

Coefficient of

Variation:

10.65

Median: 1595.74

Variance: 27987.69 
North/South: 119

East/West: 30 119 North, Rt

Approach studied: onto 30 east

Weather: 80, Hazy

Pavement

Condition: dry
City: Greensburg

State: $\mathrm{Pa}$.

Technician: BMD

Time: 1:30-2:10pm

Date: $6 / 12 / 2002$

\begin{tabular}{|c|c|c|c|c|}
\hline \# of Counts & $\begin{array}{c}\text { Elapsed Time } \\
\text { (sec.) }\end{array}$ & Total \# of vehicles & $\begin{array}{c}\text { \# of heavy } \\
\text { vehicles }\end{array}$ & $\begin{array}{c}\text { Calculated } \\
\text { SFR }\end{array}$ \\
\hline 1 & 8.59 & 4 & 1 & 1676.37 \\
\hline 2 & 14.22 & 4 & 1 & 1012.66 \\
\hline 3 & 14.69 & 4 & 1 & 980.26 \\
\hline 4 & 10.22 & 5 & 0 & 1761.25 \\
\hline 5 & 8.94 & 4 & 0 & 1610.74 \\
\hline 6 & 10.4 & 5 & 1 & 1730.77 \\
\hline 7 & 10.41 & 4 & 0 & 1383.29 \\
\hline 8 & 12.84 & 6 & 0 & 1682.24 \\
\hline 9 & 11.09 & 6 & 0 & 1947.70 \\
\hline 10 & 16.35 & 5 & 1 & 1100.92 \\
\hline 11 & 12.38 & 4 & 0 & 1163.17 \\
\hline 12 & 10.78 & 6 & 0 & 2003.71 \\
\hline 13 & 8.47 & 5 & 0 & 2125.15 \\
\hline 14 & 9.34 & 4 & 0 & 1541.76 \\
\hline 15 & 13.21 & 4 & 1 & 1090.08 \\
\hline 16 & 11.3 & 6 & 0 & 1911.50 \\
\hline 17 & 9.56 & 5 & 0 & 1882.85 \\
\hline 18 & 11 & 5 & 0 & 1636.36 \\
\hline 19 & 12.69 & 5 & 1 & 1418.44 \\
\hline 20 & 10.97 & 5 & 0 & 1640.84 \\
\hline & 227.45 & 96 & 31300.05 \\
\hline Sum: & & & & \\
\hline & & & 5 & 0 \\
\hline
\end{tabular}

$g=+.3 \%$
$L W=11^{\prime}$
$\%$ heavy veh.:

Average SFR:

Weighted Average

SFR:

Standard deviation:

Coefficient of

Variation:

Median:

Variance:

\begin{tabular}{lcc} 
& $\frac{7.3}{1565.00}$ & 1829 \\
\hline$\frac{1519.45}{346.66}$ & 1776 \\
\hline$\frac{22.81}{1638.60}$ & \\
\hline 120173.44 & 1915 \\
\hline
\end{tabular}


North/South: 119

East/West: 30 119 south, St only

Approach studied: at McD's

Weather: 82, Hazy

Pavement

Condition: dry
City: Greensburg

State: $\mathrm{Pa}$.

Technician: BMD

Time: 1:40-2:20pm

Date: $\quad 6 / 12 / 2002$

\begin{tabular}{|c|c|c|c|c|}
\hline \# of Counts & $\begin{array}{c}\text { Elapsed Time } \\
(\text { sec.) }\end{array}$ & Total \# of vehicles & $\begin{array}{c}\text { \# of } \\
\text { heavy } \\
\text { vehicles }\end{array}$ & $\begin{array}{c}\text { Calculated } \\
\text { SFR }\end{array}$ \\
\hline 1 & 7.43 & 4 & 0 & 1938.09 \\
\hline 2 & 10.37 & 5 & 0 & 1735.78 \\
\hline 3 & 9.34 & 5 & 0 & 1927.19 \\
\hline 4 & 7.78 & 4 & 0 & 1850.90 \\
\hline 5 & 9.59 & 4 & 0 & 1501.56 \\
\hline 6 & 8.4 & 4 & 0 & 1714.29 \\
\hline 7 & 8.57 & 4 & 0 & 1680.28 \\
\hline 8 & 8.31 & 4 & 0 & 1732.85 \\
\hline 9 & 10.46 & 4 & 1 & 1376.67 \\
\hline 10 & 8.6 & 4 & 0 & 1674.42 \\
\hline 11 & 8.72 & 4 & 0 & 1651.38 \\
\hline 12 & 8.63 & 4 & 0 & 1668.60 \\
\hline 13 & 9.72 & 4 & 0 & 1481.48 \\
\hline 14 & 8.35 & 4 & 0 & 1724.55 \\
\hline 15 & 8.46 & 4 & 1 & 1702.13 \\
\hline 16 & 7.88 & 4 & 0 & 1827.41 \\
\hline 17 & 8.4 & 4 & 1 & 1714.29 \\
\hline 18 & 9.56 & 4 & 0 & 1506.28 \\
\hline 19 & 8.66 & 4 & 0 & 1662.82 \\
\hline 20 & 7.25 & 4 & 0 & 1986.21 \\
\hline & 174.48 & 82 & 3 & 34057.16 \\
\hline
\end{tabular}

$g=-.6 \%$
$L W=11$
$\%$ heavy veh.:

Average SFR:

Weighted Average

SFR:

Standard deviation:

Coefficient of

Variation:

Median:

Variance:

$\frac{3.7}{1702.86}$

1691.88

156.84

9.27

1708.21

24600.33
Ideal: 1818 1807 1824 
North/South: Silvers

East/West: Rt. 21 (East high Street)

Approach studied: 21 East St. only

Weather: 65, overcast

Pavement

Condition: dry
City: Wanesburg

State: Pa.

Technician: BMD

Time: 6:50-8:10am

Date: $6 / 4 / 2002$

\begin{tabular}{|c|c|c|c|c|}
\hline \# of Counts & Elapsed Time (sec.) & Total \# of vehicles & $\begin{array}{c}\text { \# of } \\
\text { heavy } \\
\text { vehicles }\end{array}$ & $\begin{array}{c}\text { Calculated } \\
\text { SFR }\end{array}$ \\
\hline 1 & 7.9 & 4 & 0 & 1822.78 \\
\hline 2 & 13.79 & 5 & 0 & 1305.29 \\
\hline 3 & 11.44 & 5 & 0 & 1573.43 \\
\hline 4 & 8.2 & 4 & 0 & 1756.10 \\
\hline 5 & 10.35 & 5 & 0 & 1739.13 \\
\hline 6 & 7.35 & 4 & 0 & 1959.18 \\
\hline 7 & 10.56 & 4 & 0 & 1363.64 \\
\hline 8 & 11.63 & 6 & 1 & 1857.27 \\
\hline 9 & 10.29 & 4 & 0 & 1399.42 \\
\hline 10 & 10.34 & 4 & 0 & 1392.65 \\
\hline 11 & 9.82 & 4 & 0 & 1466.40 \\
\hline 12 & 9.94 & 5 & 0 & 1810.87 \\
\hline 13 & 13.63 & 6 & 0 & 1584.74 \\
\hline 14 & 13.03 & 6 & 0 & 1657.71 \\
\hline 15 & 8.79 & 4 & 0 & 1638.23 \\
\hline 16 & 10.43 & 5 & 0 & 1725.79 \\
\hline 17 & 12.28 & 5 & 0 & 1465.80 \\
\hline 18 & 9.5 & 4 & 0 & 1515.79 \\
\hline 19 & 11.75 & 5 & 0 & 1531.91 \\
\hline 20 & 8.5 & 4 & 1 & 1694.12 \\
\hline Sum: & 209.52 & 93 & 2 & 32260.23 \\
\hline
\end{tabular}

$g=-1 \%$
$L W=14^{\prime}$
$\%$ heavy veh.:

Average SFR:

Weighted Average

SFR:

Standard deviation:

Coefficient of

Variation:

Median:

$$
\frac{2.2}{1613.01}
$$$$
1597.94
$$$$
182.61
$$

1611.48
Ideal: 1539 1524 1536 
North/South: Rt. 19

East/West: Rt. 21

19 south Lt. Turn to

Approach studied: 21 East

Weather: 75, overcast

Pavement

Condition: dry
City: Wanesburg

State: $\mathrm{Pa}$.

Technician: BMD

Time: 8:20-9:20am

Date: $6 / 4 / 2002$

\begin{tabular}{|c|c|c|c|c|}
\hline \# of Counts & Elapsed Time (sec.) & Total \# of vehicles & $\begin{array}{c}\text { \# of } \\
\text { heavy } \\
\text { vehicles }\end{array}$ & $\begin{array}{c}\text { Calculated } \\
\text { SFR }\end{array}$ \\
\hline 1 & 11.72 & 5 & 1 & 1535.84 \\
\hline 2 & 9.63 & 4 & 0 & 1495.33 \\
\hline 3 & 9.25 & 4 & 0 & 1556.76 \\
\hline 4 & 11.47 & 5 & 0 & 1569.31 \\
\hline 5 & 9.35 & 4 & 0 & 1540.11 \\
\hline 6 & 7.5 & 4 & 0 & 1920.00 \\
\hline 7 & 8.59 & 4 & 0 & 1676.37 \\
\hline 8 & 9.9 & 4 & 0 & 1454.55 \\
\hline 9 & 10.75 & 4 & 0 & 1339.53 \\
\hline 10 & 11.82 & 5 & 0 & 1522.84 \\
\hline 11 & 11.28 & 5 & 0 & 1595.74 \\
\hline 12 & 11.13 & 6 & 0 & 1940.70 \\
\hline 13 & 11.63 & 4 & 0 & 1238.18 \\
\hline 14 & 8.25 & 4 & 0 & 1745.45 \\
\hline 15 & 9.97 & 4 & 0 & 1444.33 \\
\hline 16 & 11.18 & 4 & 0 & 1288.01 \\
\hline 17 & 8.16 & 4 & 0 & 1764.71 \\
\hline 18 & 12 & 4 & 0 & 1200.00 \\
\hline 19 & 9.43 & 4 & 0 & 1527.04 \\
\hline 20 & 12.03 & 5 & 0 & 1496.26 \\
\hline & 205.04 & 87 & 1 & 30851.06 \\
\hline Sum: & & & & \\
\hline & & 4 & 4 & 0 \\
\hline
\end{tabular}

$$
\mathrm{g}=+3.4 \%
$$$$
\mathrm{LW}=12
$$

\begin{tabular}{rcc} 
\% heavy veh.: & 1.1 & Ideal: \\
Average SFR: & 1542.55 & 1667 \\
\cline { 2 - 2 } Seighted Average & & 1651 \\
SFR: & 1527.507 & \\
Standard deviation: & 198.89 & \\
Coefficient of & & \\
Variation: & 13.02 & 1655 \\
Median: & 1531.44 & \\
Variance: & 39558.00 &
\end{tabular}


North/South: U.S. 19

East/West: Trinity Pt/ Strabane Sq. From Trinity Pt Lt turn

Approach studied: only

Weather: 85, Hazy

Pavement

Condition: dry
City: Washington

State: $\mathrm{Pa}$.

Technician: BMD

Time: 1:00-1:45pm

Date: $7 / 7 / 2002$

\begin{tabular}{|c|c|c|c|c|}
\hline \# of Counts & Elapsed Time (sec.) & Total \# of vehicles & $\begin{array}{c}\text { \# of } \\
\text { heavy } \\
\text { vehicles }\end{array}$ & $\begin{array}{c}\text { Calculated } \\
\text { SFR }\end{array}$ \\
\hline 1 & 9.23 & 4 & 0 & 1560.13 \\
\hline 2 & 10.15 & 4 & 0 & 1418.72 \\
\hline 3 & 9.11 & 4 & 0 & 1580.68 \\
\hline 4 & 9.47 & 4 & 0 & 1520.59 \\
\hline 5 & 7.82 & 4 & 0 & 1841.43 \\
\hline 6 & 8.13 & 4 & 0 & 1771.22 \\
\hline 7 & 7.72 & 4 & 0 & 1865.28 \\
\hline 8 & 9.11 & 4 & 0 & 1580.68 \\
\hline 9 & 7 & 4 & 0 & 2057.14 \\
\hline 10 & 8.01 & 4 & 0 & 1797.75 \\
\hline 11 & 8.56 & 4 & 0 & 1682.24 \\
\hline 12 & 9.75 & 5 & 0 & 1846.15 \\
\hline 13 & 9.96 & 4 & 0 & 1445.78 \\
\hline 14 & 8.25 & 4 & 0 & 1745.45 \\
\hline 15 & 8.16 & 4 & 0 & 1764.71 \\
\hline 16 & 11.13 & 5 & 0 & 1617.25 \\
\hline 17 & 8.33 & 5 & 0 & 2160.86 \\
\hline 18 & 8.66 & 4 & 0 & 1662.82 \\
\hline 19 & 9.31 & 4 & 0 & 1546.72 \\
\hline 20 & 8.84 & 4 & 0 & 1628.96 \\
\hline Sum: & 176.7 & 83 & 0 & 34094.59 \\
\hline
\end{tabular}

$$
\begin{aligned}
& g=-8 \% \\
& L W=12^{\prime}
\end{aligned}
$$

$\%$ heavy veh.:

Average SFR:

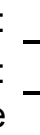

0.0

Ideal:

Weighted Average

SFR: $\quad 1691.00$ 1742

Standard deviation: 190.5835

Coefficient of

Variation:

11.27

Median: 1672.53

1709

Variance: 36322.07 
North/South: U.S. 19

East/West:

Trinity Pt/ Strabane

Approach studied: 19 North Lt turn only

Weather: 83, Hazy

Pavement

Condition: dry
City: Washington

State: $\mathrm{Pa}$.

Technician: BMD

11:45am-

Time: 12:30pm

Date: $\quad 7 / 7 / 2002$

\begin{tabular}{|c|c|c|c|c|}
\hline \# of Counts & Elapsed Time (sec.) & Total \# of vehicles & $\begin{array}{c}\text { \# of } \\
\text { heavy } \\
\text { vehicles }\end{array}$ & $\begin{array}{c}\text { Calculated } \\
\text { SFR }\end{array}$ \\
\hline 1 & 8.85 & 5 & 0 & 2033.90 \\
\hline 2 & 7.11 & 4 & 0 & 2025.32 \\
\hline 3 & 7.01 & 4 & 0 & 2054.21 \\
\hline 4 & 8.97 & 5 & 0 & 2006.69 \\
\hline 5 & 7.88 & 4 & 0 & 1827.41 \\
\hline 6 & 8.11 & 4 & 0 & 1775.59 \\
\hline 7 & 8.95 & 5 & 0 & 2011.17 \\
\hline 8 & 7.83 & 4 & 0 & 1839.08 \\
\hline 9 & 7.35 & 4 & 0 & 1959.18 \\
\hline 10 & 8.07 & 4 & 0 & 1784.39 \\
\hline 11 & 7.19 & 4 & 0 & 2002.78 \\
\hline 12 & 6.5 & 4 & 0 & 2215.38 \\
\hline 13 & 6.72 & 4 & 0 & 2142.86 \\
\hline 14 & 8.22 & 4 & 0 & 1751.82 \\
\hline 15 & 8.31 & 4 & 0 & 1732.85 \\
\hline 16 & 8.18 & 4 & 0 & 1760.39 \\
\hline 17 & 6.5 & 4 & 0 & 2215.38 \\
\hline 18 & 8.81 & 4 & 0 & 1634.51 \\
\hline 19 & 7.91 & 4 & 0 & 1820.48 \\
\hline 20 & 7.6 & 4 & 0 & 1894.74 \\
\hline & 156.07 & 83 & 0 & 38488.13 \\
\hline
\end{tabular}

$g=-7.1 \%$
$L W=11^{\prime}$
$\%$ heavy veh.:

Average SFR:

0.0

1924.41

Ideal: 2034

Weighted Average

SFR:

1914.53 2024

Standard deviation:

166.27

Coefficient of

Variation:

Median: 1926.96 2036

Variance: 27645.87 
North/South: U.S. 19

East/West: Sq.

Trinity Pt./Strabane

$$
19 \text { South, thru (Rt }
$$

Approach studied: lane)

Weather: 85, Hazy

Pavement

Condition: dry
City: Washington

State: $\mathrm{Pa}$.

Technician: BMD

Time: 1:00-1:40pm

Date: $\quad 7 / 7 / 2002$

\begin{tabular}{|c|c|c|c|c|}
\hline \# of Counts & Elapsed Time (sec.) & Total \# of vehicles & $\begin{array}{c}\text { \# of } \\
\text { heavy } \\
\text { vehicles }\end{array}$ & $\begin{array}{c}\text { Calculated } \\
\text { SFR }\end{array}$ \\
\hline 1 & 11.18 & 5 & 0 & 1610.02 \\
\hline 2 & 17.14 & 5 & 1 & 1050.18 \\
\hline 3 & 9.11 & 4 & 0 & 1580.68 \\
\hline 4 & 7.62 & 4 & 0 & 1889.76 \\
\hline 5 & 10.38 & 5 & 0 & 1734.10 \\
\hline 6 & 10.56 & 6 & 0 & 2045.45 \\
\hline 7 & 8.69 & 4 & 0 & 1657.08 \\
\hline 8 & 10.94 & 5 & 0 & 1645.34 \\
\hline 9 & 12.19 & 7 & 0 & 2067.27 \\
\hline 10 & 9.1 & 4 & 0 & 1582.42 \\
\hline 11 & 12.63 & 5 & 0 & 1425.18 \\
\hline 12 & 8.75 & 4 & 0 & 1645.71 \\
\hline 13 & 8.5 & 4 & 0 & 1694.12 \\
\hline 14 & 9.94 & 5 & 0 & 1810.87 \\
\hline 15 & 12.64 & 6 & 0 & 1708.86 \\
\hline 16 & 12.94 & 7 & 0 & 1947.45 \\
\hline 17 & 8.24 & 4 & 0 & 1747.57 \\
\hline 18 & 8.68 & 4 & 0 & 1658.99 \\
\hline 19 & 10.33 & 5 & 0 & 1742.50 \\
\hline 20 & 11.06 & 5 & 0 & 1627.49 \\
\hline & 210.62 & 98 & 1 & 33871.03 \\
\hline
\end{tabular}

$$
\begin{aligned}
& g=+6.7 \% \\
& L W=11^{\prime}
\end{aligned}
$$

\begin{tabular}{|c|c|c|}
\hline$\%$ heavy veh.: & 1.0 & Ideal: \\
\hline Average SFR: & 1693.55 & 1833 \\
\hline $\begin{array}{r}\text { Weighted Average } \\
\text { SFR: }\end{array}$ & 1675.05 & 1814 \\
\hline Standard deviation: & 219.68 & \\
\hline $\begin{array}{l}\text { Coefficient of } \\
\text { Variation: }\end{array}$ & 13.11 & \\
\hline Median: & 1676.55 & 1815 \\
\hline Variance: & 48260.42 & \\
\hline
\end{tabular}


North/South: U.S. 19

East/West: Trinity Pt./Strabane Sq. from Strabane Sq, Thru

Approach studied: and Lt. Turn

Weather: 83, Hazy

Pavement

Condition: dry
City: Washington

State: $\mathrm{Pa}$.

Technician: BMD

11:50am-

Time: $12: 45 \mathrm{pm}$

Date: $\quad 7 / 7 / 2002$

\begin{tabular}{|c|c|c|c|c|c|}
\hline \# of Counts & Elapsed Time (sec.) & Total \# of vehicles & $\begin{array}{c}\text { \# of } \\
\text { heavy } \\
\text { vehicles }\end{array}$ & $\begin{array}{c}\text { \# of Lt. } \\
\text { Turns }\end{array}$ & $\begin{array}{c}\text { Calculated } \\
\text { SFR }\end{array}$ \\
\hline 1 & 8.28 & 5 & 0 & 0 & 2173.91 \\
\hline 2 & 7.81 & 4 & 0 & 1 & 1843.79 \\
\hline 3 & 7.84 & 4 & 0 & 0 & 1836.73 \\
\hline 4 & 7.64 & 4 & 0 & 0 & 1884.82 \\
\hline 5 & 7.76 & 4 & 0 & 0 & 1855.67 \\
\hline 6 & 8.33 & 5 & 0 & 0 & 2160.86 \\
\hline 7 & 8.19 & 4 & 0 & 0 & 1758.24 \\
\hline 8 & 7.59 & 4 & 0 & 1 & 1897.23 \\
\hline 9 & 8.83 & 5 & 1 & 1 & 2038.51 \\
\hline 10 & 13.11 & 6 & 1 & 1 & 1647.60 \\
\hline 11 & 10.51 & 5 & 0 & 1 & 1712.65 \\
\hline 12 & 8.22 & 5 & 0 & 2 & 2189.78 \\
\hline 13 & 8.06 & 4 & 0 & 0 & 1786.60 \\
\hline 14 & 9.57 & 4 & 0 & 1 & 1504.70 \\
\hline 15 & 7.78 & 4 & 0 & 1 & 1850.90 \\
\hline 16 & 9.82 & 4 & 1 & 1 & 1466.40 \\
\hline 17 & 9.31 & 5 & 0 & 1 & 1933.40 \\
\hline 18 & 8.65 & 4 & 0 & 0 & 1664.74 \\
\hline 19 & 8.66 & 5 & 0 & 1 & 2078.52 \\
\hline 20 & 11.13 & 6 & 0 & 2 & 1940.70 \\
\hline Sum: & 177.09 & 91 & 3 & 14 & 37225.77 \\
\hline
\end{tabular}

$$
\begin{aligned}
& g=-8 \% \\
& L W=12^{\prime}
\end{aligned}
$$

$\%$ heavy veh.:

$\%$ Rt turns.:

Average SFR:

Weighted Average

SFR:

$\frac{3.3}{15.4}$

1861.29

deal:

1881

1870

Standard deviation: 204.43

Coefficient of

Variation:

Median: 1853.28

1873

Variance: 41792.81 
North/South: 40 access

East/West: Rt. 21

21 Westbound Lt.

Approach studied: Turn

Weather: 67, steady rain

Pavement

Condition: wet
City: Uniontown

State: $\mathrm{Pa}$.

Technician: BMD

Time: 2:30-3:30pm

Date: $10 / 11 / 2002$

\begin{tabular}{|c|c|c|c|c|}
\hline \# of Counts & Elapsed Time (sec.) & Total \# of vehicles & $\begin{array}{c}\text { \# of } \\
\text { heavy } \\
\text { vehicles }\end{array}$ & $\begin{array}{c}\text { Calculated } \\
\text { SFR }\end{array}$ \\
\hline 1 & 9.28 & 4 & 0 & 1551.72 \\
\hline 2 & 17.03 & 8 & 0 & 1691.13 \\
\hline 3 & 16.69 & 8 & 1 & 1725.58 \\
\hline 4 & 19.19 & 8 & 0 & 1500.78 \\
\hline 5 & 16.25 & 9 & 0 & 1993.85 \\
\hline 6 & 13.78 & 7 & 0 & 1828.74 \\
\hline 7 & 12.94 & 6 & 0 & 1669.24 \\
\hline 8 & 9.75 & 5 & 0 & 1846.15 \\
\hline 9 & 16.78 & 6 & 0 & 1287.25 \\
\hline 10 & 19.13 & 9 & 0 & 1693.67 \\
\hline 11 & 15.66 & 6 & 0 & 1379.31 \\
\hline 12 & 17.53 & 8 & 0 & 1642.90 \\
\hline 13 & 13.81 & 6 & 0 & 1564.08 \\
\hline 14 & 16.5 & 8 & 0 & 1745.45 \\
\hline 15 & 16.66 & 7 & 0 & 1512.61 \\
\hline 16 & 17.31 & 8 & 0 & 1663.78 \\
\hline 17 & 9.62 & 5 & 0 & 1871.10 \\
\hline 18 & 14.06 & 7 & 0 & 1792.32 \\
\hline 19 & 18.93 & 9 & 0 & 1711.57 \\
\hline 20 & 12.39 & 6 & 0 & 1743.34 \\
\hline & 303.29 & 140 & 1 & 33414.59 \\
\hline
\end{tabular}

$g=-2 \%$
$L w=10^{\prime}$
$\%$ heavy veh.:

Average SFR:

Weighted Average

SFR:

Standard deviation:

Coefficient of

Variation:

Median:

Variance:
0.7

1670.73

1661.78

169.18

10.18

1692.40

28620.21
Ideal:

1860

1872

1897 
North/South: 40 access

East/West: Rt. 21 from $40 \mathrm{Lt}$

Approach studied: turn

Weather: 67, steady rain

Pavement

Condition: wet
City: Uniontown

State: $\mathrm{Pa}$.

Technician: BMD

Time: 2:30-3:20pm

Date: $10 / 11 / 2002$

\begin{tabular}{|c|c|c|c|c|}
\hline \# of Counts & $\begin{array}{c}\text { Elapsed } \\
\text { Time (sec.) }\end{array}$ & Total \# of vehicles & $\begin{array}{c}\text { \# of } \\
\text { heavy } \\
\text { vehicles }\end{array}$ & $\begin{array}{c}\text { Calculated } \\
\text { SFR }\end{array}$ \\
\hline 1 & 8.69 & 4 & 0 & 1657.08 \\
\hline 2 & 11.72 & 5 & 1 & 1535.84 \\
\hline 3 & 16.07 & 6 & 2 & 1344.12 \\
\hline 4 & 14.6 & 6 & 0 & 1479.45 \\
\hline 5 & 23.85 & 9 & 1 & 1358.49 \\
\hline 6 & 24.6 & 10 & 1 & 1463.41 \\
\hline 7 & 12.03 & 7 & 0 & 2094.76 \\
\hline 8 & 10.13 & 4 & 0 & 1421.52 \\
\hline 9 & 12.63 & 5 & 1 & 1425.18 \\
\hline 10 & 18.06 & 8 & 1 & 1594.68 \\
\hline 11 & 20.88 & 10 & 1 & 1724.14 \\
\hline 12 & 9.72 & 5 & 0 & 1851.85 \\
\hline 13 & 19.84 & 10 & 1 & 1814.52 \\
\hline 14 & 22.63 & 10 & 0 & 1590.81 \\
\hline 15 & 16.5 & 8 & 0 & 1745.45 \\
\hline 16 & 18.44 & 9 & 0 & 1757.05 \\
\hline 17 & 19.09 & 8 & 0 & 1508.64 \\
\hline 18 & 13.06 & 7 & 0 & 1929.56 \\
\hline 19 & 19.03 & 8 & 1 & 1513.40 \\
\hline 20 & 14.94 & 5 & 0 & 1204.82 \\
\hline & 326.51 & 144 & 10 & 32014.77 \\
\hline Sum: & & & & \\
\hline & & & 0 & 0 \\
\hline
\end{tabular}

$g=+1 \%$
$\%$ heavy veh.:

Average SFR: Weighted Average

SFR:

Standard deviation:

Coefficient of

Variation:

Median:

Variance:
6.9

1600.74

1587.70

220.40

13.88

1563.32

48577.52 
North/South: 40 access

East/West: Rt. 21 from Walmart towards

Approach studied: 40 St. / Rt.

Weather: 67 , steady rain

Pavement

Condition: wet
City: Uniontown

State: $\mathrm{Pa}$.

Technician: BMD

Time: 3:40-4:30pm

Date: $10 / 11 / 2002$

\begin{tabular}{|c|c|c|c|c|c|}
\hline \# of Counts & Elapsed Time (sec.) & Total \# of vehicles & $\begin{array}{c}\text { \# of } \\
\text { heavy } \\
\text { vehicles }\end{array}$ & $\begin{array}{c}\text { \# of Rt. } \\
\text { Turns }\end{array}$ & $\begin{array}{c}\text { Calculated } \\
\text { SFR }\end{array}$ \\
\hline 1 & 12.79 & 6 & 0 & 1 & 1688.82 \\
\hline 2 & 12.16 & 6 & 0 & 0 & 1776.32 \\
\hline 3 & 12.3 & 5 & 0 & 0 & 1463.41 \\
\hline 4 & 13.29 & 6 & 0 & 1 & 1625.28 \\
\hline 5 & 12.06 & 6 & 0 & 0 & 1791.04 \\
\hline 6 & 11 & 6 & 0 & 0 & 1963.64 \\
\hline 7 & 15.43 & 7 & 0 & 0 & 1633.18 \\
\hline 8 & 13.69 & 5 & 1 & 1 & 1314.83 \\
\hline 9 & 13.18 & 6 & 0 & 0 & 1638.85 \\
\hline 10 & 14.28 & 7 & 0 & 0 & 1764.71 \\
\hline 11 & 13.78 & 6 & 0 & 1 & 1567.49 \\
\hline 12 & 17.63 & 9 & 0 & 0 & 1837.78 \\
\hline 13 & 19.82 & 9 & 0 & 0 & 1634.71 \\
\hline 14 & 18.37 & 10 & 0 & 0 & 1959.72 \\
\hline 15 & 21.28 & 10 & 0 & 0 & 1691.73 \\
\hline 16 & 18.75 & 9 & 0 & 0 & 1728.00 \\
\hline 17 & 19 & 9 & 0 & 0 & 1705.26 \\
\hline 18 & 16.13 & 8 & 0 & 0 & 1785.49 \\
\hline 19 & 14.13 & 6 & 0 & 0 & 1528.66 \\
\hline 20 & 22.19 & 10 & 0 & 0 & 1622.35 \\
\hline & 311.26 & 146 & 1 & 4 & 33721.27 \\
\hline & & & & & \\
\hline & & & 6 & 0 & 0 \\
\hline
\end{tabular}

$\mathrm{g}=-7.7 \%$

$\mathrm{Lw}=12^{\prime}$
$\%$ heavy veh.:

$\%$ Rt turns.:

Average SFR:

Weighted Average

SFR: $\quad 1688.62$

Ideal:

1623

Standard deviation: 154.58

Coefficient of

Variation:

9.15

Median: 1690.27

1663 
\# 3-12

$\begin{aligned} & \text { North/South: } 40 \text { access } \\ & \text { East/West: } \text { Rt. } 21 \\ & \text { from } 40 \mathrm{Lt} \\ & \text { Approach studied: } \text { turn } \\ & \text { Weather: } 52, \text { cloudy } \\ & \text { Pavement } \\ & \text { Condition: } \text { dry }\end{aligned}$

City: Uniontown

State: $\mathrm{Pa}$.

Technician: BMD

Time: 12:00-1:00

Date: 10/23/2002

\begin{tabular}{|c|c|c|c|c|}
\hline \# of Counts & $\begin{array}{c}\text { Elapsed } \\
\text { Time (sec.) }\end{array}$ & Total \# of vehicles & $\begin{array}{c}\text { \# of heavy } \\
\text { vehicles }\end{array}$ & $\begin{array}{c}\text { Calculated } \\
\text { SFR }\end{array}$ \\
\hline 1 & 11.79 & 4 & 1 & 1221.37 \\
\hline 2 & 11.97 & 5 & 0 & 1503.76 \\
\hline 3 & 11.02 & 4 & 0 & 1306.72 \\
\hline 4 & 9.38 & 4 & 1 & 1535.18 \\
\hline 5 & 16.31 & 6 & 2 & 1324.34 \\
\hline 6 & 8.06 & 4 & 0 & 1786.60 \\
\hline 7 & 9.72 & 4 & 0 & 1481.48 \\
\hline 8 & 8.56 & 4 & 0 & 1682.24 \\
\hline 9 & 8.5 & 4 & 0 & 1694.12 \\
\hline 10 & 10.05 & 5 & 0 & 1791.04 \\
\hline 11 & 17.47 & 7 & 0 & 1442.47 \\
\hline 12 & 10.66 & 5 & 1 & 1688.56 \\
\hline 13 & 15.5 & 7 & 0 & 1625.81 \\
\hline 14 & 15.63 & 6 & 1 & 1381.96 \\
\hline 15 & 9.07 & 4 & 0 & 1587.65 \\
\hline 16 & 10.73 & 5 & 0 & 1677.54 \\
\hline 17 & 11.2 & 4 & 0 & 1285.71 \\
\hline 18 & 14.13 & 6 & 0 & 1528.66 \\
\hline 19 & 8.88 & 4 & 0 & 1621.62 \\
\hline 20 & 9.41 & 4 & 0 & 1530.29 \\
\hline Sum: & 228.04 & 96 & 6 & 30697.13 \\
\hline
\end{tabular}

$g=+1 \%$
$L w=12^{\prime}$
$\%$ heavy veh.:

Average SFR:

Weighted Average

SFR:

Standard deviation:

Coefficient of

Variation:

Median:

Variance:

$\frac{6.3}{1534.86}$

1515.52

167.20

11.03

1532.73

27955.79 deal:

1814 1791 1812 
North/South: 40 access

East/West: Rt. 21 from $40 \mathrm{Lt}$

Approach studied: turn

Weather: 53, cloudy

Pavement

Condition: dry
City: Uniontown

State: $\mathrm{Pa}$.

Technician: BMD

Time: $1: 00-2: 00$

Date: $10 / 23 / 2002$

\begin{tabular}{|c|c|c|c|c|}
\hline \# of Counts & $\begin{array}{c}\text { Elapsed } \\
\text { Time (sec.) }\end{array}$ & Total \# of vehicles & $\begin{array}{c}\text { \# of } \\
\text { heavy } \\
\text { vehicles }\end{array}$ & $\begin{array}{c}\text { Calculated } \\
\text { SFR }\end{array}$ \\
\hline 1 & 10.2 & 4 & 0 & 1411.76 \\
\hline 2 & 14.04 & 7 & 1 & 1794.87 \\
\hline 3 & 11.33 & 5 & 0 & 1588.70 \\
\hline 4 & 11.03 & 4 & 0 & 1305.53 \\
\hline 5 & 10.83 & 4 & 1 & 1329.64 \\
\hline 6 & 9.28 & 4 & 1 & 1551.72 \\
\hline 7 & 18.03 & 9 & 0 & 1797.00 \\
\hline 8 & 16.56 & 6 & 1 & 1304.35 \\
\hline 9 & 9.03 & 4 & 1 & 1594.68 \\
\hline 10 & 17.91 & 6 & 1 & 1206.03 \\
\hline 11 & 16.73 & 6 & 0 & 1291.09 \\
\hline 12 & 9.85 & 4 & 0 & 1461.93 \\
\hline 13 & 8.88 & 4 & 0 & 1621.62 \\
\hline 14 & 14.72 & 7 & 1 & 1711.96 \\
\hline 15 & 9.18 & 4 & 0 & 1568.63 \\
\hline 16 & 10 & 4 & 0 & 1440.00 \\
\hline 17 & 11.16 & 4 & 0 & 1290.32 \\
\hline 18 & 15.89 & 6 & 1 & 1359.35 \\
\hline 19 & 11.21 & 5 & 0 & 1605.71 \\
\hline 20 & 9.86 & 4 & 0 & 1460.45 \\
\hline & 245.72 & 101 & 8 & 29695.35 \\
\hline Sum: & & & & \\
\hline & & & & 0 \\
\hline
\end{tabular}

$\mathrm{g}=+1 \%$

$\mathrm{Lw}=12$
$\%$ heavy veh.:

Average SFR: 1484.77

Weighted Average

SFR:

Standard deviation:

Coefficient of

Variation:

Median:

Variance:

$\frac{7.9}{1484.77}$

1479.73

174.56

11.80

1461.19

30471.56
Ideal:

1755

1749

1727 
North/South: 40 access

East/West: Rt. 21 from $40 \mathrm{Lt}$

Approach studied: turn

Weather: 53, cloudy

Pavement

Condition: dry
City: Uniontown

State: $\mathrm{Pa}$.

Technician: BMD

Time: 2:00-3:00

Date: $10 / 23 / 2002$

\begin{tabular}{|c|c|c|c|c|}
\hline \# of Counts & $\begin{array}{c}\text { Elapsed } \\
\text { Time (sec.) }\end{array}$ & $\begin{array}{c}\text { \# of } \\
\text { heavy } \\
\text { vehicles }\end{array}$ & $\begin{array}{c}\text { Calculated } \\
\text { SFR }\end{array}$ \\
\hline 1 & 11.37 & 6 & 0 & 1899.74 \\
\hline 2 & 9.19 & 4 & 1 & 1566.92 \\
\hline 3 & 12.59 & 5 & 1 & 1429.71 \\
\hline 4 & 10.04 & 4 & 0 & 1434.26 \\
\hline 5 & 9.89 & 4 & 0 & 1456.02 \\
\hline 6 & 10.69 & 4 & 0 & 1347.05 \\
\hline 7 & 9.4 & 4 & 0 & 1531.91 \\
\hline 8 & 17.28 & 6 & 2 & 1250.00 \\
\hline 9 & 10.32 & 4 & 0 & 1395.35 \\
\hline 10 & 14.53 & 6 & 0 & 1486.58 \\
\hline 11 & 18.88 & 8 & 2 & 1525.42 \\
\hline 12 & 14.19 & 6 & 0 & 1522.20 \\
\hline 13 & 12.44 & 5 & 1 & 1446.95 \\
\hline 14 & 10.06 & 4 & 0 & 1431.41 \\
\hline 15 & 9.01 & 4 & 0 & 1598.22 \\
\hline 16 & 9.48 & 4 & 0 & 1518.99 \\
\hline 17 & 13.69 & 5 & 1 & 1314.83 \\
\hline 18 & 9.38 & 4 & 0 & 1535.18 \\
\hline 19 & 11.59 & 5 & 0 & 1553.06 \\
\hline 20 & 14.44 & 5 & 0 & 1246.54 \\
\hline & 238.46 & 97 & 8 & 29490.34 \\
\hline & & & & \\
\hline Sum: & & 4 & 5 & 0 \\
\hline
\end{tabular}

$g=+1 \%$

$\%$ heavy veh.:

Average SFR:

8.2

1474.52

1744

Weighted Average

SFR:

1464.40

1731

Standard deviation: 141.75

Coefficient of

Variation:

9.68

Median: 1471.30

1739

Variance: 20093.27 
North/South: 40 access

East/West: Rt. 21 from $40 \mathrm{Lt}$

Approach studied: turn

Weather: 53, cloudy

Pavement

Condition: dry
City: Uniontown

State: $\mathrm{Pa}$.

Technician: BMD

Time: 3:00-4:00

Date: $10 / 23 / 2002$

\begin{tabular}{|c|c|c|c|c|}
\hline \# of Counts & $\begin{array}{c}\text { Elapsed } \\
\text { Time (sec.) }\end{array}$ & $\begin{array}{c}\text { \# of } \\
\text { heavy } \\
\text { vehicles }\end{array}$ & $\begin{array}{c}\text { Calculated } \\
\text { SFR }\end{array}$ \\
\hline 1 & 17.07 & 8 & 0 & 1687.17 \\
\hline 2 & 11.82 & 6 & 0 & 1827.41 \\
\hline 3 & 17.4 & 8 & 0 & 1655.17 \\
\hline 4 & 18.16 & 8 & 1 & 1585.90 \\
\hline 5 & 11.12 & 4 & 2 & 1294.96 \\
\hline 6 & 19.71 & 9 & 1 & 1643.84 \\
\hline 7 & 11.63 & 5 & 1 & 1547.72 \\
\hline 8 & 19.53 & 9 & 0 & 1658.99 \\
\hline 9 & 16.81 & 8 & 0 & 1713.27 \\
\hline 10 & 10.83 & 4 & 0 & 1329.64 \\
\hline 11 & 10.92 & 5 & 0 & 1648.35 \\
\hline 12 & 11 & 5 & 0 & 1636.36 \\
\hline 13 & 14.56 & 6 & 1 & 1483.52 \\
\hline 14 & 22.94 & 10 & 0 & 1569.31 \\
\hline 15 & 17.86 & 9 & 0 & 1814.11 \\
\hline 16 & 19.31 & 9 & 0 & 1677.89 \\
\hline 17 & 17.65 & 8 & 2 & 1631.73 \\
\hline 18 & 9.72 & 4 & 1 & 1481.48 \\
\hline 19 & 19.74 & 8 & 1 & 1458.97 \\
\hline 20 & 16.19 & 8 & 1 & 1778.88 \\
\hline & 313.97 & 141 & 11 & 32124.66 \\
\hline Sum & & & & \\
\hline & & 9 & 0 & 0 \\
\hline
\end{tabular}

$\mathrm{g}=+1 \%$

$\mathrm{Lw}=12$
$\%$ heavy veh.:

Average SFR:

Weighted Average

SFR:

Standard deviation:

Coefficient of

Variation:

Median:

Variance: 20310.79 $\frac{7.8}{1606.23}$

1616.71

142.52

8.82

640.10
1938

Ideal:

1898

1910 
North/South: 40 access

East/West: Rt. 21 from $40 \mathrm{Lt}$

Approach studied: turn

Weather: 55, cloudy

Pavement

Condition: dry
City: Uniontown

State: $\mathrm{Pa}$.

Technician: BMD

Time: 4:00-5:00

Date: $10 / 23 / 2002$

\begin{tabular}{|c|c|c|c|c|}
\hline \# of Counts & $\begin{array}{c}\text { Elapsed } \\
\text { Time (sec.) }\end{array}$ & Total \# of vehicles & $\begin{array}{c}\text { \# of } \\
\text { heavy } \\
\text { vehicles }\end{array}$ & $\begin{array}{c}\text { Calculated } \\
\text { SFR }\end{array}$ \\
\hline 1 & 12.72 & 6 & 0 & 1698.11 \\
\hline 2 & 18.19 & 7 & 1 & 1385.38 \\
\hline 3 & 13.22 & 6 & 0 & 1633.89 \\
\hline 4 & 12.44 & 6 & 0 & 1736.33 \\
\hline 5 & 9.56 & 4 & 1 & 1506.28 \\
\hline 6 & 18.84 & 7 & 2 & 1337.58 \\
\hline 7 & 20.81 & 10 & 0 & 1729.94 \\
\hline 8 & 9.57 & 4 & 0 & 1504.70 \\
\hline 9 & 15.43 & 7 & 0 & 1633.18 \\
\hline 10 & 14.78 & 7 & 1 & 1705.01 \\
\hline 11 & 11.31 & 5 & 2 & 1591.51 \\
\hline 12 & 17.59 & 8 & 0 & 1637.29 \\
\hline 13 & 9.41 & 4 & 0 & 1530.29 \\
\hline 14 & 22.21 & 10 & 0 & 1620.89 \\
\hline 15 & 22.34 & 10 & 1 & 1611.46 \\
\hline 16 & 19.06 & 8 & 1 & 1511.02 \\
\hline 17 & 19.18 & 9 & 1 & 1689.26 \\
\hline 18 & 13.97 & 7 & 0 & 1803.87 \\
\hline 19 & 16.21 & 7 & 1 & 1554.60 \\
\hline 20 & 13.06 & 6 & 1 & 1653.91 \\
\hline Sum: & 309.9 & 138 & 12 & 32074.48 \\
\hline
\end{tabular}

$g=+1 \%$
$L w=12^{\prime}$

\begin{tabular}{rcc} 
\% heavy veh.: & 8.7 & Ideal: \\
Average SFR: & 1603.72 & 1895 \\
\cline { 2 - 2 } Weighted Average & & 1895 \\
SFR: & $\frac{1603.10}{}$ \\
Standard deviation: & 117.02 & \\
Coefficient of & & \\
Variation: & $\frac{7.30}{1627.04}$ & 1923 \\
Median: & $\frac{162.04}{13694.37}$ &
\end{tabular}




\section{Appendix IV}

(ANOVA analysis output sheets) 
Weighted Average SFR ANOVA analysis

\begin{tabular}{|r|r|r|r|}
\hline 1 & 2 & 3 & 4 \\
\hline 1721 & 1799 & 1524 & 1728 \\
\hline 1872 & 1776 & 1651 & 2024 \\
\hline 1670 & 1807 & & 1814 \\
\cline { 1 - 1 } 1629 & \multicolumn{1}{|r}{} & & 1870 \\
\cline { 1 - 1 } & & &
\end{tabular}

1626

1707

1454

1589

1567

ANOVA: Single Factor

SUMMARY

\begin{tabular}{lrrrr}
\hline Groups & Count & \multicolumn{1}{c}{ Sum } & Average & Variance \\
\hline Column 1 & 9 & 14835 & 1648.333 & 13499 \\
Column 2 & 3 & 5382 & 1794 & 259 \\
Column 3 & 2 & 3175 & 1587.5 & 8064.5 \\
Column 4 & 4 & 7436 & 1859 & 15510.67 \\
\hline
\end{tabular}

ANOVA

\begin{tabular}{|c|c|c|c|c|c|c|}
\hline $\begin{array}{l}\text { Source of } \\
\text { Variation }\end{array}$ & SS & $d f$ & $M S$ & $F$ & $P$-value & F crit \\
\hline Between Groups & 174082 & 3 & 58027.17 & 4.980674 & 0.014773 & 3.343885 \\
\hline Within Groups & 163107 & 14 & 11650.46 & & & \\
\hline Total & 337188 & 17 & & & & \\
\hline
\end{tabular}

Samples are statistically different. 
Unweighted Average SFR ANOVA analysis

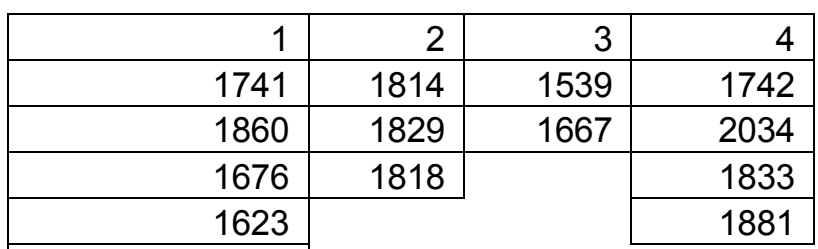

1636

1721

1478

1610

1593

ANOVA: Single Factor

SUMMARY

\begin{tabular}{lrrrr}
\hline \multicolumn{1}{c}{ Groups } & Count & \multicolumn{1}{c}{ Sum } & Average & Variance \\
\hline Column 1 & 9 & 14938 & 1659.778 & 11574.44 \\
Column 2 & 3 & 5461 & 1820.333 & 60.33333 \\
Column 3 & 2 & 3206 & 1603 & 8192 \\
Column 4 & 4 & 7490 & 1872.5 & 14915 \\
\hline
\end{tabular}

ANOVA

\begin{tabular}{lcrrrrr}
\hline \multicolumn{1}{c}{$\begin{array}{c}\text { Source of } \\
\text { Variation }\end{array}$} & \multicolumn{1}{c}{ SS } & df & \multicolumn{1}{c}{ MS } & \multicolumn{1}{c}{$F$} & P-value & F crit \\
\hline Between Groups & 182231 & 3 & 60743.76 & 5.838612 & 0.008379 & 3.343885 \\
Within Groups & 145653 & 14 & 10403.8 & & & \\
Total & & & & & & \\
\hline
\end{tabular}

Samples are statistically different. 
Unweighted Average SFR ANOVA analysis

\begin{tabular}{|c|c|c|c|}
\hline 1 & 2 & 3 & 4 \\
\hline 1741 & 1814 & 1539 & 1742 \\
\hline 1860 & 1829 & 1667 & 2034 \\
\hline 1676 & 1818 & & 1833 \\
\hline 1623 & & & 1881 \\
\hline 1636 & & & \\
\hline 1721 & & & \\
\hline 1478 & & & \\
\hline 1610 & & & \\
\hline 1593 & & & \\
\hline
\end{tabular}

ANOVA: Single Factor

SUMMARY

\begin{tabular}{lrrrr}
\hline Groups & \multicolumn{1}{c}{ Count } & \multicolumn{1}{c}{ Sum } & Average & Variance \\
\hline Column 1 & 9 & 14938 & 1659.778 & 11574.44 \\
Column 2 & 3 & 5461 & 1820.333 & 60.33333 \\
Column 3 & 2 & 3206 & 1603 & 8192 \\
Column 4 & 4 & 7490 & 1872.5 & 14915 \\
\hline
\end{tabular}

ANOVA

\begin{tabular}{|c|c|c|c|c|c|c|}
\hline $\begin{array}{l}\text { Source of } \\
\text { Variation }\end{array}$ & SS & $d f$ & $M S$ & $F$ & $P$-value & $F$ crit \\
\hline Between Groups & 182231 & 3 & 60743.76 & 5.838612 & 0.008379 & 3.343885 \\
\hline Within Groups & 145653 & 14 & 10403.8 & & & \\
\hline Total & 327885 & 17 & & & & \\
\hline
\end{tabular}

Samples are statistically different. 
Median SFR ANOVA

analysis

\begin{tabular}{|c|c|c|c|}
\hline 1 & 2 & 3 & 4 \\
\hline 1729 & 1828 & 1536 & 1709 \\
\hline 1897 & 1915 & 1655 & 2036 \\
\hline 1702 & 1824 & & 1815 \\
\hline 1663 & & & 1873 \\
\hline
\end{tabular}

1645

1684

1526

1612

1596

ANOVA: Single Factor

SUMMARY

\begin{tabular}{lrrrr}
\hline Groups & \multicolumn{1}{c}{ Count } & \multicolumn{1}{c}{ Sum } & Average & Variance \\
\hline Column 1 & 9 & 15054 & 1672.667 & 10802 \\
Column 2 & 3 & 5567 & 1855.667 & 2644.333 \\
Column 3 & 2 & 3191 & 1595.5 & 7080.5 \\
Column 4 & 4 & 7433 & 1858.25 & 18652.92 \\
\hline
\end{tabular}

ANOVA

\begin{tabular}{|c|c|c|c|c|c|c|}
\hline $\begin{array}{l}\text { Source of } \\
\text { Variation }\end{array}$ & SS & $d f$ & $M S$ & $F$ & $P$-value & F crit \\
\hline Between Groups & 178321 & 3 & 59440.19 & 5.377676 & 0.011301 & 3.343885 \\
\hline Within Groups & 154744 & 14 & 11053.14 & & & \\
\hline Total & 333065 & 17 & & & & \\
\hline
\end{tabular}

Samples are statistically different. 
ANOVA analysis between Fayette and Greene counties using weighted SFR

\begin{tabular}{|r|r|}
\hline Fayette & Greene \\
\hline 1721 & 1524 \\
\hline 1872 & 1651 \\
\hline 1670 & \\
\hline 1629 & \\
\hline 1626 \\
\cline { 1 - 1 } 1707 \\
\cline { 1 - 1 } 1454 \\
\cline { 1 - 1 } 1589 \\
\cline { 1 - 1 } 1567 \\
\cline { 1 - 1 } \\
\cline { 1 - 1 }
\end{tabular}

ANOVA: Single Factor

SUMMARY

\begin{tabular}{crrrr}
\hline Groups & \multicolumn{1}{c}{ Count } & \multicolumn{1}{c}{ Sum } & Average & Variance \\
\hline Column 1 & 9 & 14835 & 1648.333 & 13499 \\
Column 2 & 2 & 3175 & 1587.5 & 8064.5 \\
\hline
\end{tabular}

ANOVA

\begin{tabular}{|c|c|c|c|c|c|c|}
\hline $\begin{array}{c}\text { Source of } \\
\text { Variation }\end{array}$ & SS & $d f$ & MS & $F$ & $P$-value & F crit \\
\hline Between Groups & 6055.68 & 1 & 6055.682 & 0.469609 & 0.51043 & 5.117357 \\
\hline Within Groups & 116057 & 9 & 12895.17 & & & \\
\hline Total & 122112 & 10 & & & & \\
\hline
\end{tabular}

Samples are not statistically different. 
ANOVA analysis between Washington and Westmoreland counties using weighted SFR

\begin{tabular}{|r|r|}
\hline Washington & Westmoreland \\
\hline 1728 & 1799 \\
\hline 2024 & 1776 \\
\hline 1814 & 1807 \\
\hline 1870 & \\
\hline &
\end{tabular}

ANOVA: Single Factor

SUMMARY

\begin{tabular}{|c|c|c|c|c|}
\hline Groups & Count & Sum & Average & Variance \\
\hline Column 1 & 4 & 7436 & 1859 & 15510.67 \\
\hline Column 2 & 3 & 5382 & 1794 & 259 \\
\hline
\end{tabular}

ANOVA

Source of

Variation

Between Groups

SS

df

MS

$\mathrm{F}$

P-value

F crit

Within Groups

7242.86

17242.857

47050

$5 \quad 9410$

Total

54292.9

6

Samples are not statistically different. 
Counties Fayette\&Greene vs. Washington\&Westmoreland Weighted SFR ANOVA analysis

\begin{tabular}{|c|c|}
\hline$F \& G$ & W\&W \\
\hline 1721 & 1728 \\
\hline 1872 & 2024 \\
\hline 1670 & 1814 \\
\hline 1629 & 1870 \\
\hline 1626 & 1799 \\
\hline 1707 & 1776 \\
\hline 1454 & 1807 \\
\hline 1589 & \\
\hline 1567 & \\
\hline 1524 & \\
\hline 1651 & \\
\hline
\end{tabular}

ANOVA: Single Factor

SUMMARY

\begin{tabular}{lrllr}
\hline \multicolumn{1}{c}{ Groups } & Count & Sum & Average & Variance \\
\hline Column 1 & 11 & 18010 & 1637.273 & 12211.22 \\
Column 2 & 7 & 12818 & 1831.143 & 9048.81 \\
\hline
\end{tabular}

ANOVA

\begin{tabular}{|c|c|c|c|c|c|c|}
\hline $\begin{array}{l}\text { Source of } \\
\text { Variation }\end{array}$ & SS & $d f$ & $M S$ & $F$ & $P$-value & F crit \\
\hline Between Groups & 160783 & 1 & 160783 & 14.58307 & 0.001512 & 4.493998 \\
\hline Within Groups & 176405 & 16 & 11025.31 & & & \\
\hline Total & 337188 & 17 & & & & \\
\hline
\end{tabular}

Samples are statistically different. 
Lane type, weighted SFR ANOVA analysis

\begin{tabular}{|r|r|r|}
\hline LT & \multicolumn{1}{l|}{ TH } & \multicolumn{1}{l|}{ Shared } \\
\hline 1 & 2 & 3 \\
\hline 1872 & 1626 & 1721 \\
\hline 1670 & 1807 & 1629 \\
\hline 1799 & 1524 & 1707 \\
\hline 1776 & 1814 & 1454 \\
\hline 1651 & & 1589 \\
\cline { 1 - 1 } \cline { 1 - 1 } 1728 & & 1567 \\
\cline { 1 - 1 } \cline { 1 - 1 } 2024 & & 1870 \\
\cline { 1 - 1 } \cline { 3 - 4 } & &
\end{tabular}

ANOVA: Single Factor

SUMMARY

\begin{tabular}{lrrrr}
\hline Groups & Count & \multicolumn{1}{c}{ Sum } & \multicolumn{1}{c}{ Average } & Variance \\
\hline Column 1 & 7 & 12520 & 1788.571 & 16551.29 \\
Column 2 & 4 & 6771 & 1692.75 & 20228.92 \\
Column 3 & 7 & 11537 & 1648.143 & 17688.81 \\
\hline
\end{tabular}

ANOVA

\begin{tabular}{lcrcccc}
\hline \multicolumn{1}{c}{$\begin{array}{c}\text { Source of } \\
\text { Variation }\end{array}$} & \multicolumn{1}{c}{$S S$} & df & MS & $F$ & P-value & F crit \\
\hline Between Groups & 71060.7 & 2 & 35530.34 & 2.002632 & 0.169485 & 3.682317 \\
Within Groups & 266127 & 15 & 17741.82 & & & \\
& & & & & & \\
Total & 337188 & 17 & & & & \\
\hline
\end{tabular}

$0.16>.05$, hypothesis is correct, they are the same

$2.003<3.682$, hypothesis is correct, they are the same 


ANOVA analysis to test grade factor using weighted SFR
\begin{tabular}{|r|r|r|}
\hline negative grade & 0 grade & positive grade \\
\hline 1721 & 1707 & 1670 \\
\hline 1872 & 1589 & 1626 \\
\hline 1629 & 1567 & 1799 \\
\hline 1454 & 1776 & 1651 \\
\hline 1807 & & 1814 \\
\hline 1524 & 1728 \\
\hline 2024 \\
\hline 1870 \\
\hline
\end{tabular}

ANOVA: Single Factor

SUMMARY

\begin{tabular}{lrrrr}
\hline \multicolumn{1}{c}{ Groups } & \multicolumn{1}{c}{ Count } & \multicolumn{1}{c}{ Sum } & \multicolumn{1}{c}{ Average } & Variance \\
\hline Column 1 & 9 & 15629 & 1736.556 & 32580.03 \\
Column 2 & 4 & 6639 & 1659.75 & 9784.917 \\
Column 3 & 5 & 8560 & 1712 & 7713.5 \\
\hline
\end{tabular}

ANOVA

\begin{tabular}{|c|c|c|c|c|c|c|}
\hline Source of Variation & SS & $\overline{d f}$ & $\overline{M S}$ & $\bar{F}$ & $P$-value & F crit \\
\hline Between Groups & 16339 & 2 & 8169.514 & 0.381933 & 0.688992 & 3.682317 \\
\hline Within Groups & 320849 & 15 & 21389.93 & & & \\
\hline Total & 337188 & 17 & & & & \\
\hline
\end{tabular}

Samples are not statistically different. 
ANOVA analysis to test lane width factor using weighted SFR

\begin{tabular}{|c|c|c|}
\hline$<12^{\prime}$ lanes & $\begin{array}{l}12^{\prime} \\
\text { lanes }\end{array}$ & $\begin{array}{l}>12^{\prime} \\
\text { lanes }\end{array}$ \\
\hline 1721 & 1670 & 1567 \\
\hline 1872 & 1629 & 1524 \\
\hline 1707 & 1629 & \\
\hline 1799 & 1454 & \\
\hline 1776 & 1589 & \\
\hline 1807 & 1651 & \\
\hline 2024 & 1728 & \\
\hline 1814 & 1870 & \\
\hline
\end{tabular}

Anova: Single Factor

SUMMARY

\begin{tabular}{crcrr}
\hline Groups & \multicolumn{1}{c}{ Count } & Sum & Average & Variance \\
\hline$<12^{\prime}$ lanes & 8 & 14520 & 1815 & 9896 \\
$>=12^{\prime}$ lanes & 10 & 16502 & 1650.2 & 11096.18 \\
\hline
\end{tabular}

\begin{tabular}{lcrrrrr} 
ANOVA & \multicolumn{1}{c}{ Source of } \\
\multicolumn{1}{c}{ Variation } & SS & df & \multicolumn{1}{c}{ MS } & \multicolumn{1}{c}{$F$} & P-value & F crit \\
\hline Between Groups & 120707 & 1 & 120706.8 & 11.41857 & 0.003825 & 4.493998 \\
Within Groups & 169138 & 16 & 10571.1 & & & \\
Total & & & & & & \\
\hline
\end{tabular}

Samples are statistically different. 
12 ' lanes vs. greater than and less than using a factor of 1

\begin{tabular}{|r|r|}
\hline \multicolumn{1}{|l|}{} & \multicolumn{2}{|l|}{$\begin{array}{l}\text { all others } \\
\text { 12' }\end{array}$} \\
\hline 1670 & 1664 \\
\hline 1629 & 1747 \\
\hline 1626 & 1650 \\
\hline 1454 & 1739 \\
\hline 1589 & 1716 \\
\hline 1651 & 1746 \\
\hline 1728 & 1957 \\
\hline 1870 & 1753 \\
\hline & 1671 \\
\hline & 1611 \\
\hline
\end{tabular}

Anova: Single Factor

SUMMARY

\begin{tabular}{lrrrr}
\hline \multicolumn{1}{c}{ Groups } & Count & Sum & Average & Variance \\
\hline $12^{\prime}$ & 8 & 13217 & 1652.125 & 14000.41 \\
all others F=1 & 10 & 17254 & 1725.4 & 9007.378 \\
\hline
\end{tabular}

ANOVA

\begin{tabular}{lrrrrrr}
\hline \multicolumn{1}{c}{$\begin{array}{c}\text { Source of } \\
\quad \text { Variation }\end{array}$} & \multicolumn{1}{c}{ SS } & df & MS & $F$ & P-value & F crit \\
\hline Between Groups & 23863.2 & 1 & 23863.23 & 2.132201 & 0.163591 & 4.493998 \\
Within Groups & 179069 & 16 & 11191.83 & & & \\
Total & & & & & & \\
\hline
\end{tabular}

Not Significanlty Different 
ANOVA analysis to test Heavy vehicle factor using weighted SFR

\begin{tabular}{|c|c|c|}
\hline$<4 \%$ & $\begin{array}{l}4 \text { to } \\
10 \%\end{array}$ & $>10 \%$ \\
\hline 1872 & 1589 & 1721 \\
\hline 1629 & 1776 & 1670 \\
\hline 1626 & 1707 & \\
\hline 1454 & 1799 & \\
\hline 1567 & & \\
\hline 1807 & & \\
\hline 1524 & & \\
\hline 1651 & & \\
\hline 1728 & & \\
\hline 2024 & & \\
\hline 1814 & & \\
\hline 1870 & & \\
\hline
\end{tabular}

ANOVA: Single Factor

SUMMARY

\begin{tabular}{lrrrr}
\hline Groups & Count & \multicolumn{1}{c}{ Sum } & Average & Variance \\
\hline Column 1 & 12 & 20566 & 1713.833 & 28044.7 \\
Column 2 & 4 & 6871 & 1717.75 & 8895.583 \\
Column 3 & 2 & 3391 & 1695.5 & 1300.5 \\
\hline
\end{tabular}

ANOVA

\begin{tabular}{lcrcccc}
\hline \multicolumn{1}{c}{$\begin{array}{c}\text { Source of } \\
\text { Variation }\end{array}$} & \multicolumn{1}{c}{ SS } & $d f$ & $M S$ & $F$ & P-value & F crit \\
\hline Between Groups & 709.083 & 2 & 354.5417 & 0.015805 & 0.984335 & 3.682317 \\
Within Groups & 336479 & 15 & 22431.93 & & & \\
Total & 337188 & 17 & & & & \\
\hline
\end{tabular}

Samples are not statistically different. 
Appendix V

(Duncan's Multiple Range test) 
Duncan's Multiple range test:

The test is to be preformed on the four studied counties Fayette, Greene, Westmoreland, and Washington.

All equations and needed variables are from (Walpole, 1998)

Used a 95\% confidence interval and 19 degrees of freedom

\begin{tabular}{|c|c|c|}
\hline County & $\begin{array}{c}\text { Weighted } \\
\text { Ideal SFR }\end{array}$ & $\mathrm{s}^{\wedge} 2$ \\
\hline Fayette (F) & 1656 & 13456 \\
\hline Greene (G) & 1585 & 256 \\
\hline $\begin{array}{c}\text { Westmoreland } \\
\text { (WM) }\end{array}$ & 1793 & 8100 \\
\hline Washington (W) & 1857 & 15625 \\
\hline
\end{tabular}

\begin{tabular}{c|c|c|c}
$\mathrm{p}$ & 2 & 3 & 4 \\
\hline $\mathrm{rp}$ & 2.96 & 3.107 & 3.199 \\
\hline $\mathrm{Rp}$ & 114.453 & 161.44 & 199.94 \\
\hline
\end{tabular}

Duncan's equation:

$\operatorname{Rp}=\operatorname{rp}\left(\operatorname{sqrt}\left(\mathrm{s}^{\wedge} 2 / \mathrm{n}\right)\right)$
$\mathrm{Rp}=$ least significant range

$\mathrm{rp}=$ least significant studentized range

$\mathrm{s}^{\wedge} 2=$ variance

$\mathrm{n}=$ sample size

rp values obtained from table A.12 (Walpole,1998)
1

(G)

1585
2

(F) 1656
3

(WM)

1793
4

(W) 1857

a. $(4-1)=272>R 4(199.938)$ therefore we conclude there is a significant difference between the two

b. $(4-2)=201,(3-1)=208$ both are $>$ R3 (161.444 therefore both are significantly different

c. $(3-2)=137,>$ R2 $(114.453)$ thus we conclude they are significantly different

d. $(4-3)=64,(2-1)=71$ both are $(<)$ less than 114.453 thus we conclude that Fayette and Greene are not significantly different as well as Washington and Westmoreland

The result of Duncan's Multiple Range test are conclusive with ANOVA analysis in that both found the combinations of Fayette/Greene, and Washington/Westmoreland to be not significantly different from each other. 


\section{Vita}

Bruce McNeil Dunlap was born in Beckley, West Virginia, on August 26, 1979. He was raised in Greenville, West Virginia, attended James Monroe Senior High School, and graduated in 1997. Bruce received his Bachelor of Science in Civil Engineering in the fall of 2001 from West Virginia University. Currently, he is employed by the West Virginia Department of Transportation and is a Candidate for the Master of Science in Civil Engineering at West Virginia University specializing in Transportation

Engineering. 